\title{
Get Out of La La Land! Naturalizing the Colour Line with "Colour-Blind" Cinema
}

by

Gavin Ward

A thesis submitted to the Faculty of Graduate and Postdoctoral Affairs in partial fulfillment of the requirements for the degree of

\author{
Master of Arts \\ in
}

Sociology

\section{Carleton University \\ Ottawa, Ontario}

\author{
(C) 2019 \\ Gavin Ward
}




\section{$\underline{\text { Abstract }}$}

This thesis is grounded in semiotics, discourse, and critical race theory to identify and analyze contemporary racial representations in Hollywood cinema during the "post-race" era. "Postrace" has been used sporadically since 1971 when the concept was first published in James Wooton's New York Times article Compact Set Up for 'Post-Racial' South, however I appropriate it here to more accurately reflect the time period from 2008 to 2019. During this time, the United States of America had elected its first African-American president to the White House. For many, this act had symbolically legitimized America as a "post-race" nation in which contemporary racial inequalities could be explained by the principles of universal liberalism and meritocracy, thus "naturalizing" contemporary racial inequalities with nonracial dynamics. This ideology minimizes the impact of historical racisms and uses racial "colour-blindness" to construct a false sense of racial harmony. Antonio Gramsci had proposed that mass media, such as films, have been used to reinforce dominant ideology through cultural hegemony. In the United States, Hollywood has been an important vehicle of discursive formation and narrative control and contributes to the cementing of America's "post-race" la la land. In this thesis, I conclude that Hollywood films continue to placate concerns of race relations for the dominant ingroup through cinematic escapism, glamour and romance. In refining its art of "naturalizing" an ideological racial status quo, Hollywood has evolved from its blatant racial cinematic representations of the past. Now, mainstream cinema employs racial "colour-blindness" to maintain the colour line, further embedding racism into the fabric of American society. 


\section{$\underline{\text { Acknowledgements }}$}

To Dr. Amina Mire, who has been an inspiration and a mentor since my undergraduate years. I can't thank her enough for her guidance and for making university fun again.

To my parents, who have (somehow) always supported me, no matter the path I choose.

To my boys, who have kept me grounded, given me perspective, and who have taught me lessons you won't find in any texts.

To Viki, who consistently believes in my abilities before I do. I am confident that I could not have done this without you. 


\section{Table of Contents}

Chapter 1 - Introduction ............................................................................................................... pg. 6

Introduction and Statement of Research Problem ……........................................... pg. 6

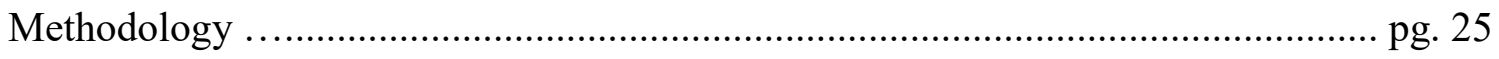

Film Selection Process ...................................................................................... pg. 31

Chapter Breakdown …………………........................................................... pg. 37

Chapter 2 - Naturalizing Colour-blindness ........................................................................... pg. 40

Colour-blind Hollywood, Strategies of Deference …………………………….... pg. 53

Chapter 3 - "Post-Race" Plantations and Peculiar Narratives ......................................... pg. 67

Neo-Slavery Tourism and Whitewashing Plantations .......................................... pg. 67

Controlling the Narrative and Enacting Power ....................................................... pg. 73

Black Panther, Subversion or Submission? .......................................................... pg. 78

Chapter 4 - Get Out of La La La, A Critical Analysis ...................................................... pg. 85

Colour-blindness and Case Study: Reel Bad Arabs............................................... pg. 85

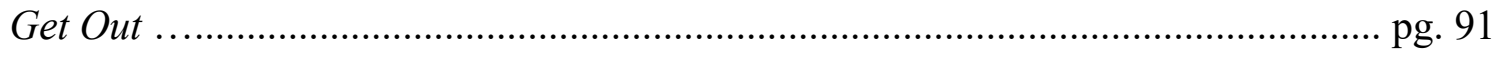

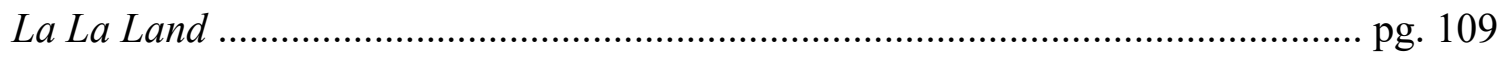

Chapter 5 - Conclusion ........................................................................................................ pg. 118

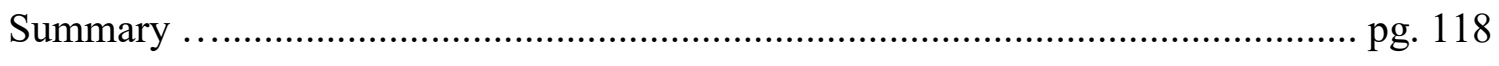

Areas of Future Study and Limitations ……...................................................... pg. 121

References .......................................................................................................... pg. 124

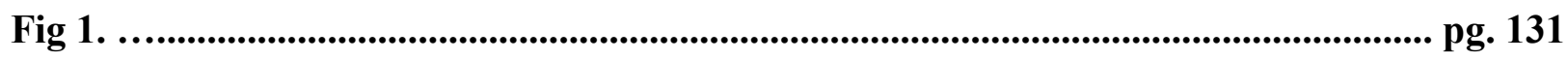


"The greatest thing our art does and our industry does

is to erase the lines in the sand. We should continue doing

that when the world tells us to make them deeper"

- Guillermo Del Toro, 2018

\section{Chapter 1: Introduction}

\section{Introduction and Statement of Research Problem}

In a third year Race \& Ethnicity course at Carleton University, I began to understand the true value of critical analysis and applying critical theory to the topics that personally interested me, such as Hollywood cinema. It was the first time that I had begun scrutinizing popular films with the theoretical tools and concepts within the discipline of sociology to see past the face-value of what was being shown onscreen compared to what was implicitly meant. Though I had reviewed films, have held opinions about whether or not I enjoyed them or not, and though I would tune in to the Academy Award ceremonies (the Oscars) to see if my favourite films rightfully got the recognition they deserved (I am still amiss about Whiplash not winning for Best Picture in 2014), I never fully went beyond watching films for what they are; "just entertainment".

However, in the final year of my undergraduate degree, I began relentlessly reading texts on critical race theory and the social implications of being raced or 'othered'. In these readings, the dominant narratives of American (and Canadian) history and triumph typically occluded marginalized voices in favour of the "natural" order of white male supremacy through colonialism and discourse. Richard Dyer makes the argument that "enterprise" was an important attribute of "upper-class white men" during colonialism and that;

'Enterprise' is an aspect of both spirit itself - energy, will, ambition, the ability to think and see things through - and of its effect - science, business, wealth creation, the building of nations, the organisation of labour (carried out by racially lesser humans)" (Dyer, 1997. pg.31).

Dyer notes that enterprise and "spirit" are central values in 'Western' culture and that the most important vehicle for enterprise is through imperialism (1997, pg.31). American history is much 
the product of enterprise and imperialism, and Dyer asserts that a conflation of race, history, and narrative were part of the US colonialist ideas which are evident in fictional, escapist and entertainment forms today (1997,pg.32).

Escapist forms of entertainment allow for the telling and re-telling of the great white narratives of conquest that engender the sense of a "natural order" in racially organized societies. What these narratives have typically left out from the plot are those racialized and gendered accounts of marginalized groups. For example, In Black Feminist Thought (1990), Patricia Hill Collins argues that African-American women intellectuals have remained outsiders to the dominant feminist, social, and political thought because the "assumptions on which full group membership are based - whiteness for feminist thought, maleness for Black social and political thought, and the combination for mainstream scholarship - all negate a Black female reality" (1990, pg.12). Mainstream scholarship and mainstream films share the commonality of being dominated by maleness and by whiteness.

The privileging of maleness and whiteness in mainstream American society are the effects of imperialism and narrative construction that insisted that "white people [will] lead humanity forward because of their temperamental qualities of leadership: will power, farsightedness, [and] energy" (Dyer, 1997, pg.31). Though white women are also marginalized based on their gender, Collins asserts that "denying black women the status as fully human has long been used to justify Black women's sexual exploitation” (Collins, 1990, pg.70, my emphasis). Thus, black women and black people have struggled in establishing a self-defined standpoint because of their "lack of control over the ideological apparatuses of society" (Collins, 1990, pg.26). Collins argues that "those who control the schools, media, and cultural institutions of society prevail in establishing their viewpoint as superior than others" (1990, pg.26). Thus, 
with a lack of power and control in self-definition, "when faced with stereotypical, controlling images of black women, [some] women internalize the controlling images and come to believe that they are the stereotypes" (Collins, 1990, pg.23). Because Hollywood maintains control over the ideological apparatus of cinema, race, racism, and representation continue to be hot topics in popular film.

In Reel Inequality (2017), Nancy Yuen argues that "through countless reiterations in popular media, racial stereotypes can become real in the minds of the audiences” (pg. 7-8) supplementing the lack of knowledge white people have about people of colour (Yuen, 2017, pg.8). Yuen further notes that when white audiences "learn" about racial minorities through popular media it can exacerbate pre-existing racist fears they have by reducing people of colour to their stereotypes (2017, pg.8). In "post-race" cinema, blatant racial stereotypes have become less ubiquitous, but Hollywood films continue to fill the epistemological gap for audiences in terms of naturalizing racial differences. Consuming media continues to impact how audiences "learn" about things, and Hollywood continues to refine its art of ideologically maintaining the colour line, but without the easily recognizable tropes of the past. Instead, Hollywood favourably re-imagines historical period dramas which smooth over race relations and continues to keep white representation as "non-raced" and as central.

I began to consider the power of imagery and stereotypes and the impact they have on the perceptions of who people are and how people see themselves. I noticed the ubiquity of denigrating stereotypes of African-Americans in popular culture while I studied critical race theory in my undergraduate years at Carleton University. Stuart Hall argued that stereotyping "reduces people to a few, simple, essential characteristics, which are represented as fixed by Nature" (1997, pg. 257). Furthermore, he wrote that "stereotyping as a signifying practice is central to the representation of racial difference [and] tends to occur where there are gross inequalities of power" (1997, pg.257-258). The signifying practice of stereotyping is a "key element in [the] exercise of symbolic violence" (Hall, 1997, pg.259) and remains a subtle way of maintaining the colour line in America because it "normalizes" racial difference. Donald Bogle had identified five main stereotypes of blacks in American films since the beginning of 
mainstream Hollywood films. There are the "Toms, Coons, Mulattos, Mammies and Bucks" (Hall, 1997, pg.251).

Toms - the "good negroes" who never turn against their masters despite constant insults and enslavement, Coons - the "eye-popping piccanninnies" who provide slapstick entertainment and comedic relief, The Tragic Mulatto - the mixed-race woman, beautiful and attractive, but whose "stain" of black blood condemns her to tragedy, Mammies - the house-servants who are big, bossy and cantankerous, and the Bad Bucks - physically big and strong, overly sexualized and who have a desire for revenge against white people (Hall, 1997, pg.251).

Hall argues that these stereotypes symbolically fix the social order, and that the repertoire of “stereotypical figures drawn from 'slavery days' have never entirely disappeared" (Hall, 1996, pg.252) from contemporary mainstream cinema. Although these images have been altered or changed by Hollywood, the essence of racial representation continues to "naturalize" racial differences and maintain the dominant racial order. Instead of Bogle's blatant stereotypes, which would no longer be acceptable in America's "post-race" era, Hollywood films began to refine their art of masking racism with plausible deniability. This art has become even more refined during the last decade during President Obama's eight-year-term in the White House which, for proponents of the "post-race", had symbolically legitimized racial equality. During this time, there has been a surge of historical dramas that imagine white, "colour-blind" heroes at the center of black freedom struggles including Oscar nominated films such as The Help (2012), Django Unchained (2013), 12 Years a Slave (2014), Hidden Figures (2017), and Green Book (2019). The narrative theme of these films re-imagine past racisms more progressively in order to ideologically align viewers with "post-race" views of increasingly improved race relations Dr. F.W. Gooding, Jr. argues that "stereotypes are typically derogatory in nature and are specific in their application" (2017, pg.54), but he suggests paying closer attention to the surfacing of archetypes in Hollywood films. Gooding argues that archetypes are "more neutral in nature and more general in their application" (2017, pg.54) than stereotypes of the past. In other 
words, archetypes have satisfied racial colour-blind ideology by simply re-coding racist intent.

Gooding outlines six archetypes in contemporary Hollywood film which "illustrate the pervasive pattern of marginalization that limits the majority of all minority images onscreen" (2017, pg.56);

The Angel - usually found in a servile position or functioning as a sidekick, Background Figure - inconsequential to the overall storyline, serves to reinforce a visual message of diversity,

Comic Relief - this character's culture serves as the fodder for most of the jokes including boisterous and improper grammar, exaggerated motions and intense emotion, often in stark contrast to standardized, White, middle-class behavior, Menace to Society - this character is portrayed as possessing a value system that poses a threat to civil normalcy,

Physical Wonder - this character is regarded for their physical or sexual prowess, and Utopic Reversal - occupying a high social position, mostly symbolic in nature (2017, pg.56-57).

Though these archetypes present as more politically correct than Bogle's stereotypes, they are fundamentally the same in how they function to limit racial representation on the silver screen and help supplement a particular "knowledge" about racial minorities. Furthermore, by reimagining historical period dramas in which white characters are central to black liberation, Hollywood placates feelings of white guilt in audience members who are no longer duped by blatantly racist anti-black stereotypes in mainstream cinema. Rather than focusing on putting black characters down, Hollywood is bringing white characters $u p$ while also portraying a rosier recollection of anti-black racism in America.

While pondering the frequent portrayal of racial archetypes in "post-race" era films, I continued to think of the "real world" impact that racial stereotypes had on people of colour. I still remember the sobering moment when I read Sapna Cheryan and Benoit Monin's study "Where are you really from?": Asian-Americans and Identity Denial (2005) in my undergraduate years. This study demonstrates the identity strain that being visibly non-white has on belonging to the American standard of whiteness. Cheryan and Monin's work was based on 
qualitative interviews with Asian-Americans to gain insight on how they see themselves within the context of a broader American society along with the coerciveness of racial homogenization. Cheryan and Monin concluded that the respondents in the study felt that because they are not white, they had to "prove" their American-ness through "everyday behaviours" such as demonstrating an awareness of American popular culture and engaging more in American practices. Respondents noted that being asked "where are you really from?" symbolically acted as a challenge to their Asian-American identities and that, because they are not white, they must constantly justify their American-ness through an exaggerated sense of white cultural participation and appreciation.

Minelle Mahtani had found similar results in her study Interrogating the Hyphen-Nation: Canadian Multicultural Policy and 'Mixed-Race’ Identities (2004). Mahtani's study also conducted qualitative interviews with non-white respondents to better understand how mixedrace women see themselves in the context of Canada's multicultural policy. The women in Mahtani's study noted that to be Canadian "it is assumed that one must be white" (2004, pg.3) and that to be asked "where are you from?" assumed foreignness. Furthermore, Mahtani's study revealed that facial features, hair length, and the colour and complexion of participants played a role in the way women were racialized. Dyer argues that in Western myth and fairy-tale, “blondness and beauty" are synonymous (1997, pg.71), because in Western tradition, "white is beautiful because it is the colour virtue" (1997,pg.72). Dyer further notes that the history of representations of Cleopatra provides one of the clearest instances of the conviction that whiteness is the pinnacle of human beauty evidenced by her light skin, strawberry blonde curls and glass-blue eyes (1997,pg.72). Collins argues that, "skin color, facial features, and hair texture is one concrete example of how controlling images denigrate African-American women" 
(1990, pg.79). In a system in which white skin and straight hair is both privileged and preferred, women in Mahtani's studies noted how these physical features contributed to their racialized identities.

In both Cheryan and Monin and Mahtani’s studies, whiteness was regarded as the norm. The question of "where are you really from?" also acted as a micro-aggression towards nonwhite Americans and Canadians which symbolically reminded them that did not resemble the prototypical ingroup of Canadian and American-ness. Routine subtle acts of symbolic violence normalize what is acceptable and expected in Canadian and American societies. Though Cheryan and Monin's study demonstrated that respondents had to overemphasize their participation in traditional American practices to ideologically "pass for white", Mahtani's study highlighted the limitations that "non-white" physical features, including skin colour, had on identity politics and fully belonging to the dominant ingroup. This contradiction highlights how, despite masquerading as "post-race", these countries continue to be deeply impacted by race.

Cheryan and Monin, and Mahtani's studies have also highlighted the ways in which nonwhite Canadians and Americans routinely face 'othering' through racial "micro-aggressions". Micro-aggressions were first described to me by one of my peers in the master's program as "little fires that constantly must be put out". But you can only put out so many, he told me. Micro-aggressions are the subtle actions, words or stereotypes that are directed at "non-whites" which serve as constant reminders that they are different from the prototypical white norm. Micro-aggressions "are conveyed through the banalities of everyday language and the seemingly petty gestures of daily interaction" (Fleras, 2017, pg.76). Fleras further argues that microaggressions are part of a discursive transformation of racism in which 
"a focus on consequences (not intent), the subliminal (not conscious), and the unintended (not deliberate) reinforces its status as banal - even boring - rather than egregious, predictable rather than extraordinary, implicit rather than explicit, and fundamental rather than incidental" (2017, pg.77).

Micro-aggressions seek to maintain the racial status quo through the everyday and routinized pattern of symbolically reminding "non-white" Canadians and Americans that they are other. Fleras elaborates that contemporary racism in North American culture is enacted through "micro-racist practices that infiltrate the routines of everyday life by becoming a normal part of what is accepted by society" (2018, pg.99). Fleras provides examples of "tokenism, infantilization, denial of promotions, work allocation bias, targeting, scapegoating, excessive monitoring, lack of accommodation, segregation" (2018,pg.99) and words and language which "define and demonize the other as an object yet simultaneously confirms the privileged position of the normal and natural subject" (Fleras, 2018,pg.99). These strategies are enacted without the need to explicitly mention race or colour, making them "colour-blind" and conforming to the “colour-conscious" and "post-racial" ideology of contemporary Canadian and American society. The omnipresence of micro-aggressions in everyday life attempts to naturalize a racial order while also seeming innocuous enough to deny racial intent. Like the racial archetypes ubiquitous in Hollywood films, a little plausible deniability goes a long way in normalizing racism as acceptable behaviour in America.

Micro-aggressions successfully normalize racism because of they are veiled by racial colour-blindness. Since racial colour-blindness is critical to the maintenance of "post-race" ideology, it is important to unpack what the concept entails. In the context of critical race theory, "colour-blindness" is often used interchangeably with "colour-blind racism". In Racism without Racists (2018), Eduardo Bonilla-Silva uses both "color-blind racism" and "color blindness" to delineate a relatively new ideology which "explains contemporary racial inequalit[ies] as the 
outcome of nonracial dynamics" (pg.2). Bonilla-Silva insists that colour-blindness (or, colourblind racism) is a "formidable political tool for the maintenance of the racial order" (pg.3). Bonilla-Silva argues that the ideology of colour-blind racism acquired cohesiveness and dominance in the late 1960s (2018,pg.2), and emerged from laissez-faire racism which "encompasses an ideology that blames blacks themselves for their poorer relative economic standing" (2018, pg.7). However, he argues that the new form of "color-blind racism has rearticulated elements of traditional liberalism for racially illiberal goals" (2018, pg.7), that whites today "rely more on cultural rather than biological tropes to explain black's position" (2018, pg.7) in America, and that "whites do not perceive discrimination to be a central factor shaping blacks' life chances" (2018, pg.7).

For example, although Bonilla-Silva states that some whites fight against white supremacy, they still benefit from the ruling ideology which has been increasingly couched as "common sense" (2018, pg.9). The contradiction of "being colour-blind" while benefitting from systemic racial ideology is mediated by what Bonilla-Silva calls "racial grammar" (Thomas, 2013). Racial grammar is produced and reproduced in communicative interaction (2018, pg.11) and through the consumption of media texts, such as in mainstream cinema. Within the last decade, Obama's presidency exacerbated a growing sense of ideological "racial colour blindness". In the late 1960s post-civil rights era, although African Americans were "equal" before the law, there continued to be only lukewarm receptions of colour-blindness in terms of social attitudes towards black people. However, within the last few decades, "this view has [now] gone viral" (Bonilla-Silva, 2018, pg.17, my emphasis). The use of "colour-blind" in this thesis is also grounded in the context of critical race theory and will therefore be used to specifically denote manifestations of race and racist ideology. 
Colour-blind racism establishes "whiteness", through power dynamics, as a norm and the standard of merit" (Goldberg, 2002, pg.223). In the Racial State (2002), David Goldberg argues that "colorblindness is committed to seeing and not seeing all as white, though not all ever as quite, while claiming to see those traditionally conceived as "of color" in living color and yet colorless" (2002, pg. 223). In other words, colour-blind racism attempts to homogenize all "nonwhite" groups into America's "standard of whiteness". However, noted in Cheryan and Monin (2005), and Mahtani's (2004) studies, despite this attempt of assimilation, non-whites still felt like outsiders to the 'norm'. Therefore, colour-blindness steeply downplays the impact that being raced has on people of colour and how that impacts their daily lives through prejudices, lifechances, othering, and micro-aggressions. Colour-blindness is also used to discredit current social inequalities which have been the direct results of historical, and ongoing racisms.

One example of downplaying the extent of anti-black racism centers on the Black Lives Matter social movement. Black Lives Matter began as response to police brutality against black people in America when seventeen-year-old Trayvon Martin was shot and killed by George Zimmerman in 2012. Zimmerman was allegedly a member of the neighborhood watch who was “charged, tried, and acquitted" (Bonilla-Silva, 2017, pg.36) for the murder of Martin. BonillaSilva argues that the ever-lengthening list of names, like Martin, who have been killed by law enforcement begins to "normalize" police brutality against black people in America (2017, pg.36). Despite this, in response to the online presence of Black Lives Matter, the online social media hashtag of "All Lives Matter" began trending on twitter, arguing that "black lives" are no more important than any other group, including white people. In response to Black Lives Matter, Bonilla-Silva also claims that several American states have enacted "Blue Lives Matter", making the killing of law enforcement officers classified as a hate crime (2017, pg.37). 
"Blue Lives Matter" and "All Lives Matter" both downplay the extent of anti-black violence in America, and in doing so, safeguard the racial status quo. Since "post-race" ideology assumes that race no longer matters, social movements like Black Lives Matter get less sympathy from proponents of colour-blindness who have subscribed to the fabrication of American racial equality and blame racialized minorities for their own individual shortcomings.

Another property of colour-blind racism is to ignore whiteness as a racial category, thus eliminating the "traces of its ghostly power" (Goldberg, 2002, pg.22). In doing so, white people can stake an equal claim to being discriminated against as people of colour. Richard Dyer discusses the "ruse" in which whiteness has been curiously excluded as a racial category in American discourse and in Western representation. In, White (1997), Dyer argues that the "sense of whites as non-raced is most evident in the absence of reference to whiteness in the habitual speech and writing of white people in the West" (pg.2). Through colonialism and conquest, Dyer argues that the assumption that "white people are just people" positions people of colour as "something else". Furthermore, he notes that the invisibility of whiteness as a racial position makes white people them the standard in Western representation (1997, pg.2-3). Dyer further argues that there is something at stake by continuing to ignore white racial imagery and "as long as race is something only applied to non-white peoples, [white people] function as a human norm" (1997, pg.1, my emphases). Dyer's insight was important to consider when analyzing films in the "post-race" era which do not explicitly deal with themes of race or racism. A central question to this thesis was what makes a film 'about race' when race influences nearly all aspects of the American social order? More specifically, why is race and racism so central in films such as Black Panther (2018) or Moonlight (2016), yet seems to be insignificant in films like I, Tonya (2017) and La La Land (2016)? Investigating mainstream films such as I, 
Tonya and La La Land can offer valuable insight into how whiteness is naturalized as a "human norm". Furthermore, critically analyzing their narrative themes can eliminate essentialist white/black dichotomies by adding layers of complexity to race and highlighting the contradictions of race as something "natural" and fixed. Because race is socially constructed, but individually meaningful, it is important to de-mystify it as "one or the other", and to begin to recognize the multi-dimensional social layers that race constitutes.

As far as cinematic representations are concerned, there are no dominating stereotypes of "whiteness" to consider. This is problematic when consuming media images because whiteness therefore opens itself up to the infinite variety of human representations in mainstream cinema. By ignoring whiteness as a racial category, white cinematic representations are less readily considered as racially meaningful. Gooding Jr. notes that mainstream movies include "broad themes and general storylines that are familiar and expected - if not outright desired - by movie audiences" and that "white actors will most likely be showcased as the primary characters in most - if not all - of [mainstream] movies" (2017, pg.12-14). Equating whiteness to a human "norm" thus allows for mainstream cinema to deny partaking in maintaining the racial status quo by insisting that, because race no longer matters, Hollywood films are simply giving audiences what they want by way of universal appeal. Furthermore, by denying whiteness as a racial category, films such as I, Tonya (2017), and La La Land (2016), escape the scrutiny of maintaining whiteness as central in cinematic visual representation. This naturalizing effect problematizes how race is constructed and conceived by assuming that "race" is something that does not apply to white people. Racializing white people can illuminate the intersections of class and race and de-mystify whiteness as a homogenous position of privilege. For example, in I, Tonya, Tonya's lower-class 
status as "white trash" dislodges her from a position of power and highlights the layers of whiteness that are beyond skin colour and the multi-dimensionality of individual identity.

During my studies, I continued to grapple with the complex nature of the ways in which race based inclusion and exclusion shapes our lives and frames our everyday experiences. I wondered how white privilege became "naturalized" in countries like Canada and the United States which have assumed the narrative of being founded on immigration and which celebrate multiculturalism. I thought of Antonio Gramsci's concept of hegemony, which outlined by Richard Dyer, is

"the establishment of normalcy through social- and stereo- types [which] attempt to fashion the whole of society according to their own world view, value system, sensibility and ideology. So right is this world view for the ruling groups that they make it appear as 'natural' and 'inevitable'" (Hall, 1996, pg.259).

It is because of hegemony that the participants of Cheryan and Monin's study felt the need to be more engaged in white American popular culture and practices in order to "fit in" with the dominant ingroup. It is also through this concept that black women "who have accepted the dominant image of themselves [are] paralyzed by a sense of helplessness (Collins, 1990, pg. 93) because they begin to internalize their subject position of lesser than white as a "natural" or "fixed" outcome of social dynamics in American. However, as Collins argues, the images of African-American women in media as "mammies, matriarchs, welfare mothers, mules, or sexually denigrated women" (1990, pg.93) are controlled images embedded in an ideology of domination. Collins notes that most African-American women can see the contradictions between these images and their everyday lives which opens "them up for demystification" (1990, pg.93) and a rethinking of hegemony. Collins' insight proves valuable because it suggests that there is an opportunity to reify and re-appropriate negative images in film and a possibility to subvert harmful stereotypes of racialized people in mainstream film. Furthermore, it presents the 
opportunity to de-mystify the contradictions of a "post-race" racial utopia with the lived experiences of black people in America who continue to be subjected to racist attitudes. However, in the current "post-race" state that America wishes to claim for itself, the question remains if the reification of media images is enough. It is possible that challenging the more deep-seeded ideological remnants of racism in America will be a long, uphill battle.

Rather than brute force, hegemony is enacted through the participation and the "acquiescence of its victims, who have accepted the dominant image of themselves" (Collins, 1990, pg.3). Because hegemony creates a binary opposition of the dominant group and the "subdominant minority group" (Fleras, 2017, pg.17), there is a desire on both ends to either belong to the dominant group, or to be liberated from its control. Jack Hitt details a personal example of his desire to belong to the dominant group in his article Mighty White of You (2005). Hitt writes, after his cousin told him he was a direct descendent of King Charlemagne, that

"It's an important feeling for most people - knowing where they come from. And being heir to Charlemagne would serve me just fine on the gentlemen's party circuit. Over the next few years, I became as cunning at hefting this lumbering chunk of self-esteem into passing conversation as a Harvard grad is at alluding to his alma mater" (pg.39).

Like Tonya, Hitt recognizes that the prestige of "whiteness" is more than skin deep and is enmeshed in class as well. Identity and belonging are both important to the ideological maintenance in which hegemony depends on. Oral histories, narratives, media images and movies are all ways that culture and identity are passed down in a society. In Cheryan and Monin (2005), and Mahtani's (2004) interviews and Hitt's anecdote, whiteness (or, lack of whiteness) resulted in both the confidence and privilege of belonging to the dominant in-group, or the alienation of existing outside of it. 
Another salient example of creating the image for the dominant class would be German filmmaker Leni Riefenstahl's Nazi propaganda film Triumph of the Will (1935) which successfully engendered a sense of unity among Germans and their support for Hitler. New York Times writer J. Hoberman called Triumph of the Will "brilliant, tedious and irredeemably evil" and wrote that the film's only real equivalent is D.W. Griffith's white supremacist magnum opus, The Birth of a Nation, which celebrated and glorified the Ku Klux Klan as the "valiant saviors of a post-war South ravaged by Northern carpetbaggers and immoral freed blacks" (Clark, 2018).

Having studied the impact that The Birth of a Nation had at the time of its release on dividing America along the colour line and emboldening white supremacist rhetoric, I became increasingly interested in the role that cinema played in ideologically maintaining the colour line. M.M. Manring argued in Slave in a Box (1998) that a primary focus of The National Association for the Advancement of Colored People (NAACP) had been to "highlight black dissent against images in media, but it had concentrated its efforts largely on film" (pg.164). Only six years old in 1915, the NAACP 'swiftly responded to The Birth of a Nation's advanced technical rendering of the traditional stereotypes of docile, loyal slaves, glad to be part of a benign, paternal slave system... [to] the film debut of the black as a brute and a vicious rapist of white women" (Guerrero, 1993, pg.13). NAACP executive secretary, Walter White, felt that the racially reductive depictions onscreen hurt efforts to pass federal antilynching laws because American audiences were so familiar with the unfavourable representations of black people that white Americans believed it must have constituted some "truth" about them (Manring, 1998, pg.164). The ongoing fight with "post-race" cinema is that colour-blindness is replacing unfavourable stereotypes to continue naturalizing these "truths". Furthermore, colour-blindness 
has more ideological justifications than biological racism allowing supporters of a "post-race" utopia to feel more legitimized in their viewpoint.

The Birth of a Nation became the "first feature film to be shown in the White House" (Guerrero, 1993, pg.13) and was immensely popular, influential and dangerous because of the timing of its release. During the period of 1890 to 1920 , "Jim Crow segregation was on the rise; lynching was at its height; and in general mob violence, murder, and oppression against African Americans was rampant and intense throughout the land" (Guerrero, 1993, pg.13). Guerrero notes that a favourite ritual to whip up excitement for the film was to "have a troop of horsemen dressed in the white sheets of the Ku Klux Klan ride through towns on their hooded horses in advance of showings of the film" (1993, pg.14). Thus, as Guerro puts it, "African Americans had every reason to fear that what was depicted on the screen could easily be acted out against them in reality" (1993, pg.14).

The NAACP continued to mount political pressure against mainstream cinematic depictions of black people. However, Hollywood's concern about its box office also allowed for a certain moderation (Guerrero, 1993, pg.17). In comparing The Birth of a

Nation with Gone With the Wind (1939), Guerrero noted that

"both epic features focus on the South during and after the Civil War, and both are spectacular, hegemonic masterpieces of antiblack sentiment. The notable difference is that Gone With the Wind avoids the overt inflammatory propaganda and plea of The Birth of a Nation, revealing how much Hollywood had refined the art of suggestion" (1993, pg.17).

Hollywood had already begun maneuvering its depictions of black people onscreen during this time to appease the political climate in America, however the overall maintenance of racial difference remained ideologically unphased. 
The racial and political climate in America began to change in the mid-1900s, beginning with the first Freedom Rides in 1947 and continuing with the Montgomery bus boycott in 1956" (Guerrero, 1993, pg.29). Because of this, "it would no longer be possible to produce biased epics with the blissfully ignorant attitudes of Gone with the Wind" (Guerrero, 1993, pg.29). With the rise of the civil rights movement, the NAACP kept "continuous pressure on the industry throughout the 1960s to upgrade the cinematic images of blacks and to employ more blacks in all capacities within the film industry" (Guerrero, 1992, pg.29), however the practice of maintaining the devalued image of African Americans within an "ideological web of myths, stereotypes, and caricatures" (1992, pg.9) continued in future cinematic productions. Guerrero argues that the practice of devalued black imagery in contemporary cinema can be confirmed by taking a trip to any video store where

"Indiana Jones loots the Third World and subdues its people with whip and gun; where one can view the antiblack, anti-Asian allegory of Gremlins (1984) or the exoticprimitive $\mathrm{Mr}$. T as he grunts and intimidates; or where race is erased from the lily-white worlds of suburban America in, say, Roseanne (1987) and Home Alone (1990)" (1992, pg.10).

Since the political climate in the United States had contributed to the racial imagery in mainstream cinema in the past, what I wanted to reveal with this study was how racial imagery has changed and evolved in the "post-race" era through colour-blindness. For example, when the movie La La Land (2016) came to theatres, online publications were comparing it to classic movie musicals of the 1940s to the 1960s (Burr, 2016), a time period before and during the Civil Rights Movement in America. Like the classic movie musicals of the past, the cast of $\mathrm{La} \mathrm{La}$ Land is entirely white aside from the minor role played by African-American singer John Legend. It occurred to me that "classic cinema" also had within it the coded language of a time period when black Americans were second class citizens, and that $L a$ La Land visually reflected that. Guerrero had argued that the "lily white worlds" of Roseanne and Home 
Alone kept whiteness at the center of representation (1992, pg.10), and La La Land had also seemingly erased "colour" from its setting in Los Angeles. Despite the city of Los Angeles having a diverse ethnic makeup, $L a$ La Land portrays a vividly white world. Furthermore, because of La La Land's primarily white cast and formulaic storyline, I questioned why La La Land and mainstream movies like it are never considered to be movies about race and how that contributes to the naturalizing of white representation in movies as the norm.

Friends outside of academia whom I have spoken to have frequently responded to my critical evaluation of race portrayal in films with either "it's just a movie", or that movies are "not meant to be taken seriously". Despite this, awards ceremonies in recent years have become the platform for discussing racial and gender inequalities in the film industry. Hollywood's decision to routinely stereotype or typecast black people on the silver screen has continued to be an issue more than one-hundred-years after the NAACP's protest of The Birth of a Nation in 1915.

In 2016, African-American filmmaker, Spike Lee, had called for a boycott of the award ceremony because of the Oscars' failure to nominate even a single black actor in either category for Best Actor or Best Actress. Taking to social media, Lee wrote;

"\#OscarsSoWhite... Again... I will not be attending the Oscar ceremony this coming February. We cannot support it... How is it possible for the $2^{\text {nd }}$ consecutive year all 20 contenders under the actor category are white? And let's not even get into the other branches. 40 white actors in 2 years and no flava at all. We can't act?! WTF!!" (Yuen, 2017, pg.1)

Lee's frustrations against the Oscars is the result of the homogeneity in existing positions of power and control in Hollywood. Though, in 2013, whites made up 62 percent of the American population, they made up between 74 and 96 percent of Hollywood personnel; 
including filmmakers, directors, actors, and decision makers responsible for movie casting choices (Yuen, 2017, pg.19). The small percentage of members who make up the elite positions in Hollywood are also responsible for constructing narrative and discourse of race through cinema. Furthermore, although people of colour make up nearly 38 percent of the US population, only 16.7 percent played lead roles in films. Actors of colour are seen through a racist lens and reduced to tokens and caricatures (Yuen, 2017, pg.5). As a result, they get limited chances to reconfigure their subject-position in the dominant cinematic narrative of white centrality and black subordination. The protests of early members of the NAACP in 1915, and more contemporarily from Spike Lee in 2016, articulate that the image of black folks continue to be misrepresentative, misconstrued, and misaligned even during the so-called "post-race" era. Hollywood continues to refine its art of ideologically maintaining a racial status quo while veiling racist intent.

Furthermore, Oscar nominated films such as Twelve Years a Slave (2013), Hidden Figures (2016), Fences (2016), Moonlight (2016), and Green Book (2018) continue to address racism in the United States. These films shed light on the reality that America is far from the "post-race" utopias that it wishes to be. The disconnect from "post-race" ideology and the ongoing issues of racial representation in cinematic visual culture are evident in the contradiction of cinematic narratives and the realities of ongoing racism. This contradiction suggests that there are discrepancies between a new era of racial harmony and an entrenched continuation of racebased exclusion and inclusion. Like Collins (1990) had asserted that black women could see the contradictions between the controlled images of themselves and their lived experiences, so too are the contradictions between "post-race" ideology and the realities of racism readily apparent. 
An aim of this work is to illuminate these contradictions with the hope of dislodging the "norm" of white as a standard of merit.

\section{Methodology}

My thesis is grounded in qualitative media content analysis (QMCA), which according to Macnamara (2011) has been a research method since Max Weber "saw media content as a means of monitoring the "cultural temperature"' (pg.1). QMCA is used to study a "broad range of 'texts' from transcripts of interviews and discussions in clinical and social research to the narrative and form of films, TV programs and the editorial and advertising content of newspapers and magazines... [and] has been a primary research method for studying portrayals of violence, racism and women in television programming as well as in films" (Macnamara, 2011, pg.1). When grounded in critical theory, QMCA provides the best analytical tools in assessing cinematic representations and their symbolic and assigned meanings within the 'real world' context of American society. Scholars such Richard Dyer (1997), Stuart Hall (1996), Patricia Hill Collins (2002), Ed Guerrero (1996) and Vincent Rocchio (2000), have used QCMA to delve deeper into race portrayal, meaning and representation elicited through film since the inception of mainstream modern cinema beginning with The Birth of a Nation in 1915.

Macnamara (2011) outlines three objectives of QMCA which include; 1) Descriptive, 2)

Inferential, and 3) Predictive that can be used in a variety of applications. He writes that;

"descriptive, provides insights into the messages and images in discourse and popular culture represented in mass media. The inferential and predictive roles of content analysis, even though they are 'facilitating' rather than conclusive, allow researchers to go further and explore what media content says about society and the potential effects mass media representations may have on audiences" (2011, pg.4).

This thesis is primarily concerned with the descriptive qualities of messages and images in discourse and popular culture. The focus of my work is on Hollywood's contribution to 
naturalizing racial difference which ideologically privileges whiteness, and which maintains whiteness as "non-raced" and "norm". The inferential and predictive roles are not meant to infer causality of these images, but to generate insight of how racial representation in cinema is interpreted during an era which has increasingly become more colour conscious and colour-blind since the election of President Obama. If America is ideologically "post-race", then what is achieved from the influx of historical period dramas in the last decade which focus explicitly on anti-black racism in the United States?

In this work, race and racism are "conceived as a complex, multidimensional, and evolving social phenomenon [which] effects individual beliefs, attitudes, and actions - separately and collectively - [and] become the support and foundation for social dimensions" (Rocchio, 2000, pg.5). In The Racial State (2002), David Goldberg argues that it is near impossible in American culture to ever omit race from any social practice because it exists silently "in virtually all, or at least all significant, social practices" (2002, pg.117). Considering this, race and racism are such complex and multidimensional concepts that researchers such as Rocchio (2000) and Guerrero (1993) have relied on mixed-methods for their qualitative analyses on race and film. Furthermore, Goldberg's insight in which race exists in virtually all social practices, whiteness should not be let off the hook of benefitting from the maintenance of a racial hierarchy.

In Reel Racism (2000), Vincent Rocchio combines theories of "history, aesthetics, economic organization, and rhetoric" (pg.5) to analyze messages disseminated in mainstream cinema. Furthermore, he combines discourse and semiotics to interpret how media "texts" reinforce the status quo of racism (pg.5). From these mixed methods of QMCA, Rocchio attempts to; 
"make the study of racism and media accessible to everyone, not by taking overly simplistic approaches like positive-negative image analysis, conspiracy theories of media, and the search for stereotypes, but by defining terms and discussing methods that helps develop more critical perspectives towards the messages of the mass media in general, and towards race specifically" (pg.6)

Macnamara further outlines that semiotics is particularly relevant to qualitative content analysis which "focuses attention on signs and sign systems in texts and how readers might interpret (decode) those signs" (2011, pg.15). Semiotics as analysis "exposes the ideological, latent meaning behind the surface of texts, allowing us to grasp the power relations within them" (Macnamara, 2011, pg.16). The purpose of this thesis is not to point out individual moments of racism in films, or to dwell on singular stereotypes as "evidence" that race still matters or exists, but to use a combination of theoretical tools to provide a richer critical perspective on contemporary colour-blind racism. Hall notes that stereotypes and representations are ambivalent (1997, pg. 263). Therefore, adding more positive images of black people in mainstream cinema will not suddenly displace the negative ones (1997, pg.274) and focusing solely on cinematic moments which seem to celebrate diversity only distract from the plethora of other films which cement racial difference as "natural".

Rocchio suggested that because media texts are a significant site for information and socialization, films in particular have wider capacity in disseminating narratives which shape and normalize "core American values" and "cultural norms". These core values and cultural norms come from the dominant/mainstream group of "mostly Whites/Caucasians" who control every aspect of power (Neuendorf, 2015). Although numerous researchers "have attributed citizens' acquisition of social norms and expectations to their learning from the media ... critical and cultural theorists have, however, questioned "whose" cultural expectations and ideas are transmitted via the media" (Neuendorf, 2015). Yuki Fujioka and Kimberly Neuendorf have noted 
that media plays an important role in reproducing and conveying ideologies and interests of those in power. Neuendorf argued socialization through dominant narratives can be problematic for racial minorities because it results in losing identification with a racial culture through assimilation in order to "fit in" with the "mainstream characteristics" of white American identity (Neuendorf, 2015) which had also been noted in Cheryan and Monin's (2005) study of AsianAmerican identities. Furthermore, Neuendorf notes that the "media consistently stress and reinforce an impermeable boundary between White domination and non-White subordinated roles, with stereotyping and underrepresentation across old and new media" (Neuendorf, 2015). I do not agree that "white" and "non-white" are entirely homogenous or that there is an impermeable boundry between dominated and subordinated roles. However, colourblindness aims to ideologically maintain a racial hierarchy in which "white" is mainstream and the "norm". Films such as Imitation of Life (1959) have explored how light skinned minorities can "pass" for white, and Cheryan and Monin's studies have shown that "whiteness" can (sometimes) be achieved through mainstream cultural participation. Furthermore, in films such as I, Tonya, Tonya is not privileged by her whiteness, but rather she is oppressed because of her class, demonstrating the contradiction of whiteness and white privilege. Though I generally accept Neuendorf's assertion on the impact of media-controlled images and harmful stereotyping, the "impermeable boundary" is more of an arbitrary line in the sand that depends on racial ideology to make it deeper.

In Reel Racism (2000), Vincent Rocchio uses Jacques Lacan's theories to more fruitfully analyze race in film. Lacan explores the intricate relationships and effects that communications and symbols have on individuals, individual behaviour, and individual identity and "distinguishes between image-based symbols and language in terms of their relationship to the 
individual" (Rocchio, 2000, pg. 16). Rocchio argues that Lacan's most radical contribution to the study of race is the "fictive nature of identity", which is constructed from "images and signs with which the individual has identified" (Rocchio, 2000, pg.16). This is particularly insightful as to why representation is so meaningful. Lacan argues that individual consciousness results from "a relationship between identification with and the taking in - or introjection - of signs, terms, and concepts" (Rocchio, 2000, pg.17). Therefore, although media texts are consumed on an individual bases with a variety of subjective interpretations, colour-blind representations in mainstream cinema continue to naturalize racial difference which plays an "enormous role in the construction and maintenance of identity" (Rocchio, 2000, pg.18). Because race is so ubiquitous in American society, and as Goldberg had suggested, exists silently "in virtually all, or at least all significant, social practices" (2002, pg.117), race and racism become a large part of individual identity, and individual attachment to the "meaning of race and racism are not readily disengaged" (Rocchio, 2000, pg.18).

Media texts are not inherently meaningful, and as Hall notes, "because meanings are always changing and slipping, codes operate more like social conventions than like fixed laws or unbreakable rules" (1996, pg.62). In "post-race" colour-blind America, the codes which constitute meaning are embedded into the "social relations and practices that reinforce white privilege" (Bonilla-Silva, 2018, pg.9) in order to uphold the racial structure. In Affect and the Sociology of Race: A Program for Critical Inquiry (2013), James Thomas proposes an affective program to better understand the nuances of studying race in sociology. Thomas delineates that an affective program "is not centred on the emotional causes of effects of racialization, as emotions are not affects, but rather qualitatively coded feelings based on shared meanings of a situation" (2013). Hollywood's domination of controlled images, which are 
consumed by audiences, depends on a sense of a cultural understanding and a shared meaning of these "always changing and slipping" codes. It is the task of colour-blindness to make race, and the codes that veil race, as "common sense" and as "natural" as possible so that when audiences watch mainstream film, there is a collective and implicit understanding of what they are consuming. Though agency is involved when individuals read media texts, colour-blindness seeks to ideologically "get everyone on the same page" to widen the net of racial inclusions and exclusions.

Furthermore, a criticism that Thomas outlines in Systemic Racist Theory (SRT) is that SRT insists that elite White males have been most directly involved in the maintenance of racial domination (2013). Thomas demonstrates that in SRT, "whites" refers to all whites; "white elites, dominant whites, and anti-racist whites" (2013) thus limiting agency in both whites and non-whites in how larger structures of domination influence their understanding of race relations. Since this work seeks to also include whiteness as a racial category and to nuance the relationship between whiteness and blackness as more complex than simply binary oppositions, it is important to note that films do not uniformly impact white and non-white viewers as homogenous groups. However, in examining mainstream cinema and the large-scale impact of Hollywood, I focus on the messages disseminated rather than the often split-readings of individual consumers. Further, I wish to analyze more specifically how mainstream cinema contributes to cementing "race" as "natural" through colour-blindness. In other words, although films are not the cause of racism and racist attitudes, they present an opportunity to ideologically align with racial colour-blindness through a "social-symbolic system" that considers both the individual's own dynamic history and their interaction with generally accepted symbolic meanings. This includes how race becomes naturalized through the coded 
meanings and symbols which become generally accepted by the dominant group. Rocchio argues that "the individual need for identity confirmation in discourse creates the economic demand for the messages of the mass media" (2000, pg.18), thus colour-blind cinema offers the "racially neutral" utopia that proponents of "post-race" America wish to see.

\section{Film Selection Process}

In selecting films for my thesis, I draw on Newbold et al. (2002) who had proposed three steps outlined in QMCA methodology: Selection of media forms, Selection of issues or dates, and Sampling of relevant content from within from media (Macnamara, 2011).

1) Selection of media forms and genre: The media forms of this study are mainstream Hollywood films.

2) Selection of issues or dates: The period of the selection is the "post-race" era from 2008 to 2019.

3) Sampling of relevant content from within those media: For the sampling of relevant content, I selected key films within the "post-race" decade which dealt with themes of race and American race relations. For example, I considered such films as, The Help (2011), 12 Years a Slave (2013), Hidden Figures (2016), Moonlight (2016) and BlackKklansman (2018). In selecting these films, I wanted to compare them to the "mainstream" narratives of "American core values" in films which primarily had white characters, and which told stories meant for "universal appeal" (ie/ appealing to the dominant ingroup of white audiences). Dyer asserts that American hegemony is maintained through the display of the "white man at the centre of global representation" (2002, pg.39). He argues that white Hollywood stars are both at once “special and ordinary" (2002, pg. 39). The strategy of having (white) Hollywood stars appear "ordinary" assists in how audiences perceive and relate to them. Through colour-blindness, and 
the "ruse" that Dyer outlined of white people not being raced, audiences can justify that their relation to Hollywood stars has nothing to do with race and everything to do with relatability. Thus, by presenting white Hollywood stars as "ordinary", and by presenting white mainstream films as "universally appealing", Hollywood films naturalize the racial status quo through the plethora of movies which "are not about race".

It was also important to choose "hit" films which were not niche or obscure because of their potential to reach the broadest audience possible. Though independent films can provide a counter narrative to Hollywood's dominant discursive control, my decision was to focus on big budget mainstream films to highlight how Hollywood has continued to refine its art in disguising the racial order. Ed Guerrero's critical analysis of Hollywood films in his book Framing Blackness (1993) focused on the biggest "hit" films for two reasons;

"First, Hollywood has played a significant, if colonizing role in shaping all other narrative cinema languages and formal conventions and its most successful features are arguably its most influential in this regard. Second, in these films we can most readily see both the industry's ideological power to shape the audience's conceptions of race and its mediation of the audience's racial and social attitudes" (pg. 4-5)

Guerrero had suggested it is critically important to pay close attention to the cinematic moments in which black films break through Hollywood's ideological chokehold of black subordination and which present independent challenges and alternative perspectives to the dominant cinematic narrative of white superiority. I selected films that challenge and expose the normality of whiteness promulgated though Hollywood films. These films also expose and challenge "postrace" ideology through the ubiquity of micro-aggressions and colour-blind racism. I also wanted to consider cinematic moments which effectively subverted stereotypes and tropes in order to illuminate the contradictions of "post-race" ideology with the realities of racial differences through films. 
A final suggestion in sampling for qualitative analysis was informed by the need to "investigate certain issues or themes in detail... driven by a conceptual question, not by concern for "representativeness" (Macnamara, 2011). In this regard the purpose of this study is to pay close attention to the rare cinematic moments in which popular films go against the grain and challenge dominant Hollywood themes.

In my final selection; I viewed over thirty films in the "post-race" era which were nominated for an Academy Award. Many of these films dealt specifically with anti-black racism or had "race" as a central theme in the development of the plot. Films such as The Help (2011), Twelve Years a Slave (2013), Django Unchained (2012), and Green Book (2018) focused primarily on black freedom struggles and positioned African-Americans as subordinate to a white dominant social order. I also viewed films which were "not about race" such as La La Land (2016) and I, Tonya (2017). Though "race" or "racism" was not central to the plot in these films, both films offered meaningful contributions to whiteness as a racial category and how colour-blindness accepts whiteness as a norm in American society. I selected Get Out (2017) and La La Land (2016) for the primary focus of my analysis of colour-blindness in "postrace" films. I also included a brief analysis of the film I, Tonya (2017) to demonstrate how class politics influence white racialization. In this thesis, I have also included a discussion focused on Black Panther (2018) and whether or not this film succeeds in providing meaningful representation for marginalized audiences who finally get to see a black lead character in a big budget Marvel superhero film. On the other hand, it is possible that the film has instead used a sense of false consciousness to drive in massive financial profits. Paul Gormley notes in The New-Brutality Film: Race and Affect in Contemporary Hollywood Cinema (2005) that "each transformative moment in the history of American film has founded itself on the surplus 
symbolic value of blacks, the power to make African Americans stand for something besides themselves" (pg.8). The novelty of the first black superhero might simply be a strategy to "create a new cinematic affect" (Gormley, 2005, pg.8) and financially profit off the highly commercialized Black Panther.

In my analysis of La La Land (2016), I use the film to demonstrate the "typical" representation of contemporary Hollywood narrative, core values, and "norms" of American society as it tells the story of two white, central characters falling in love while attempting to follow their dreams of success in Hollywood. The constant placement of whiteness at the center of representation in Western media naturalizes whiteness, thus further obscuring racialized individuals from belonging and continuing to see them as peripheral to "core American values. As Richard Dyer puts it in his book White (1997);

"Research - into books, museums, the press, advertising, films, television, software repeatedly shows that in Western representation whites are overwhelmingly and disproportionately predominant, have the central and elaborate roles, and above all are placed as the norm, the ordinary, the standard. White are everywhere in representation. Yet precisely because of this and their placing as norm they seem not to be represented to themselves as whites but as people who are variously gendered, classed, sexualised and abled. At the level of racial representation, in other words, whites are not of a certain race, they're just the human race" (pg.3)"

When in 2016 the film La La Land was nominated for the Best Picture category, it was expected to win by a landslide because it was a "feel-good romance with infinitely likable stars that hearkens back to a bygone Hollywood era" (Montgomery, 2017). La La Land's main competition at the Awards was Moonlight, a film that centers on a black man struggling with his homosexuality. At the Academy Awards, Faye Dunaway and Warren Beatty had mistaken announced that La La Land won the award for Best Picture, however Moonlight ended up as the rightful winner. La La Land and Moonlight were treated as a "litmus test about race and the 
entertainment industry" (Rosenberg, 2017). Montgomery argues that "voting for Moonlight might have felt like a symbolic victory in the face of rising anti-immigrant, antiMuslim, white supremacist sentiment" (Montgomery, 2017). In the wake of the political climate of the United States of America during President Trump's election, one online columnist wrote that

“only Donald Trump can save La La Land... the Oscars have been made to be about subtext rather than text. The Best Picture race is black vs. white, progressive vs conservative, good vs. Bad" (Cea, 2017).

Because I have referred to "post-race" America as a "la la land", Cea's assertion that "only Donald Trump can save La La Land" provides an ironic insight. In recent years, Trump rallies have "provided a safe space for not only virulent, xenophobic rhetoric but physical violence as his supporters attacked protestors and held offensive signs on a number of occasions" (BonillaSilva, 2018, pg.222). Bonilla-Silva argues that Trump's rhetoric "reflects that color-blind racism has shaped his racial ideology" (2018, pg.222). For example, despite Trump's desire to build a US-Mexico border wall to keep Mexicans rapists and criminals out of America (Wolf, 2018), and calling for a ban on Muslims entering the country (Bonilla-Silva, 2018, pg.222), Trump insists that he is "the least racist [person]" (Bonilla-Silva, 2018, pg.222). While Trump employs colour-blind strategies of racial deference, he has also emboldened white supremacist rhetoric, "stoked the racialized feelings of poor whites" (Bonilla-Silva, 2018, pg.224), and claimed to be the victim of reverse-racism during Spike Lee's Oscar Award speech (Marshall, 2019). While claiming to have done more for African-Americans than almost any other president (Marshall, 2019), perhaps only Donald Trump can save the "la la land" of "post-race" America from being exposed as having serious and ongoing racial issues. 
What these opinions on films and the Oscars demonstrate is how saliently politics continue to seep in to the subtext of cinema since Guerrero had noted that The Birth of a Nation "most certainly contributed to the public's tolerance of Klan criminality and its expansion to its greatest membership ever" (1993, pg.13). With Donald Trump as president during the "post-race" era, anxieties about race-relations have resurfaced in the general public discourse and especially in the film industry.

The second film, Get Out (2017), subverts the "white saviour" narrative of mainstream cinema. This film focuses on the evil nature of white people and sheds light onto the contemporary state of colour-blind racism in America through the ubiquity of micro-aggressions and symbolic violence. Though "colour-blind racism" and micro-aggressions may seem like improvement from Jim Crow America, Bonilla-Silva argues that;

"instead of relying on name calling (niggers, spics, chinks), color-blind racism otherizes softly ("these people are human, too"); instead of proclaiming that God placed minorities in the world in a servile position, it suggests that are behind because they do not work hard enough; instead of viewing interracial marriage as wrong on a straight racial basis, it regards it as "problematic" because of concerns over the children, location, or the extra burden it places on couples" (2018, pg.3).

These examples outlined by Bonilla-Silva demonstrate how modern racism becomes more nuanced and more easily justifiable. As a result, colour-blind racism continues 'othering' and maintains a symbolic boundary between white and black that is "natural" because of "cultural differences". What Get Out so effectively accomplishes is the constant 'othering' that the central character, Chris, must deal with as a black man in America visiting his white girlfriend's family during an era in which race allegedly does not matter. Furthermore, Get Out succeeds by the cultural understanding of race relations in America and the incongruity of tropes that audiences expect from big budget mainstream film. For example, rather than the 'white saviour' so 
ubiquitous in contemporary Hollywood films, Get Out introduces Rose as an anti-racist character who is proactive in combatting racist attitudes, but concludes by positioning every white character in the film as evil.

This work is important because it demonstrates that racism is a process and not a static "thing". Through analysis of films, this work highlights how racist attitudes and stereotyping can lead to real world prejudices through the continuous representations of white superiority. Furthermore, this work demonstrates how racial colour-blindness justifies contemporary racism by adopting "post-race" ideology. Through the investigation of two "hit" Hollywood films, I demonstrate how colour-blindness has replaced old methods of racial othering in cinematic representation. Despite an impulse to celebrate America as "post-race" since Obama's presidency, symbolic violence through micro-aggressions and "colour-blind" discrimination have replaced the more obvious forms of racism of the past. Racism as a process has evolved in ways which maintain its power through the symbolic order, narrative control, and attempting to fix the colour line "natural", and this is continues to be seen in contemporary films.

\section{Chapter Breakdown}

Chapter 2 - Naturalizing Colour-blindness, I delineate theories that have inspired this thesis; including semiotics, discourse, and the concept of racial colour-blindness. Furthermore, I argue that the 2008 election and 2012 reelection of Barack Obama as the President of the United States of America has become an allegorical expression of the "la la land" that celebrated the arrival of a new age of the "post-race" era. This ideological ruse is maintained by re-grounding the "truths" of white supremacy from the dated biological explanations used in the past which legitimized slavery and colonialism. With new contemporary justifications of racial difference grounded in 
new racially colour-blind "truths", American racial inequalities are instead legitimized through the principles of universal liberalism and meritocracy. These principles lay the blame on racialized minorities for their own short-comings rather than considering the historical factors that continue to have an impact on sustained racial inequalities. I then explicate the strategies of naturalizing racial colour-blindness in the film industry, which through the principles of universal liberalism and meritocracy, aim to symbolically fix the racial status quo in America. Chapter 3 - "Post-race" Plantations and Peculiar Narratives, I discuss the erasure of historical racisms to smooth over contemporary race relations. To make the argument, I use a series of examples such as how slave era plantations are transformed and reconfigured as tourist attractions complete with brochures containing specific narratives which downplay or minimize historical racism. I argue that discourses and narratives are part of power inequalities, and that the ability to control narrative is integral at disseminating a particular knowledge about marginalized or subjugated groups. I assert that because contemporary cinema is also concerned with colour-blind discursive strategies which minimize racism, I discuss whether or not the Hollywood blockbuster, Black Panther (2018), has successfully subverted black stereotypes or if it has submitted to the similar commodification of racism into post-racial colour-blind entertainment. I argue that if Black Panther becomes commodified as post-racial colour-blind entertainment, it runs the risk of appropriating one of the most prominent black activist groups during the Civil Rights Movement, the Black Panther Party.

Chapter 4 - "Hollywood Villains? Get Out of La La Land! I use Jack Shaheen's Reel Bad Arabs as a case study to further articulate the impact Hollywood films have on "real world" experiences for those subjected to its dominating images. By unpacking the theoretical concepts of Orientalism and Xenophobia, I demonstrate how anti-Arab racism in Hollywood films have 
contributed to moviegoers' negative perceptions of Arabs and Muslims in America. I then delve into the movie analysis of Get Out which successfully subverts the expected black racial stereotypes ubiquitous in Hollywood films and which makes all white people in the film "evil". By villainizing white people throughout the film, white audiences are strategically forced to sympathize with the black lead character, Chris, as he is subjected to racism, micro-aggressions, and anti-black sentiments. Finally, I unpack the movie La La Land which presents itself as a "non-race" film yet subtly suggest anti-immigration sentiments, white savior narratives, and which promotes a white beauty standard. Through the critical analyses of these two films, I delineate how Hollywood films are discursively invested in maintaining the racial status quo through colour-blind ideology.

In Chapter 5 - Conclusion, I conclude and summarize my findings and include limitations of this work and areas requiring further investigation. 
“Tonight we celebrate Hollywood's best and

whitest, sorry... brightest"

- Neil Patrick Harris, Oscars 2015

\section{Chapter 2 - Naturalizing Colour-blindness}

Critical researchers such as Hall (1996), Dyer (1997), Guerrero (1993), Rocchio (2000), Yuen (2017), and Shaheen (2011) have demonstrated in their works that Hollywood films have done their part in maintaining a racial hierarchy through the dissemination of narrative themes and stereotypes. Cheryan and Mahtani's studies show that these narratives have often depicted "white" as both the dominant group and as a "norm" in American (and, Canadian) society which has put strain on non-white identity living in these countries (2005; 2004). Patricia Hill Collins argues that the central ideological component of all systems of domination in Western society is either/or dichotomous thinking which therefore inherently opposes white with black and subject with object (Collins, 1990, pg. 68-69). Therefore, the "naturalization" of whiteness as a norm in American discourse creates a binary opposition of non-whites as deviant. In the mainstream Hollywood cinema, non-white characters have typically been assigned to play the roles of villains, buffoons, sidekicks and the comic relief (Yuen, 2017, pg.10). It is worth remembering that for all its critical acclaim and Academy Award wins and nominations, Breakfast at Tiffany's (1961) also portrayed actor Mickey Rooney in full yellow-face (Rey, 2017).

Val Rey argues that, Mr. Yunioshi's character is "rooted in racist, anti-Asian stereotypes towards Japanese people" (2017) and notes that the racialization of Asians in theater became mainstream as a result of Yellow Peril and other Post WWII phenomena" (2017). Mr. Yunioshi embodies a slew of racial stereotypes meant to "other" him from the norm 
of American whiteness through his aggressive presence, buck teeth, bathrobe and exaggeratedly narrow eyes (Rey, 2017). Those who are subjected to racist stereotypes in mainstream media become the butt of the cultural joke and have a limited repertoire of cinematic characters in which to positively identify with. Instead of subverting the stereotypical representations to more positive depictions, modern cinema hopes to consume non-white audiences to the hegemony of a white norm, inviting them along to "participate" in their domination. To quote American poet Ella Wheeler Wilcox; laugh, and the world laughs with you; weep, and you weep alone.

Through this study, I wanted to uncover the extent to which racist cinematic representation had evolved in mainstream movies from the early days of Hollywood during a time period in which Mr.Yunioshi would have been a socially acceptable portrayal to the "postrace" era. Exclusions of characters like Mr. Yunioshi from "post-era" films does not necessarily indicate racial progress, but it instead provides a false sense of improved race relations. The simple erasure of black-face or yellow-face characters only corrects the most obvious offense, distracting from the larger picture of racial inequalities embedded in visual culture and cinematic representations. Rocchio argued in Reel Racism, that it is "not because audiences are more sophisticated than spectators of the past, but because the "truths" that grounded the processes of racism in the past... have been by and large discredited by all but the most fanatic" (2000, pg.31). The "truths" grounding the process of racism are no longer concerned with biological inferiority or outdated pseudoscience but are now intimately intertwined with the concept of racial "colourblindness". The "post-race" ideological underpinning of being "blind to colour" has replaced the low-hanging and spoon-fed stereotypes of the past in favour of more subtle tactics of "naturalizing" the racial order. Therefore, in this study I also want to illuminate these methods of colour-blind racism which justify holding the colour line in place while seemingly 
"extinguishing" the fires of racial inequality. Finally, it was important to me to bridge the epistemological gap between critical academic research, and the social attitudes outside of academia which have told me again-and-again that "movies are just entertainment" and that "there is no race problem".

Ferdinand de Saussure's concept of semiotics has been influential as a method to better understand culture as a "language" that can be "read" by society. This approach argues that words, signs and symbols disseminated through mass media are socially specific and culturally relevant instead of having "fixed" and longstanding meanings. Though arbitrary, the meanings attached to these signs and symbols become the "knowledge" that viewers and consumers of media internalize. The semiotics approach is useful at explaining how blatantly racist portrayals used in early cinema constructed a "truth" about race which has negatively impacted the social wellbeing of African-Americans. As Foucault had argued "knowledge, once applied in the real world, has real effects, and in that sense at least, 'becomes true' (Hall, 1996, pg.49), providing a cautionary warning for the impact that mass media has on knowledge production and the population groups who suffer from the symbolic violence of stereotyping. Though semiotics has its limitations when it comes to power, domination and narrative control because it is more focused on the relationship between a symbol and what it represents. However, semiotics provides valuable insight to the malleability of symbolic imagery and the potential for renegotiating and subverting stereotypes.

To better understand the link between meaning and representation, French sociologist Michel Foucault's concept of discourse helps navigate how the logic of knowledge production is enmeshed with fiction. Outlined by Hall, discourse is a;

"Group of statements which provide a language for talking about - a way of representing the knowledge about - a particular topic at a particular historical moment... Discourse is 
about the production of knowledge through language. But... since all social practices entail meaning, and meanings shape and influence what we do - our conduct - all practices have a discursive aspect" (1996, pg.44)

Concerned with the inextricable link between knowledge and power, Foucault further articulated that discourse never consists of just one text or source but appears across a range of texts in many institutional sites within society that share the same style and pattern thus belonging to what he called a discursive formation (Hall, 1996, pg.44). In other words, when a symbol is constantly and consistently associated with the same "meaning" through a variety of mediums over time, the symbol and what it represents seem to connotate apparent "truths" or "naturally" fixed explanations. Discourse provides a "fuller" understanding of how meanings become "naturally fixed" and the consideration of history is essential in discursive formation. What I have discovered is that a successful strategy of maintaining the racial status quo with colourblindness is the attempt at re-writing, or erasing history. By eliminating a historical context, those oppressed by colour-blind ideology lose the deep roots required to justify their struggle. For example, colour-blind racism typically minimizes or downplays racial struggles because of the ideology that racism is a thing of the past, or that it isn't as bad as it once was.

Because symbols are culturally specific and contextually relevant, what they represent instead becomes what Roland Barthes calls the "myth", or a subjective interpretation about the symbol. The interpretation of the "myth" typically falls in the hands of the dominant group and is then disseminated throughout society to solidify a particular ideological understanding. For example, when European colonizers first came to North America, indigenous populations were reduced to the racial stereotypes of savages without civilization and were "degraded and dehumanized by equating them with animals" (Rocchio, 2000, pg.22). However, it still required a certain ideological finagling to garner support for the genocide and conquest of an entire 
peoples. By discursively situating indigenous group as inferior to the "race" of European whiteness, and by contrasting indigenous ways of life with European Christianity (which had powerful explanatory power at the time, yet nowadays is more ideologically weakened), genocide and conquest could be more easily justified.

Rocchio argues that because "racism has been an integral component of American culture since its founding upon the genocide of Native Americans, and the forced slavery of Africans and Afro-Americans" (2000, pg.4) that it has persisted through the continued assigning of difference in "us" and "them" binaries. Rocchio further argues that "contemporary American society is multiethnic and multiracial, but it is not color-blind - much as it would like to claim to be" (2000, pg.4). Indeed, Augie Fleras similarly argues in Unequal Relations (2017) that "despite claims that we live in a post-racial and pro-multicultural society, reinforcing its contested status is one of the defining issues of contemporary times" (pg.70). Fleras writes;

"References to racism consist of those ideologies that explicitly extol racial superiority, those beliefs or practices involving coded comments about inferiority, and those individuals and institutions without any clear racialized reference but whose actions may exert adverse consequences on marginalized minorities... racism refuses to go away even though we would like it to. Instead, racism has proven notoriously resistant and adaptive" (pg. 71-72).

"Post-race" presumes to be "merit-based and achievement oriented" (Fleras, 2017, pg.36)

and therefore references of race are deemed to be "retrograde or offensive" (Fleras, 2017, pg.36). Despite the "colour-blind" principles of meritocracy, race continues to "profoundly mold a person's life or life chances [and] remains a marker of a person's worth and a predictor of success" (Fleras, 2017, pg.36).

This has been demonstrated in a variety of studies such as Sonia Kang et al.'s Whitened Resumes: Race and Self-Presentation in the Labor Market (2016). In this study, researchers investigated the benefits of "whitening" resumes by eliminating "racial cues". Techniques of 
resume whitening included respondents presenting a more "American-sounding name" and removing certain experiences from their resume which suggested that they were not white (Kang, 2016). For example, one responded explained that because she had worked for a lot of black organizations on her college campus, she felt the need to remove them in order to "tone down [her] blackness" (Kang, pg. 476, 2016). Kang et al. discovered that "black participants who described engaging in resume whitening emphasized that an important reason for doing so was to signal their ability to fit in with white employers and coworkers" (2016, pg.17). By removing racial cues from their resumes, respondents felt that it would eliminate the stereotypes of being radical, outspoken, or involved in racial identity politics” (2016, pg.17, my emphasis). This study demonstrates that companies that promote "valuing diversity" did not have reduced discrimination against unwhitened resumes and that "racial cues" on resumes contribute to hiring discrimination practices. The researchers had concluded that "racial inequality in labor markets persists despite organizational and individual efforts to reduce bias" (pg. 40, 2016). Even though America considers itself as "post-race" and ideologically "colour-blind”, deeply rooted racial prejudices and stereotypes continue to have "real world" impact.

Fleras argues that the "colour-blind" and "post-racial" stance of America presumes that race no longer matters because a black man had been elected as the President of the United States. Based on the election of Obama as the first black President, racial inequalities are viewed as relics of the past and meritocracy is asserted as the most important indicator of success. Proponents of colour blind racism often assert that racialized minorities have only themselves to blame for their shortcomings, and there is no justification for race-based equity programs because since everybody is "equal", it would be "anti-racist", "unfair to whites", and a violation 
of the core values of meritocracy based on individual effort instead of racial affiliation (Fleras, 2017,pg.55). Fleras concluded that colour-blind ideology resembles the "proverbial Trojan horse in concealing the centrality of systemic racism, individual minority problems, securing social control through consent rather than coercion, and assuming a de-raced playing field where none exists" (2017, pg.55-56).

Racism has become so nuanced and complex in contemporary society, and the mechanisms of colour-blindness and post-race ideology only further complicate the matter. Like the child who hides under the covers out in the open and insists that "if I can't see you, you can't see me!", colour-blindness has become the ideological justification for the omission of racist historical state formation and of contemporary racial inequalities. Though more subtle than the genocide of the Native Americans during European colonialism, colour-blind racism disseminates narratives, symbols, and texts which are interpreted by the dominant class as knowledge. In other words, through semiotics and a collective agreement of the "natural" order of things; the myth. This contributes to the way individuals read media texts and see themselves, and others, through the mythological construction of race which positions them in society as either part of the dominant group or the sub-dominant group.

What implicates Hollywood films in the discursive formation of a racial status quo, and of the mythological construction of blackness is the familiar patterning and denigrating stereotyping of black people which has persisted over one-hundred years in mainstream cinema. The frequency of films that depict whiteness as central and norm in contrast to the ubiquity of black people as villains or sidekicks demonstrates the saliency of discursively positioning black as being inferior to white. Classifying and symbolically fixing black people as 'other' or subordinate to white is a form of symbolic violence (Hall, 1996, pg.259) used to maintain the racial status quo in American society through cinematic representation. Over this one-hundredyear period of cinema, the underlying goal of maintaining white superiority above all else has not 
changed, but the strategies employed to ideologically justify racism has had to. Ever since President Woodrow Wilson had declared that The Birth of a Nation (1915) was like writing history with lightning, black people in mainstream cinema have been subjected to the discursive positioning of being lesser than white people through film, however biology or religion no longer hold enough explanatory power to legitimize the continued denigration of black people and other racialized minorities in popular culture.

In Hollywood films today, historical accuracy and racial representation continue to be a site of controversy. During a backstage interview at the 2019 Academy Awards ceremony, African-American film director, Spike Lee, had urged America to be on the "right side of history" for the upcoming presidential election. Lee's film, BlackKklansman (2018), which won the Oscar for Best Adapted Screenplay, concluded with the harrowing images of the death of Heather Heyer at a "Unite the Right" rally in Charlottesville in 2017. In his interview, Lee said;

"Heather Heyer, her murder was an American terrorist act. That car drove down that crowded street... and the president of the United States did not refute, did not denounce the Klan, alt-right and neo-nazis. This film - whether we won best picture or not - this film will stand the test of time being on the right side of history" (Wang, 2019).

BlackKklansman subverts the stereotypical character tropes in mainstream films and tells the true story of African-American detective Ron Stallworth who sets out to infiltrate and expose the $\mathrm{Ku}$ Klux Klan. BlackKklansman uncharacteristically places white Americans as the villains of the film, challenging the discursive formation which for so long has made white people the saviours and heroes. Furthermore, Lee's insistence that Donald Trump did not refute the Klan and those responsible for Heather Heyer's death is an important detail for narrative control. History is crucial in acting as reference points for racial atrocities, and with the President declaring that there were very fine people on both sides, the narrative switches from an act of neo-Nazi violence to a neutral incident in which a tragedy occurred. Because colour-blind racism and 
"post-race" ideology depend on smoothing over historical racisms and presenting contemporary race relations as "much better than before", Trump's discursive gymnastics attempt to maintain the colour line by insisting that this tragedy was not racially motivated, relieving anxieties for the dominant in-group of American society.

Since the early 1900s, the constant dissemination of negative racial stereotypes and imagery through the monopolistic cinematic apparatus of Hollywood has been the site of perpetual contestation for African-Americans who have been determined "since the inception of commercial cinema to militate against this limiting system of representation" (Guerrero, 1996, pg.3). Furthermore, the narratives which have favoured the "myths" of white supremacy, centrality, and norms in films continue to be scrutinized by the likes of Spike Lee. Insisting he is on the "right side of history", Lee continues to produce and write films which illuminate an opposing ideology of contemporary "post-race" relations in the United States. What Foucault's discourse approach outlines is not just the relationship between the sign and symbol and their meaning, but also the relations of power and knowledge in who is defining and producing the objects of knowledge. Discourse is concerned with the power of narrative control which constructs "knowledge" and which "governs the way that a topic can be meaningfully talked about and reasoned about [and] how ideas are put into practice and used to regulate the conduct of others" (Hall, 1996, pg.44). Furthermore, what discourse results in is the construction of subject-positions;

"the position from which we/they must locate ourselves/themselves in the position "from which the discourse makes the most sense, and thus become its 'subjects' by 'subjecting' ourselves to its meanings, power and regulation” (Hall, 1996, pg.56).

Proponents of colour-blindness in the murder of Heather Heyer, for example, would therefore locate themselves from the ideological positioning that the attack was not racially motivated or charged by hate, thus removing oneself from the guilt of benefitting from racism, or from being 
part of racism. Furthermore, in popular discourse, because there is limited representations for black people in Hollywood films, it reduce opportunities for black people to position themselves in the discursive formation of anything other than that of the marginalized, deviant, subjugated, or inferior. This socializes black people in mainstream society to see themselves as outside of the "norm" of "American core values" and demonstrating the need for more humanizing and multifaceted portrayals of blackness in future films. What Spike Lee and other prominent black film producers, directors, and writers are striving for is to combat the grand narrative of white superiority by subverting stereotypes and racial imagery while being on the "right side of history". Jordan Peele, another African-American screenwriter responsible for the genius script of Get Out, has also effectively subverted racial stereotypes and challenged the "post-race" era through his film.

Despite Lee and Peele's successes, it was revealed in 2013 that only 8 percent of film studio heads were people of colour, and "compared with the rest of corporate America, Hollywood executives rank last in terms of racial diversity" (Yuen, 2017, pg.32). What this data suggests is that because "white men are overrepresented as directors" (Yuen, 2017, pg.34) in television and film, discourse and narrative are primarily controlled by "White America", who produce and reproduce the symbolically fixed borders of insiders and outsiders, appearing as "natural", through stereotyping and cinematic representation (Hall, 1996, pg.258). Hall argues that because meaning and representation is, in fact, not natural or fixed, it opens itself up radically to history and change (1996, pg.31-32). Thus, because representations and meanings are interpretative, they subject themselves to the constant "play" or slippage of meaning and opens the possibility to new meanings and interpretations (Hall, 1996, pg.32). It is with this in mind that Peele and Lee optimistically hope to open up new meanings and interpretations for the 
denigrated images of black people that have persisted in mainstream films. This insight suggests the possibility for changing how race is represented through outlets of discursive formation, such as through Hollywood films, and gives hope for more positive portrayals of blackness in films. Hall further suggests that by increasing the range of racial representations on the silver screen and by broadening the complexity of what it means to be black in more humanizing and diverse roles in cinema, films can challenge the reductionism of earlier offensive and denigrating stereotypes (Hall, 1996, pg. $272-273$ ).

However, because Hollywood has adopted the stance of colour-blindness which has successfully disguised symbolic violence, pinpointing racism in films have become more difficult, and supporting anti-racism sentiments towards Hollywood films in general has also become more difficult. Because popular Hollywood films typically reflect dominant societal ideology, to call Hollywood racist is to call American society at large racist. Hollywood has been as successful as American society at postulating itself as "post-race" and colour-blind.

\section{"Yes We Can!" The Obama Era and the "Post-Race" Lie}

In 2009, Barack Obama became the first African-American and the 44 $4^{\text {th }}$ President of the United States. His election into the White House was a ground-breaking moment and the symbolism of his presidency carried the extra weight of profound racial implications. For the first time ever, a "black man would occupy a White House built by slaves... a history-defying as well as history-making achievement" (Bryant, 2017). This event had caused conservatives and liberals alike to agree that "the election signified America has truly become a "post-racial" society" (Dawson, 2009). Critical scholars wrote that "with Obama's victory, the urge to erase clean the nation's four-century racist slate [had] become even more irresistible" (Pettigrew, 2009) and that Americans seemed to be collectively shouting "we have a black president, so we 
are finally beyond race!" (Bonilla-Silva, 2018, pg.17). Like Jesus on the cross, Obama had seemingly absolved America of its sins of its racist history, which as previously mentioned, is important at maintaining the colour line. The desire to "erase" four-hundred-years of racism in an instant is what makes "post-race" America comparable to a "la la land". Obama had suddenly become the symbolic representation of the American Dream and improved race relations: Yes We Can!

In the film Get Out (2017), African-American director, Jordan Peele, wrote and developed the film during the Obama administration, an era which he personally had considered was the "post-race" lie (Ramos, 2017). Peele wrote the script intentionally to subvert movie tropes that have been rampant in cinema, such as the "white saviour" narrative, which Peele points out is a way of reassuring white audience members that "they aren't racist" by including characters who end up "doing the right thing" regardless of race, class or gender. In Get Out, Peele instead wrote the script which "every white person in the movie is evil" (Ramos, 2017) as a way of re-articulating the dominant cinema narrative of white as norm, central, or saviour. Peele understands that, at least in part, white audiences view films to escape, to dream, and to identify with central characters. The "white saviour" narrative is so ubiquitous because it appeases such a large percentage of the American population. Furthermore, the white saviour typically "does the right thing" regardless of race, because audience members can then feel good about themselves as a reflection of what they would do. Peele challenges the dominant cinematic apparatus and brilliantly illuminates the contradictions of the "post-race" era which assume race doesn't matter. By subverting character tropes, and making "every white person evil”, white audiences can only positively identify with the black lead character, Chris, putting them in the ideological positioning of rethinking race and why it still matters. 
What Spike Lee's boycott of the Oscars, \#OscarsSoWhite, his interview about being on the "right side of history", and Jordan Peele's clever subversion of dominant narratives in cinema offers is an insider perspective of the continued misrepresentation and underrepresentation of blackness within Hollywood films in what is supposedly a society of the "post-race". Clearly in terms of meaningful lead roles in major films and acting nominations, the Oscars show another side of the coin; the reality that race still matters, and the ongoing frustration of black directors and writers in mainstream film who vehemently disagree with "post-race" ideology. What has made it more and more difficult over the last few years to combat racial representations in films are the ideological justifications of "colour-blindness", which accordingly to the "post-race" era, equally assume that race doesn't matter, and even more poignantly, that race isn't even visible. It is the dismissing of Lee and Peele for being outspoken, radical or extreme, or even racist, which continues to confuse society about the focal point of racism. An example of this came in response to Lee's 2019 Oscar speech in which he said "The 2020 presidential election is around the corner. Let's all mobilize. Let's all be on the right side of history. Make the moral choice between love versus hate. Let's do the right thing!" (Wang, 2019). Once again, President Donald Trump attempted to "colour-blindly" hold the racial status quo in place by writing on Twitter "Be nice if Spike Lee could read his notes, or better yet not have to use notes at all, when doing his racist hit on your President, who has done more for African Americans... than almost any other Pres!" (Wang, 2019). President Donald Trump, who has insisted he is "the least racist person", has also managed to publicly flip the script on Spike Lee by calling him racist. In a strategy which displaces racism from himself onto Lee, Trump's response demonstrates how white people in America can equally feel victimized by racism and invoke colour-blindness to justify their claim. 


\section{Colour-blind Hollywood, Strategies of Deference}

In The Racial State (2002), David Theo Goldberg writes that; "racelessness is the neoliberal attempt to go beyond - without (fully) coming to terms with - racial histories and their accompanying racist inequities and iniquities” (pg.221). Rather than considering historical underpinnings of contemporary racial inequality, colour-blind racism would rather insist that all races have "equal treatment before the law" (Goldberg, 2002, pg.221) and "equal opportunity as process” (Goldberg, 2002, pg.221). Kang's resume study provided examples of how “equal opportunity" continues to be a "post-race" ruse based on racist hiring practices (2015). As for "equal treatment before the law", Bonilla-Silva has argued that so many black people have been killed by law enforcement that it begins to "normalize" police brutality (2017, pg.36). The facile argument that race doesn't matter continues to disregard socioeconomic and educational differentiation that resulted from racial exclusion and white privilege in the past. Therefore, as Fleras argues, "groups that are disadvantaged because of a late start will continue to fall further behind" (2017, pg.57).

Fleras argues that because the "values, agendas, and priorities of those who created or control society are deeply ingrained within its governance, institutions, and foundational principles $[\ldots]$ the result is a racialized society" (2017, pg.56). This includes Hollywood films and those in decision making positions in the film industry who maintain the racial status quo while not appearing racist. Colour-blindness sweeps racist historical state formation under the rug and denies the contemporary benefits of whiteness and the "traces of its ghostly power" (Goldberg, 2002, pg.223). Furthermore, this ideology either downplays or dismisses the impact of contemporary racial inequality and can put the blame on black people through such strategies as accusations of anti-white "reverse racism". For example, when Oscar nominee 
Charlotte Rampling called Lee's claims of \#OscarsSoWhite "racist to whites" and suggested that perhaps "black actors did not deserve to make the final list" (Yuen, 2017, pg.2).

Racial colour-blindness not only "rationalizes and justifies racial inequalities in society, but also absolves whites of any responsibility for doing something about disparate outcomes and discriminatory practices" (Fleras, 2017, pg.56). What makes colour-blindness attractive, especially to white people in America, is the erasure of historical crimes and the prospect of "leaving bygones behind" (Goldberg, 2002, pg.221). Thus, admirers of Breakfast at Tiffany's, for example, can continue to enjoy the film justifying to themselves that blatant racism in classic cinema was more acceptable "back then", but now we are above that. Contemporary Hollywood films smooth over any guilt of white privilege and historical racist sentiments through the ideological fabrication that race no longer matters, because in a colour-blind society, it is the "minorities who need to be more responsible, hardworking, and integrative" (Fleras, 2017, pg.55). The "post-race" era can be equated to a "La La Land"; an ideological escape from the ongoing issues of mass incarceration, police violence, poverty, and discriminatory hiring practices against those who continue to be racialized, yet no longer garner sympathies from the dominant ingroup.

Colour-blindness is a strategy of downplaying the extent of contemporary racism while ignoring the historical and structural formations that have led to massive disparities in just about every quantifiable metric for people of colour. Bonilla-Silva argues that in America, "blacks and dark-skinned racial minorities lag well behind whites in virtually every area of social life" (2018, pg.2); including earnings, net worth, quality of education, less access to housing markets, increased police profiling, and over representation in arrests and incarcerations (Bonilla-Silva, 2018, pg.2). Fleras found that in Canada, minorities and migrants also fall behind in income, 
unemployment, and poverty rates $(2017, \mathrm{pg}$. 151). It is misguided to suggest that historical and structural factors impacting ongoing racial inequalities are no longer relevant. The racial disparities outlined by Bonilla-Silva do not simply exist in a vacuum, however what colour-blind racism accomplishes so effectively is that it insists that they do. Consider what Lyndon B. Johnson said when addressing the Civil Rights Movement and the ongoing impact that white privilege continued to have;

"You do not wipe away the scars of centuries by saying, "Now you are free to go where you want, do as you desire, and choose the leaders your please." You do not take a man who for years has been hobbled by chains, liberate him, bring him to the starting line of a race, saying, "You are free to compete with all the others," and still justly believe you have been completely fair" (Fleras, 2017, pg.57)

Hollywood films have successfully encapsulated colour-blind ideology by downplaying the extent of racism in the past, and by creating films that continue to other softly. Guerrero argues that Hollywood has been willing to "refine the art of suggestion" ever since the NAACP protested the denigrating stereotypes of black people in The Birth of a Nation (1993, pg.17). Guerrero writes that "Hollywood had to learn to pull its ideological punches" (1993, pg.17) in Gone With the Wind to avoid "overt inflammatory propaganda" (1993, pg.17). Less interested with erasing the colour line and more with box office and financial success, Hollywood "relies heavily on past hits, formulas, and big-name actors [which] goes hand in hand with racial bias" (Yuen, 2017, pg.15) and has continued to refine how race is portrayed without separating from the ideological underpinnings of the racial status quo. Colour-blind racism and merit-based ideology have empowered Hollywood to refuse to acknowledge that it is not an equal playing field, and continues to be "one of the most powerful and flagrant (even if unconscious) perpetuators of racism through exclusionary and stereotyped storytelling and casting practices" (Yuen, 2017, pg.50) 
Through racial colour-blindness, contemporary racism operates in more covert ways than in the past which is perhaps why it has been more difficult to combat. Bonilla-Silva argues that colour-blind racism explains the racial regime of post-civil rights America, [and] the dominant racial ideology that glues this order together $(2018, \mathrm{pg} .2)$. Bonilla-Silva elaborates that colourblind racism "explains contemporary racial inequality as the outcome of non-racial dynamics" (2018, pg.2). For example, rather than using the "biologically inferior" arguments in the past which explained African-American's social poisoning in America as a mythological construction, colour-blind racism instead focuses on "market dynamics, naturally occurring phenomena and cultural limitations" (2018, pg.2) to explain contemporary, race-based inequalities. As Rocchio had suggested, "it is not because audiences are more sophisticated than spectators of the past, but because the 'truths' that grounded the processes of racism in the past... have been by and large discredited" (2000, pg.30-31).

Foucault articulated that discourse never consists of just one text or source but appears across a range of texts in many institutional sites within society. When these texts and images share the same style and pattern, they belong to, what he called, a discursive formation (Hall, 1996, pg.44). Needing new ways of cementing "truths" to maintain the colour line, colour-blind racism had become the prominent ideology for maintaining the racial status quo since the late 1960s (Bonilla-Silva, 2018, pg.2). Since its inception, Hollywood films have had peculiar representations of blackness on screen, and the stereotypes and tropes have not completely washed away simply because of colour-blindness. Though proponents for colour-blind ideology might argue that these images have greatly improved, or even let Hollywood off the hook for the past because that's just the way things were back then, they miss the point of how the 
routinization of racial imagery, ambivalent or otherwise, contributes to the discursive formation of naturalizing racial difference.

Another further example of colour-blindness which scrutinizes individual merit rather than accounting for structural inequalities is the ideology of the American Dream. The American Dream suggests that anyone, regardless of race, can rise to the top of the social order through hard work. As Bonilla-Silva points out, by adopting and promoting this ideology as a "social fact", then the lack of successes of African-Americans can be explained by their inability to work hard enough. Therefore, when black people are portrayed on screen as the welfare moms, the drug dealers, the poor, and the criminals, filmmakers can justify these portrayals through colourblindness by claiming that that's just the way it is. Thus, "whites enunciate positions that safeguard their racial interests without sounding "racist" (Bonilla-Silva, 2018, pg.4), for example when movie studios or filmmakers "write what they know" because of previous box office success or regurgitate racial stereotypes for characters because they had seen it been done in so many films before.

Included in this safeguarding of the American Dream is the antagonistic strategy which marginalizes poor whites. The movie I, Tonya (2017) brilliantly illuminates how class intersects with race demonstrating that there are "layers" to whiteness. I, Tonya tells the true story of American Olympic figure skater, Tonya Harding, who because of her "white trash aesthetic" is constantly put down by her mom, her peers, and her classmates. Judges in figure skating competitions refuse to give Tonya high scores because she has not "paid her dues" like the other girls, indicating to her that because she is poor "white trash", she does not belong in the world of figure skating, especially as a representative of the United States on the world stage. Tonya 
realizes the hindrance that her poverty is causing her professional career at a young age. An exchange between Tonya's mom, LaVona, and her figure skating coach, Diane, goes as follows;

LaVona: What's she need a fucking fur coat for? I don't have a fucking fur coat Diane: Because it's not just about skating, the judges want the figure skaters to be...

LaVona: [cutting off Diane]Yeah! Rich, prissy a-holes

Diane: [continuing] well-rounded. It's a question of fitting in.

LaVona: She's 12 and she lands fucking triples, she doesn't fit in, she stands out! Diane: She stands out because she looks like she chops wood every morning LaVona: She does chop wood every morning...

LaVona's use of profanity in the exchange demonstrates the clear class distinction between herself and Diane. What further alienates Tonya from "whiteness" is her lack of a fur coat; a symbol of status and financial capital. Diane tries to explain to LaVona that figure skating is about "fitting in" and belonging to a specific social group, however LaVona insists that Tonya's ability to "land triples" should make her stand out as a better figure skater than the other girls. Clearly, merit and ability are less important than social and financial capital in the realm of figure skating, and Tonya's "American Dream" becomes a constant uphill battle because she is "white trash".

The strategy of marginalizing poor whites works alongside colour-blindness and "postrace" ideology, because like other racialized groups in America, poor whites are blamed for their own shortcomings. Furthermore, poor whites act as the scapegoats for legitimizing that race doesn't matter, because otherwise, those like Tonya would not experience the social barriers that hold them from rising to the top. What I, Tonya effectively demonstrates is how "whiteness" is complexly enmeshed with class and that poor whites are used to justify that there is no racial agenda. 
Along with the everyday and routinized micro-aggressions that racialized people experience; colour-blind racism operates in a plethora of covert ways. Bonilla-Silva highlights some of these methods such as "steering minorities and whites into certain neighborhoods, quoting higher rents or prices to minority applicants... advertising job openings in mostly white networks, [and] steering highly educated people of color into poorly remunerated jobs" (BonillaSilva, 2018, pg.3). Colour-blind racism is subtle and couched, and as Bonilla-Silva notes, discriminates with a smiling face. Fleras calls this form of colour-blind discrimination "polite racism" (2017, pg.92). Fleras writes that polite racism is "a way that allows people to conceal their dislike of others by way of coded language [and] assign social significance to race, despite its social and legal sanctions, in large part by relying on euphemisms to express racial views without appearing racist" (2017, pg.92). By maintaining that one "doesn't see colour" and sees "only people", it also denies that race matters, and ignores a massive systemic issue which, as outlined earlier, shows numerous examples of racial disparity in terms of wages, housing, incarceration, and increased securitization. This ideology of colour-blind racism enacted through Hollywood films "can blur reality and fiction for viewers... [and] when whites and their stories are celebrated more than their fair share, audiences begin to associate significance, admiration, and power with that group over others" (Yuen, 2017, pg.20) through discursive formation.

Hollywood films reinforce the racial order through narratives, themes, stereotyping and symbolic representation. Bonilla-Silva suggested, the "collective practices that help reinforce the contemporary racial order" (2018, pg.15) is a good starting point in deconstructing modern colour-blind racism and understanding how it operates in society, highlighting the necessity for more critical analysis in contemporary media content. Deconstructing how race is seen, portrayed, and represented on the silver screen can offer insight into real-world race 
relations, especially in films like Get Out (2017) which was written by Jordan Peele as a direct response to current and ongoing race relations in America (Keegan, 2017). Movies act as a socializing agent and are part of culture and social life. Yuen argues that because, "acting has long been used as a framework to understand the process by which people create and perform social roles in everyday life" (2017, pg.17), representations on the silver screen are meaningful for "real world" social interactions and perceptions in terms of how we see ourselves and each other.

Bonilla-Silva articulates that colour-blind racism needs to be understood as a discursive practice of the "central elements of liberalism [that] have been rearticulated in post-civil rights America to rationalize racially unfair situations" (2018, pg. 56) in a modern setting. As previously outlined by Fleras, liberalism is the ideology that assumes that "our commonalities as freewheeling individuals" is more important than what "divides us racially" (Fleras, 2017, pg.36). Canada and America, which were founded upon slavery, genocide and colonialism, continue to invoke the same racialized principles as the past, only in modernized and re-coded ways, particularly through modern colour-blindness. Bonilla-Silva outlines four examples; equal opportunity, naturalization, cultural racism and minimization of racism to explain ways in which the principles of liberalism, along with the principles of colour-blindness have contributed to the ideological justifications of contemporary racism. These examples are essential in understanding how Hollywood has maintained a racial hierarchy through cinematic (mis)representation of blackness without suffering any major backlash in recent years apart from the lukewarm \#OscarsSoWhite protest. In the end, \#OscarsSoWhite fizzled without any definitive impact on diversifying the majority position of whites who control all aspects of cinema (Yuen, 2017, pg.1). These four strategies of colour-blind justification are routinely used to either promote 
colour-blind racism in film, or to legitimize racist sentiments. Because Hollywood and Hollywood films have implored these strategies, they have assisted in smoothing over feelings of guilt and anxieties about race relations because of the "La La Land" that Hollywood escapism creates for audiences.

For equal opportunity, Bonilla-Silva writes "the principle of equal opportunity central to the agenda of the civil rights movement and whose extension to people of color was vehemently opposed by most whites, is invoked by whites today to oppose affirmative-action policies because they supposedly represent the "preferential treatment" of certain groups" (2018, pg.56). This claim which "necessitates ignoring the fact that people of color are severely underrepresented in most good jobs" (2018, pg.56) is exemplified in Nancy Yuen's work in Reel Inequality: Hollywood Actors and Racism (2017) in which she details an example of Hollywood hiring practices for actors of colour in which the Motion Picture Association of America (MPAA) denied a Coalition Against Blaxploitation claims in 1972, and "instead of acknowledging institutional bias, the MPAA accused the group of "reverse discrimination" and asking for "a handout"(2017, pg.56) and "framed the lack of African Americans in the industry as a natural outcome of competition between groups" (2017, pg.56). The ignoring of institutional bias and the refocusing on racialized individuals "asking for a handout" also reinforce the narrative of the American Dream and meritocratic ideology which assumes "all races" to be evenly considered. By pretending that equal opportunity exists for everyone and that race doesn't matter, "most whites", as Bonilla-Silva had argued, feel justified in partaking in the victimhood (ie/ Reverse-racism) which suggests they can also be targets of racism and discrimination and are therefore less sympathetic or accepting of institutional and systemic inequalities that statistically disadvantage black people. This was also exemplified in I, Tonya in which Tonya felt victimized 
during her quest for Olympic gold in figure skating. When poor whites also fall victim to the mythology of the American Dream, they are less sympathetic towards black people and other racialized groups. If anything, poor whites feel most victimized because the illusion of their whiteness is shattered without benefitting from the privilege it had promised.

For Naturalization, Bonilla-Silva argues that;

"whites can claim "segregation" is natural because people from all backgrounds "gravitate toward likeness". Or that their taste for whiteness in friends and partners is just "The way things are" (Bonilla-Silva, 2018, pg.56).

Naturalization is perhaps the most important aim of colour-blind visual culture because it establishes the racial status quo as a "norm". Yuen notes that a strategy that Hollywood writers implement to maintain primarily white actors and white stories is the "write what you know" clause. This strategy naturalizes racial segregation and assumes that whites simply prefer to be with other whites. Yuen argues that "therefore, whites cannot be blamed if all they have are white relationships and experiences on which to base their writing" (2017, pg.57). This strategy was implored by Lena Dunham whose hit HBO show Girls was criticized for its lack of diversity despite being set in the very ethnically diverse New York City. Dunham justified her casting decisions and argued that the stories she writes are "super specific to her "experience" as a "halfJew, half-WASP", rather than experiences of women of color she "can't speak to accurately" (Yuen, pg.57, 2017). La La Land (2016), which I will analyze in Chapter 4, also takes place in the very ethnically diverse city of Los Angeles, but curiously lacks any sort of meaningful racial diversity in its casting. This naturalization of a white norm, especially in cities which are very ethnically diverse, show how colour-blind justifications work to legitimize omitting people of colour from the narrative and reproduce a sense that Hollywood and America are first and foremost white. Stuart Hall argues that a strategy that could be implemented to contest denigrating stereotypical representation of black people could be to expand the range and 
complexity of what it means to 'be black', and show a more positive identification in the sea of otherwise negative cinematic images (1996, pg.272-273). However, the chances of subverting anti-black stereotypes are controlled by the amount of opportunities black actors have in being casted in mainstream films and big budget productions. By continuing to only write stories of white people by white people, it limits the power of discursively constructing blackness as more than peripheral.

Bonilla-Silva argues that cultural racism, is a "frame that relies on culturally based arguments such as... "blacks have too many babies" to explain the standing of minorities in society" (2018, pg.57). Yuen provides examples of Hollywood practices that demonstrates Bonilla-Silva's example through typecasting and the use of stereotyped roles in films. Yuen writes that;

"the practice of racializing people of color and normalizing whites is common in Hollywood. This mirrors US society, in which racial and ethnic identities are largely optional and symbolic for whites but compulsory for people of color because of persistent racial labels and stereotypes" (pg.70, 2017).

The assumption that "blacks have too many babies" contributes to a variety of racial stereotypes persistent in Hollywood film, including the welfare queen, the jezebel, and the black buck, thus reinforcing social negative attitudes towards black people in real world situations. Stereotyping is a signifying practice which dominants the image of the subjugated group, and as previously mentioned, the "truths" that ground these stereotypes are constantly changing. Because biological racism since slavery has lost its explanatory power in black women's reproduction, colour-blind ideology uses the framing of cultural racism to hold prejudice in place. Important to maintaining the racial status quo is continuing the underlying ideology of white superiority but finding new ways to explain and naturalize "racial difference". 
Cultural racism is promoted through the types of Hollywood practices of disseminating the stereotypical images which engender a sense of "knowledge" about racialized groups, such as the welfare queen trope. Bonilla-Silva explains this through story lines; "socially shared tales that are fable-like and incorporate a common scheme and wording" (2018, pg.97), in which "telling and retelling these story lines, members of a social group (in this case, the dominant race) strengthen their collective understanding about how and why the world is the way it is" (2018, pg.97). Similar to Foucault's discursive formation, the ideological nature of these story lines is that "storytellers and their audiences share a representational world that makes these stories seem factual" (2018, pg.97), so the harmful continuation of stereotyped roles in films contribute to a social confirmation that these roles are "factual" rather than the myth, which previously outlined, argued that narrative control is not ideologically neutral. Story lines reinforce the racist ideologies of the past but have repackaged the way in which they are disseminated in a more easily digestible way for the dominant class to accept. By distancing themselves from racism, the dominant ingroup is reassured that they are not participating in racism but acting in accord with a natural order. Thus, it is through the storyline of Hollywood films which smooth over anxieties of white guilt and racist sentiments.

Finally, Bonilla-Silva suggests that minimization of racism is a "frame that suggests discrimination is no longer a central factor affecting minorities' life chances" (2018, pg.57). For example, whites justify contemporary racial disparities by reassuring themselves that "it's better now than in the past" (2018, pg.57) or "there is discrimination, but there are plenty of jobs out there" (2018, pg.57). Rather than paying close attention to the evidence that illuminates and debunks fair opportunity in hiring practices (ie/ Kang's resume study), this frame is instead concerned with the erasure of blatant acts of violence, hate crimes, and racial slurs. Because this 
frame sees these acts as the most heinous, micro-aggressions and cinematic representation are taken less seriously and less sympathetically, thus naturalizing the routinized and everyday acts which maintain the racial status quo. Furthermore, contemporary films in this frame are either seen as "not racist" or "not about race" because there are no heinous acts of blatant racism in which to easily identify allowing for the ubiquity of racial tropes and stereotypes to continue unhinged in cinematic visual culture.

Bonilla-Silva asserts that each of these four frames of justifying ideological racial colourblindness are not used in isolation, but rather in conjunction with one another in order to legitimize a variety of racist practices and racial exclusions (2018, pg.58). His final frame highlighted, that of "minimization of racism", is perhaps the most important in the maintenance of the "post-race" colour-blind ideology. This frame assumes that anything beyond Jim Crow is indicative of rapidly increasingly positive race relations. Instead of the ongoing racial disparities in nearly every quantifiable metric of social life, instead people turned to the election of Barack Obama as evidence of progress. Instead of looking at the "big pictures", people focused on the "moving pictures" that show a rosier depiction of contemporary race relations. However, after disastrous events such as Hurricane Katrina, the American government was extremely slow in responding to the ruin that a mostly black population suffered. This lack of prompt government response to these tragic events revealed that minimization of racism enacts further strategic defences of colour-blind racism in which minorities are accused of being hypersensitive, using race as an excuse, or "playing the infamous race card" (Bonilla-Silva, 2018, pg.57).

The symbolic minimization of racism in Hollywood films has also been used as a way of accusing black actors as being overly sensitive to racial micro-aggressions. During the 2016 Oscars, Spike Lee and Jada Pinkett Smith had announced they would be boycotting the awards 
for failing to nominate any actors of colour for major awards (Yuen, 2018, pg.1). In what was dubbed \#OscarsSoWhite, white actors and actresses defended the Academy by calling the protest "racist towards whites" and suggesting that "black actors did not deserve to make the final list" (Yuen, 2018, pg.2). Further, Michael Caine had said that "In the end, you can't vote for an actor because he's black. You can't say. 'I'm going to vote for him. He's not very good, but he's black" (Yuen, 2018, pg.2). Yuen argues that "these arguments falsely assume an equal playing field while dismissing institutional racial biases that privilege white actors for roles and recognition" (2018, pg.2). Through racial colour-blindness, it is assumed, at least by a handful of prestigious white actors, that racism is either "not as bad as it once was" or plainly that race no longer has any bearing on achievements. These dismissals of systematic racism demonstrate the difficulty that an ongoing fight against contemporary colour-blind racism experiences because of the supposed neutrality of race in the "post-race" era. Furthermore, because meritocracy is a key component to ideologically holding colour-blindness in place, actors, as Yuen had argued, feel justified in asserting that perhaps black actors simply were not good enough.

Films during the "post-race" era have also relied on colour-blind white central characters in historical dramas who are integral to black freedom struggles. Examples of this are demonstrated by Christoph Waltz's character in Django Unchained (2012), Brad Pitt in 12 Years a Slave (2013), Kevin Costner's character in Hidden Figures (2016), and Viggo Mortensen's character in Green Book (2018). These characters smooth over past racisms by offering a silver lining for proponents of colour-blindness to ideologically identify with and to re-establish their view point that race relations have greatly improved. 
"Southern trees bear strange fruit

Blood on the leaves and blood at the root

Black bodies swinging in the southern breeze

Strange fruit hanging from the poplar trees"

- a poem by Lewis Allen, 1937

\section{Chapter 3 - "Post-race" Plantations and Peculiar Narratives Neo-Slavery Tourism and Whitewashing Plantations}

Although Canada at present claims to be anti-racist and colour-blind, "racism continues to persist" (Fleras, 2017, pg.69). Taking a similarly "post-race" and "colour-blind" stance, the United States of America also has a much more riddled past than Canada with the "historical legacy of slavery and segregation as well as lynching and the Ku Klux Klan” (Fleras, 2017, pg.45). In both Canada and the United States, discursive formations rooted in racial power dynamics continue to impact race relations. The disconnect between the "post-race" ideology and the contemporary racial disparities outlined by Bonilla-Silva (2017) and Fleras (2017) are ignored in order to subscribe to racial colour-blindness. Collins had asserted that the dominated images of black women which contradicted their lived realities created the opportunity for a "demystification" of stereotypical imagery (1990, pg.93), however the contradictions of "postrace" ideology and white privilege are perhaps too alluring to demystify for the dominant ingroup. To illustrate how colour-blind narratives smooth over contemporary racial inequalities and attempt to remove racist discourse from "post-race" ideology, I wanted to include a personal experience of having visited a sugar plantation in New Orleans. In New Orleans, plantation tours 
are major tourist attractions, and curious at why anyone would want to visit a former slave plantation, I did the tourist thing and visited the Oak Alley Plantation (OAP).

The OAP was highly recommended by several kiosks in the tourist district of the French Quarter in New Orleans. The OAP was named for the distinguishing alley created by a double row of oak trees planted in the early 18 th century leading up to the "Big House". Going to visit a plantation had an entirely different meaning now than it did in the 19th century. Now, to "visit a plantation" meant an exciting bus ride to an historic and breathtaking monument which serves as a National History Landmark "for the instruction, education, enlightenment, information, edification and cultural benefit of the citizens of the State of Louisiana, the United States and the public generally" (oakalleyplantation.org). Plantation tours are framed to tourists as the romanticism of the antebellum South. Guides who work there are dressed up in traditional antebellum "Southern Belle" fashion, speak with an accent, and will even offer you mint julep. The accoutrement of the tour makes you feel as though you are on the set of Gone With the Wind, which is a good thing if you are white.

When we arrived at the OAP, I watched young, white children playing around the slave quarters laughing and running through old cabins that displayed the devices and apparatuses once used to torture black slaves. I thought of the irony in which this plantation was still able to financially profit off of slavery; not through actual labour, but through the (his)stories and subject-position of the tour guides and companies which advertise the beauty of the architecture of the Big House, the majestic landscaping and wrap around balcony, the few-hundred year old oak trees which fantastically define the plantation, and that Oscar nominated film, Interview with the Vampire (1994), that was filmed there. Noted by Guerrero, "once many plantations grew cotton; today, some grow movies. But the imperatives remain pretty much the same" (1993, 
pg.9) Though Interview With the Vampire grossed over \$220 million USD worldwide, on the same property, the OAP owners paid twenty-five dollars for a fifteen-year-old Creole slave named Louisa in 1848 (Fig.1). There seemed to be such a contradiction between today's triumphs from yesteryear's tragedy as tourists walked through the Slave Exhibition drinking mint julep. Did slavery matter to the tourists? Were people thinking about slavery? Would it take away from the experience of the plantation if they did? For the most part, tourists seemed to be enjoying themselves while visiting one of the most atrocious structures of anti-black racism that existed in America. What this signalled to me was that plantations were inviting tourists to face them head on in order for them to see for themselves that racism in the past wasn't that bad, or at least that things are a lot better now.

On the Oak Alley website, it is written that the OAP has been open to the public since 1976 and wishes to preserve and maintain narrative integrity to this iconic historic site "whose past includes serving as a place of enslavement even as it was celebrated for its stunning landscape" (oakalleyplantation.org/about). In the guided tour that I paid for, very little was said about the slaves or of slavery in general. The only time slaves were mentioned was when someone from my group asked the tour guide about the large apparatus hanging above the dining table. The tour guide explained that it was a "punkah" fan and was manually operated by young slave children while plantation owners and guests dined at the table. During my plantation tour, the guide spent most of her attention focusing our group on the architecture, the beauty of Oak Alley, and history of the families that, through their effort, kept the Big House in most of its original condition. Such little attention was paid to the slaves that it reminded me of Hollywood films and their ability to smooth over anxieties, fears and worries for the dominant in-group by 
recounting the glorious triumphs and celebrations rather than the tragedies and despairs of the past.

While being guided along this tour and informed on the various moments of the plantation owners which were worth celebrating, rather than any of the hardships and devastation that the slaves endured, I was reminded of an essay I had read by Stuart Hall entitled Old and New Identities, Old and New Ethnicities. In his essay, Hall mentions a film made by Stephen Freers and Hanif Kureishi, called My Beautiful Laundrette, which "nobody likes" because audiences who are looking for "positive images" of themselves, or relatable identifications found none. In a response to critics who wondered why Hanif Kureishi did not tell us "good stories about ourselves", Kureishi replied

"There is sometimes... too simple a demand for positive images. Positive images sometimes require cheering fictions ... And I'm glad to say that the more I looked at My Beautiful Laundrette, the less positive images I could see. If there is to be a serious attempt to understand present-day Britain with its mix of races and colors, its hysteria and despair, then writing about it has to be complex. It can't apologize, or idealize. It can't sentimentalize. It can't attempt to represent any one group as having the total, exclusive, essential monopoly on virtue" (Hall, pg.60).

Hall uses this example to illustrate that identities are not as simple as "black" and "white", and even if they were, there is a plethora of differences within blackness and within whiteness to constantly navigate. At OAP however, there was one dominant narrative that told a good, happy story, and didn't bother including the complexities of good and bad to present an opportunity to learn and develop. Hall's example illustrates the contrast of the rigidity of the colour line in America which relentlessly insists you are one or the other; black or white. Apart from the guided tour, there was a "Slavery Exhibit", which tourists were invited to visit. This "tour" is self-guided. It is an open space to aimlessly wander through without any assistance, context, additional information, or answers to questions. Aside from the few plaques and summary of torturing devices used on the slaves, the Exhibit is largely open to individual 
interpretation. Though the OAP website states they have an interest in maintenance of narrative integrity, what is offered instead is a one-sided story that celebrates the stunning landscape far more than the participation of anti-black racism and enslavement. Symbolically, the OAP reminds and reassures the tourists that "slavery is a thing of the past" and that "these atrocities would never happen again".

In 2001, David Butler conducted a study called Whitewashing Plantations: The Commodification of a Slave-Free Antebellum South. Butler examined tourist brochures from over 100 plantation and conducted a textual analysis to answer why "plantation owners and their operations under-emphasize slavery" (2001, pg.163). By analyzing 102 brochures, he concluded that "Architecture" was mentioned 72 times, "Original Owners" was mentioned 80 times, "Gardens/Grounds/Landscape" was mentioned 45 times, "Furnishings" were mentioned 36 times, and "Slaves" were mentioned just 30 times (Butler, 2001, pg.166). This data suggested to the researcher that;

"the people in charge of creating the image of a plantation to be shown to the public deliberately choose to exclude slavery from their meta-narrative... Similarly, every plantation, as a museum, may act as a site for the construction of a fictitious history, thus responding to the unconscious desire, including the hope, of the custodians that slavery did not happen, especially at this location. Furthermore, plantations act as a place for the collection of historical myths that serve to legitimate present ideologies" (Butler, 2001, pg.170).

Butler's conclusion about plantations acting as a collection of myths serving to legitimate present ideologies illustrates how contemporary colour-blind narratives seek to mitigate modern racism, as well as romanticizing the past as "not that bad" or "that's just the way things were". By omitting slavery largely from the dialogue and narrative of guided tours to tourists, plantations can instead repurpose themselves as beautiful, historic, National Landmarks, while simultaneously downplaying the extent of partaking in slavery and reaffirming present "postrace" ideologies. What Butler calls a "fictitious narrative" or "myths" is extremely relevant and 
important in how information becomes knowledge. When paying for a guided tour of a plantation by experts, most tourists would not automatically think to immediately discredit the information being disseminated to them. The power to control the narrative and inform tourists of a one-sided story is as important as the power to control the narrative in mainstream cinema. Either way, the audience and tourists are internalizing "knowledge" which more importantly serves the dominant class. Furthermore, in both cases, racial difference is naturalized through knowledge construction and discursive formations.

In questioning whether tourists are ignorant of plantations and slavery, Butler argues that the term "plantation" is undergoing a major revision. He writes that plantations are;

"no longer a stigmatized concept automatically associated with slavery. Instead it has been bestowed on places at which to stay, eat and be entertained in a grand fashion. The term now connotes opulence.... This observation is no more evident than in the most popular and highest grossing movie in American cinema, Gone with the Wind" (2001, pg.171).

When pondering what "semiotic messages are the plantations transmitting?" Butler responds to his own question insisting that "probably most visitors to plantations have seen Gone With The Wind and/or dozens of movies that adopt a similar formula" (2001, pg.172). As Guerrero had noted, because Gone With the Wind and similar films glorified chattel slavery (1992, pg.3) and white supremacy, one must wonder why visitors desired to see the plantations. Likely by positioning themselves as part of the dominant in-group, visitors probably preferred to identify with Scarlett O'Hara rather than Mammie. Butler's suggestion that Gone With The Wind could be a major factor in why tourists would want to visit a plantation speaks volumes to how mainstream Hollywood films can impact socialization and narrative control. Though the film reduced its black actors to the slaves and mammies peripheral to the love story between Scarlett O'Hara and Rhett Butler, African Americans had protested Gone with the Wind for its portrayal of servile blacks and many had called on Hattie McDaniel to refuse the Academy Award she 
won for her portrayal of Mammy" (Manring, 2002, pg. 164). This contrast in how African Americans, and (presumably white) tourists internalized and "saw" the film demonstrates how important symbolic representation can be and how meaningful narrative control is to socialization and identity politics.

Butler concludes that by purging plantations of slavery, visitors feel at harmony with the purified history "loyal to the dominant culture" (2001, pg.173), and that it is necessary for people to see, touch, and feel their past errors so that they can challenge it before it becomes institutionalized and culture becomes "desensitized to its dangers" (1998, pg.174). By removing slavery from the historical narrative of modern state formation, it only reinforces dominant "post-race" narratives resulting in the lost opportunity to better understand contemporary racial dynamics impacted by history. Instead, by controlling the dominant discourse and sweeping former racist atrocities under the rug, plantation tours empower colour-blind ideology and universal liberalism and minimizing the impact of current racisms. Previously outlined by Bonilla-Silva and Nancy Yuen in Chapter 2, colour-blind justifications for maintaining the racial order in Hollywood films, actors and production is similarly reinforced through discourse and narrative control. The power to pick and choose to audiences and tourists what is seen and shown reinforces a belief that things are not as bad as they once were. By minimizing slavery from the narrative of plantation tours, and by colour-blindly assuming a racially even playing field has magically appeared with the "post-race", audiences and tourists alike have their anxieties about race relations smoothed over by the fabrication of a "post-race" La La Land.

\section{Controlling the Narrative and Enacting Power}

From demonstrating how narrative control at the OAP constructs a specific discursive formation of race relations, it is important in considering how power dynamics work in tandem with 
signifying practices. It is not the subjugated class that is able to control their representation, but rather the dominant class who decides the "who", "what", and "how" of knowledge. American author and social activist, bell hooks, wrote in her book Where We Stand: Class Matters (2000), that

"poverty in the white mind is always primarily black... When I am shopping in Barney's, a fancy department store in my neighborhood, and a well-dressed white woman turns to me - even though I am wearing a coat, carrying my handbag, and chatting to a similarly dressed friend - seeking assistance from the first available shopgirl and demands my help, I wonder who and what she sees looking at me. From her perspective she thinks she knows who has class power, who has the right to shop here; the look of the poor and working class is always different from her own. Even if we had been dressed alike she would have looked past attire to see the face of the underprivileged she has been taught to recognize" (pg.4).

As hooks" argues, if she and the "white woman" were dressed the same, the ideology of racial colour-blindness would assume both women to be of equal social status. However, because the underpinnings of colour-blind ideology assume a racial hierarchy, the "white woman's" internal knowledge of whiteness leads her to believe that hooks' is socially beneath her. Instead of clothing, the colour of bell hooks' skin creates in the "white woman" the ideological understanding of who she is, because the "white woman" has been taught to recognize that blackness means poverty, and that whiteness means class power.

Furthermore, hooks' example also demonstrates another component of colour-blind racism in which her being confused for a "shopgirl" by the "white woman" is a form of a racial micro-aggression. Though micro-aggressions are seemingly straight forward and subtle, a more complex definition is required for the purpose of this study. Fleras articulates that;

"micro-aggressions are those overt and subtle expressions of racism (from slurs to slights) that superficially look innocuous enough but implicitly embed an affront that's experienced as such by the micro-aggressed... These brief daily exchanged are imbued with coded negative messages - from confirming stereotypes to privileging the dominant group as the normative standard and others as aberrant; from essentializing all group 
members as undifferentiated to denying the pervasiveness of both discrimination at large or the transgressor's own bias" (Fleras, 2017, pg.73).

Though hooks' was not blatantly attacked or racialized (ie/ with a racial slur), she was signified, immediately and unthinkingly, as an employee to the "white woman" because of the colour of her skin. As hooks' had explained, because the "white woman" had been taught to recognize poverty and the underclass as black, the "white woman" did not immediately associate hooks as someone who could afford to shop at Barney's. Instead, the "white woman's" automatic association was that bell hooks was an employee who should be helping her. She, bell hooks, should be helping the one with the class power. The routinized and unthinking ideological learning in which skin colour has the coded implications of status, wealth, and class power is the way in which modern race relations have taken form. The blatancy of past racisms has been replaced with the more latent forms of the "do you work here?" and the "where are you really from?"

Eduardo Bonilla-Silva notes that "compared to Jim Crow racism, the ideology of colourblindness seems like "racism lite" (2018, pg.3), however this "new ideology has become a formidable political tool for the maintenance of the racial order" and through the "new racism practices that are subtle, institutional, and apparently non-racial" (2018, pg.3), deconstructing the racial hierarchy has only become more of a challenge. Because the nature of colour-blindness is to replace race with something else, yet the desire to keep the racial hierarchy intact is still there, what hooks' example, and Bonilla-Silva's analysis provides is how race is signified, coded, and mythologized. Most concerning of colour-blindness is how then do we fight something which isn't even there? And how do those who are subject to being racialized defend themselves when they are being told that race doesn't matter? 
What hooks' furthermore contests are that "the neat binary categories of white and black... are not there when it comes to class" (2000, pg. 6), thus making it harder to combat class as a racial issue even though juxtaposing poverty with blackness is a racist act. Insofar as semiotics is concerned, because the "simplest way of marking difference is... by means of binary opposition" (Hall, 1997, pg.31). Hooks notes that "neighbors tell me the lack of diversity has nothing to do with racism, it's just a matter of class" (2000, pg. 3) which continues to demonstrate how colour-blind justifications of racism can be deflected or legitimized through class, wealth, or poverty. This method of deflection can also implicate poor whites, for example in I, Tonya by making a class-based argument to downplay racial importance. Hooks notes that her neighbors "have no memory of days when black females could not rent a room or flat here because white folks saw us all, no matter our class, as prostitutes - as bad news" (2000, pg.3). This class-based argument that hooks brings forward demonstrates a similar narrative control that plantations have used, and Hollywood films have used to instill a "racial amnesia" which paints historical racisms with a rosier colour and minimizes the impact that historical racisms continue to have on racialized people.

How black and white came to represent poor and affluent is not an innate or natural occurrence, but rather a social construction of claims and assigned representation rooted in power and domination. In her intersectional analysis, Patricia Hill Collins discusses in Black Feminist Thought (1990) how "race, class and gender oppression could not continue without powerful ideological justifications for their existence" (pg.67), and that the power to "define these symbols is a major instrument of power" (pg.68). As bell hooks had eluded in the previous example, her mistaken identity as "shopgirl" by the "white woman" was through the latter's mythological idea about the former based on a structuring of preconceptions about the servility 
of blackness. Furthermore, as hooks and Hall suggest, the easiest way of marking difference is through binary opposition or through dichotomous contrasting which "categorizes people, things, and ideas in terms of their difference from one another. For example, the terms in the dichotomies black/white, male/female, reason/emotion, culture/nature, fact/opinion, mind/body, and subject/object gain meaning only in relation to their counterparts" (Collins, 1990 pg.6869).

What occurs in these binary oppositions is that "one element is objectified as the Other and is viewed as an object to be manipulated and controlled" (Collins, 1990, pg.69). In the case of hooks' example, her contrasting of being Other from the "normative" position of power of the "white woman" demonstrates the foundation of a complex social hierarchy which invariably implies superiority and inferiority and hierarchal bonds that mesh with race, gender, and class oppression (Collins, 1990, pg.70). Collins' insight is important in both noting the intersectionality of how class, gender, and race are intimately intertwined and often difficult to isolate, and how mythologies contribute to the justification of oppression. Because social relationships are socially organized, enacted and enforced, as opposed to having any "natural" hierarchical social order, legitimations and justifications are required to maintain the ideological mindset in which superior, inferior, and Other can exist. As previously stated, signifiers, coded meaning, and myths are powerful strategies at maintaining a racial hierarchy and through the modern conventions of colour-blindness, do so without ever having to explicitly mention race or to even suggest that race doesn't matter.

In Where we Stand: Class Matters (2000), bell hooks argues that "mass media attempts to brainwash working-class and poor people" (pg.46) have contributed to the internalizing assumptions and shared values of the myth of the American Dream. By adopting the belief that 
the poor could rise to the upper class through hard work, bell hooks argues that there was "no longer need for an emphasis on communalism or sharing resources, for ongoing focus on social justice" (pg.66) and that the poor had been duped into thinking that the "oppressor class and oppressed class were no longer meaningful” (pg.66), a sentiment that has been echoed throughout this thesis so far in colour-blind ideological justifications in which universal liberalism has replaced race doesn't matter. Because the theme of the "American Dream" is still a popular narrative in contemporary Hollywood film, I will later mention in this paper how it manifests in Moonlight (2016), and La La Land (2016), and how the rewards of hard work still only apply to some, and how the social realities of others are often left out of the equation.

\section{Black Panther, Subversion or Submission?}

During the 2019 Academy Awards, Black Panther made history by taking home three Oscars, and for being the first ever Marvel film to be nominated for Best Picture. In what has become one of the most celebrated films in recent memory in black communities across America, Black Panther has become a trailblazer for black representation in big budget film which is about "neither slavery, nor poverty, and is celebratory rather than depressing" (Freeman, 2019). In her review on the Guardian, Hadley Freeman writes "I am trying to think of another American movie with an almost entirely black cast that became a global blockbuster, and all I can come up with is Coming to America, which came out 31 years ago" (Freeman, 2019).

Freeman is among many who have championed Black Panther as one of the most important films for black representation in modern times, and on one hand, it is hard to disagree with the impact of this film. For the first time ever, a black man is the lead superhero in a Marvel film, and Black Panther's massive box office success has thrown gasoline on the fire in what that 
means symbolically for black communities. In agreement with Hadley Freeman's overall celebration of what Black Panther means for the film industry and of representation, Dr. Erlanger Turner wrote;

"Many have wondered why "Black Panther" means so much to the black community and why schools, churches and organizations have come to the theaters with so much excitement. The answer is that the movie brings a moment of positivity to a group of people often not the centerpiece of Hollywood movies. Plus, what we know from the research on RES is that it helps to strengthen identity and helps reduce the likelihood on internalizing negative stereotypes about one's ethnic group... We can all agree that Wakanda is a fictional place, but "Black Panther" is more than just a movie" (2018).

Not only are movies meaningful in terms of representation but they are also important agents for the possible deconstruction of negative stereotypes. What Freeman and Turner argue is that Black Panther has subverted the negative media stereotype of black people in film and has demonstrated that a primarily black cast can financially carry not only a Marvel film, but a mainstream big-budget production as well.

However, despite Black Panther's critical acclaim and box office success, it is hard not to draw the parallels between the Blaxploitation era of Hollywood cinema and the contemporary state of modern film. Black Panther may be the exception and not the rule to a liberated black cinematic experience. Hollywood has always been a "system entirely motivated by short-term profit [and] changes only when forced to do so" (Guerrero, 1993, pg.85). Guerrero notes that despite empty promises from Hollywood to improve the black cinematic image in big budget features, it was only during the late 1960s when "mounting political pressure combined with the film industry's threatened economic position along with the allure and profitability of a rising black box office proved irresistible" (1993, pg. 85-86), leading Hollywood to the new formula of filmic representation of blacks. Such films during this era included Sweet Sweetback's Baadasssss Song (1971) and Shaft (1971) which told stories of rough and tough, 
sexually realized black men "who challenges the oppressive white system and wins" (Guerrero, 1993, pg.86).

Mounting pressure for more diversity in Hollywood films, as well as celebrity endorsement had also contributed to the box office success of Black Panther. For example, American Singer and songwriter, Chris Brown, had taken to social media to encourage black people not to bootleg the film, but to buy a ticket instead, and other celebrities such as Zendaya, Octavia Spencer and Serena Williams bought out entire theatres so that people could see the film (Loriston, 2018). During the Blaxploitation era, demands from black communities and powerful community representatives were also central in motivating ticket buyers to spend their money and celebrate the new, more humanizing depictions of black people in mainstream cinema. For example, Huey P. Newton devoted an entire issue of the Black Panther party newspaper to Sweet Sweetback and noted it was "the first truly revolutionary Black film made, presented to us by a Black man" (Guerrero, 1993, pg.87). Celebrity endorsement called on "black people" en masse to watch Black Panther, and reception of the film has demonstrated how important representation is in big budget mainstream cinema. The question remains on if audiences were blindly following orders and went to see the movie through the false consciousness of ideologically identifying with the film based on the myth of race. If we are seeking to deconstruct race as a mythological system of power dynamics with no meaningful biological imperative, is it being complicit in one's domination to accept Black Panther at face value as an important part of individual black identity? On the other hand, despite being a highly commercialized Hollywood production, it cannot be discounted how much Black Panther can positively impact the social-symbolic system which influences individual identity. 
Online journals and news outlets are saying that Black Panther is "more than just a movie, it's a movement" (Loriston, 2018; France, 2018). Once again, the cyclic celebration and optimism of reclaiming cinematic representation for black folks is almost too tempting to resist. However, with a sequel for Black Panther already planned, as well as its crossover box-office success in Avengers: Infinity War (2018), Hollywood's interest in Black Panther's financial success is likely more important than to it than the actual subversion of black stereotypes. Guerrero had noted that crossover films are "productions that would attract whites not normally inclined to attend a movie about blacks" and would rely on a "few, isolated big-name black stars for their box-office draw, rather than filling productions with casts of dozens of black actors looking for a break" (1993, pg.105-110). African-American actor, Samuel L. Jackson, had said that the film industry has tunnel vision when it comes to black talent and "if they can't get us, they say, 'Well, we'll wait till we can.' They're not looking for the next us"' (Yuen, 2017, pg.54). In the end, the systemic inequalities in which the Blaxploitation era were meant to combat had simply been overlooked by the shifting of stereotypes from sambo to "superspade", and shortterm financial profit.

Black Panther (2018), which has been praised as being a major milestone for black people in America in terms of cinematic representation (Smith, 2018), also shares similarities with Shaft (1971) in that it "plays well with whites, reflecting its essence as a commercial vehicle" (Guerrero, 1993, pg.92). So long as Black Panther maintains the standardized formula of a Hollywood superhero film without being "too political" or "too black", it can continue being a box office success in its crossover films and feature sequels without necessarily subverting racial stereotypes in modern cinema. Despite this, a TIME magazine journalist writes "after the Obama era, perhaps none of this should feel ground-breaking. But it does. In the midst of a regressive cultural and political moment fueled in part by the white-nativist 
movement, the very existence of Black Panther feels like resistance. Its themes challenge institutional bias, its characters take unsubtle digs at oppressors, and its narrative includes perspectives on black life and tradition" (Smith, 2018).

Smith's referencing of the "Obama era", and Black Panther being ground-breaking goes to show that not only was Obama's America seemingly post-race, but also that Trump's America is represented as a return to racism. Smith writes "back when the film was announced in 2014, nobody knew that it would be released into the fraught climate of President Trump's America where a thriving black future seems more difficult to see" (2018). Smith, who sees the film as resistance, along with other journalists who share this view (Loriston, 2018; France, 2018) are not wrong, however, the question remains to be answered as to what degree will Black Panther become a meaningful contribution to the subverting of omnipresent racialized stereotypes of Hollywood? Secondly, will Black Panther become the next Shaft at providing another small moment of "post-race" blaxploitation financial profit for Hollywood while being commodified by the dominant ingroup of white America?

Finally, will Black Panther fall victim to the larger systems of power and subvert not the offensive black stereotypes it meant to, but the political meaning of the Black Panther Party? In his harsh critique of Black Panther, Christopher Lebron writes that despite its black star power and portrayals of strong black women, Black Panther ultimately "depends on a shocking devaluation of black men" (2018). Lebron argues that the villain in Black Panther, Eric Killmonger, is shown as the familiar "black thug from Oakland hell bent on killing for killing's sake" (2018). Killmonger, who grows up an orphan in Oakland, wants to make good on his father's vision to use Wakanda's power to liberate black people everywhere, but instead comes across as a "receptacle for tropes of inner-city gangsterism" (2018). Lebron further writes that; 
"Black Panther presents itself as the most radical black experience of the year. We are meant to feel emboldened by the images of T'Challa, a black man clad in a powerful combat suit tearing up the bad guys that threaten good people. But the lessons I learned were these: the bad guy is the black American who has rightly identified white supremacy as the reigning threat to black well-being; the bad guy is the one who thinks Wakanda is being selfish in its secret liberation; the bad guy is the one who will no longer stand for patience and moderation - he thinks liberation is many, many decades overdue. And the black hero snuffs him out." (Lebron, 2018).

What is clear is that Black Panther is one of the biggest movies of the year, has broken box-office records and has made history as the first black Marvel superhero film. What is less clear is if Black Panther has simply become consumed a la blaxploitation era of Hollywood's profit driven formula and, as Christopher Lebron has argued, missed the mark at becoming a truly liberating moment for black representation in film. Similar to Lerone Bennett's critique on Sweetback in which he asserted that the superhero was "selfishly individualistic with no revolutionary program" (Guerrero, 1992, pg.89), Lebron finds that T'Challa is more concerned with his isolation from the rest of the world than the welfare of black people everywhere.

In a critique partially in response to Jamil Smith's Black Panther cover story for TIME magazine, Khanya Khondlo Myshali argues that by "conflating the film with the resistive efforts of grassroots activists and organizers, we risk disrespecting our radical traditions, which are increasingly being commodified by corporations whose interests have never been with the people" (2018). Myshali is referencing the Black Panther Party, a political organization founded in 1966 by Huey Newton and Bobby Seale to challenge police brutality against the African American community. The Black Panther Party was a feared group of armed black citizens and along with Malcolm X, presented a disruption to the white dominated racial status quo. Now, instead of representing a feared group of political activists concerned with liberating the black people "by any means necessary", future generations may come to remember Black Panther as 
the token black character among the rest of the Avengers. It is too early to predict the impact Black Panther will have on subverting cinematic stereotypes or succumbing to submission of Hollywood's profit driven apparatus, however if Hollywood were able to commodify Black Panther from the black radical resistance of white oppression to the colourblind vehicle of cinematic entertainment, it would no doubt be one of the greatest successes of "post-race" symbolic racism. 
"Some of my favourite movies are by straight white dudes about straight white dudes. Now, straight white dudes can watch movies starring me and you relate to that. It's not that hard. I've done it my whole life"

- Kumail Nanjiani, 2018

\section{Chapter 4 - Hollywood Villains? Get Out and La La Land!}

\section{Colour-blindness and Case Study: Reel Bad Arabs}

In Reel Bad Arabs: How Hollywood Vilifies a People (2014), Jack Shaheen argues that the repeated use of stereotypical images and themes which depict Arabs as terrorists and religious fanatics in Hollywood films have contributed to the demonization and racial othering of Arabs and Muslims in America. Fleras writes that stereotypes are "essentially generalizations about others, both unwarranted and unfounded on the basis of available evidence [which] reinforces a universal tendency to reduce a complex phenomenon to simple (or simplistic) explanations that can be generalized to a whole category" (2017, pg.83). Highlighted in Shaheen's study is the cinematic reduction of Arabs and Muslims to "bombers, billionaires, [and] belly dancers" (Fleras, 2017, pg.83). Shaheen argues that these stereotypes are so ubiquitous in mainstream cinema that it has had real-world impact for Arabs and Muslims living America. Narratives and representations are integral to knowledge production and stereotypes are used as an instrument of “social control” (Fleras, 2017, pg.84).

Stereotypes provide tacit justifications for discrimination against racialized minorities.

For example, researched evidence showed that landlords use racial bias against minorities when responding to "prospective black and Latino tenants (seen as lazy, prone to violence, and concentrated in low paying jobs" (Fleras, 2017, pg.83-84). Kang's whitened resume study also revealed that white employers saw blacks as more outspoken or politically radical (2016, 
pg.17). By juxtaposing Muslims and Arabs with nuclear warfare, violence, and threatening American democracy, Shaheen argues that Hollywood films have participated in the "unapologetic degradation and dehumanization of a people" (2003, pg.171).

Shaheen writes that when it comes to education and knowledge production that, "we learn by repeating an exercise over and over again until we can respond almost reflexively" (2003, pg.171). He continues that the mythological construction of the Middle East and of Arabs through Hollywood cinematic narratives have been so pervasive that it has led to extreme social alienation in what is supposedly a "colour-blind" and "equal" America.

"Think about it. When was the last time you saw a movie depicting an Arab or an American of Arab heritage as a regular guy? Perhaps a man who works ten hours a day, comes home to a loving wife and family, plays soccer with his kids, and prays with family members at his respective mosque or church. He's the kind of guy you'd like to have as your next door neighbor, because- well, maybe because he's a bit like you. But would you want to share your country, much less your street, with any of Hollywood's Arabs? Would you want your kids playing with him and his family, your teenagers dating them? Would you enjoy sharing your neighborhood with fabulously wealthy and vile oil sheikhs with an eye for Western blondes and arms deals and intent on world domination, or with crazed terrorist, airplane hijackers, or camel-riding bedouins?” (2003, pg.173).

In the above passage, Shaheen argued that fears and anxieties about the other can easily stem from the constant dissemination of negative representation through Hollywood films, and that the ideological construction of othering can have real world impact. Rocchio had argued that in contemporary mass society, most of our information comes through mediated texts rather than direct experience in which case Hollywood films are "significant sites for the production and integration of meanings through which societies maintain themselves and evolve" (2000, pg.5).

As Fleras notes, "people tend to view out-groups as uniformly homogenous and an undifferentiated mass rather than as individuals with personalities, skills and talents" (Fleras, 2017,pg.83) unlike whites in America who are represented as "people who are variously 
gendered, classed, sexualised and abled" (Dyer, 1997, pg.3). Lumping Arabs and Muslims together in a homogenous mass had led to a growing support for Xenophobia, "an irrational fear of the other, with a corresponding dislike because of this fear" (Fleras, 2017, pg.84). Fleras writes that this is nowhere more evident at present than hostility towards Muslims, "culminating in a paranoia that leads to hatred, hostility, and discrimination" (2017, pg.85) which has evolved since 9/11. Through the unrelenting pairing of harmful stereotypes in Hollywood films, perceptions of Muslims and Arabs have contributed to "prejudicial racism" including; disadvantages for Muslim women, bias media coverage, hostility by political parties, and conflating Islam and Muslims with extremism and of terrorism (Fleras, 2017, pg.85).

Shaheen further argues that "for more than a century Hollywood, too has used repetition as a teaching tool, tutoring movie audiences by repeating over and over, in film after film, insidious images of the Arab people" (2003, pg.172). Shaheen studied over 900 Hollywood films in his study and found that "only five percent of Arab film roles depict normal, human characters" (2003, pg.171) and that most often, Arabs are portrayed as "brute murders, sleazy rapists, religious fanatics, oil-rich dimwits, and abusers of women" (2003, pg.172). Shaheen argues that the mythology of these stereotypes is disseminated through Hollywood's motion pictures "reaching viewers in more than 100 countries" (2003, pg.174), and that

"almost all Hollywood depictions of Arabs are bad ones... repetitious and negative images of the reel Arab literally sustain adverse portraits across generations. The fact is that for more than a century, producers have tarred an entire group of people with the same sinister brush" (2003, pg. 176).

Similarly, research has shown that from the earliest days of Hollywood cinema, AfricanAmericans were portrayed as "uncivilized and animalistic" (Rocchio, 2000, pg.31). Ever since 
the Birth of a Nation (1915) was screened in the White House, African-Americans have been tarred with a similarly sinister brush of Hollywood's mythological construction and ideological discourse that blackness means "dirty, inferior, and uncivilized" (Rocchio, 2000, pg.20). These mythologies still have harmful "real-world" consequences, such as the delaying of anti-lynching laws (Manring, 1998, pg.164).

Media fueling racial misperceptions have contributed to the punishment of people of colour (Yuen, 2017, pg.8). For example, a CNN article published an American study that concluded that "we may see black men as bigger, stronger, and scarier than white men, even if they are the same size" (2017, Willingham). This study asked online participants to rate black and white men based on weight, height, strength and built, and revealed that participants rated black men as more threatening, and thus deserving of more force to detain them (Willingham, 2017). Yuen writes that Darren Wilson - the white police officer who shot and killed Michael Brown, an unarmed black man... characterized Brown as a "demon" and a "hulk" and argued that "Wilson's descriptors came from the "black brute" racial stereotype... popularized in Hollywood films" (2017. pg.8). Finally, as suggested by Shaheen, Hollywood films are viewed by a broad, global audience, in over 100 countries, and the magnitude of these stereotypes reach beyond North America.

Hollywood continues the discursive construction and mass dissemination of ideas and images which reinforce racial hierarchies through the more subtle conventions of colourblind representation on the silver screen which promote "post-race" and more "optimistic" racerelations. As Goldberg puts it, "so far as white people are concerned, there is one simple rule for interracial projects: don't try to atone for the past. Forget the past and build for the future" (2002, pg. 200). Thus, past white racial violence can be swept under the rug in favour of a "fresh start". 
As Shaheen's work demonstrates, though most viewers would give themselves the benefit of the doubt in being able to detect offensive and racist stereotyping in films,

"the elements that make stereotyping so powerful, and so hard to eliminate, is that it is self-perpetuating. Filmmakers grew up watching Western heroes crush hundreds of reel "bad" Arabs. Some naturally repeat the stereotype without realizing that, in so doing, they are innocently joining the ranks of the stereotypes' creators" (Shaheen, 2003, pg.188).

Because the representations of certain racialized groups are so ubiquitous on screen, viewers may not immediately recognize or detect the pairing of Arab and terrorist, or black woman and nanny as racist or offensive, but simply something they are used to seeing on screen. Cinematic representations can bridge the epistemological gap to viewers about what they may think about people and bring it to life, legitimizing their prejudice. Nancy Yuen illuminates in her book, Reel Inequality (2017), that "studies show that audiences substitute stereotypes they see on screen for reality when they have not had any direct interactions with particular racial groups" (pg.8), and further contests that that "given that whites greatly overestimate the share of crimes committed by blacks, media stereotypes can aggravate such misperceptions and can be used to justify violence against people of color" (pg.8). What often completes the mythological constructing of a racial stereotype into social "knowledge" is when cinematic representation transcends the silver screen and begin to manifest in the real-world.

In Sociological Thought: Beyond Eurocentric Theory, Nahla Abdo argues that "internal oppression, or oppression from within one's own society, nation or culture must also be recognized and challenged" (1996, pg.28), and that "North American popular culture disseminated through various media outlets - T.V. newspaper and commercials - feeds into the Western constructs of Orientalism and Eurocentrism" (1996, pg. 6). Abdo further argues that "Orientalism is not concerned with scientific or historical facts" (1996, pg. 6), but rather is an 
"ideological discourse with a clear political agenda, as a project constructed around more or less defined power relations" (1996, pg.6.). Scientific and historical facts are less important than ideological discourse constructed around power relations for how people see themselves and others. Fleras reveals that an online poll of "1522 Canadians commissioned by the ACS and CRRF demonstrated that 52 percent of the respondents believe Muslims can't be trusted [and that] nearly as many believe discrimination against Muslims is mainly the fault of Muslims themselves" (2017, pg.84), providing evidence of denying systemic racism in favour of blaming individuals for their own shortcomings. A key component of colour-blind racism and universal liberalism. Abdo has outlined the way in which media constructs ideological discourse regardless of scientific or historical accuracy. Without specifically mentioning race or colour, harmful negative media images of people from the Middle East are legitimized through narrative control, power dynamics, and stereotypes.

Constant representations which juxtapose the Middle East and its people with mystery, violence, veiled women and danger only serve to reinforce beliefs in audiences whose primary source of knowledge is through films, and who otherwise have little to no contact with the depth and diversity of such a large population group. This study is concerned with media constructed representations of black people through films, and the social ramifications of stereotyping. Negative images of black people in films and Orientalism have similar strategies of exclusion and othering, and in both cases, are made subject of white supremacy.

With respect to Orientalism, Jack Shaheen has contributed to this study by revealing how the ideological discourse about the other becomes a powerful driving force in othering and exclusions. Through harmful stereotypes and reductionist theories, concepts and paradigms, Shaheen's work on Arabs and Muslims in cinematic representation and the works Ed 
Guerrero (1993) and Vincent Rocchio (2000) have done on African-American cinematic representation both operate under the same principles of semiotics, representation, and being subjected to the binary opposition of white centrality. There scholarly works have contributed greatly at exposing the harmful effects of stereotyping and othering which conjure up xenophobic and racist sentiments about non-white population groups in Western culture through essentializing and racializing minorities.

\section{Get Out (2017)}

Debut-director Jordan Peele was inspired to write the script for the film Get Out (2017) hoping that it would provide a commentary on race and social issues through entertainment rather than a "lecture" where "people feel like maybe you're talking down to them" or "forcing your views on them" (Keegan, 2017). Jordan Peele has established himself as a resistor of white cinematic homogeneity by insisting that he refuses to make movies starring white actors because he has already "seen that movie" (Donaghey, 2019). Peele, who refers to the Obama era as the "post-racial lie" (Keegan, 2017) raises questions about the current state of America in which the 2017 election of President Donald Trump felt like a step back in terms of racial inequality because of the anti-immigration and white supremacist rhetoric that has paralleled his campaign (Bobo, 2017); including "building a wall along the southern border of the United States, deporting and banning all Muslims, "bombing the shit out of ISIS", and promising to return jobs to white areas experiencing economic upheaval" (Bonilla-Silva, pg. 221). Furthermore, Trump was even able to publicly question if Obama was an American citizen (Keegan, 2017), and offered to “donate $\$ 5$ million to a charity of Obama's choice if he would release his passport history and college records" (Bonilla-Silva, pg.213, 2018). 
It is integral not only to scrutinize mass-media through a critical lens, but that producers of pop culture and film continue to challenge and provide counter narratives on racism and should be urged to recognize that viewers are not simply passive consumers. The homogenous narratives of white superiority and black inferiority in film need to be challenged and reconstructed, making Peele's box office and critical sensation, Get Out (2017), an important film that challenges the ideas that claim America to be a "post-race" utopia. Peele has suggested that "people were ready to engage in thinking about [racism], and what better way to do it than with a popcorn movie" (Keegan, 2017). Peele has given the credit to viewers, and through his film, allowed them to see for themselves the interplay of overt and covert racism in contemporary society, and has been successful in creating a dialogue which attempts to deconstruct the notion that racism had ended with Obama's presidency. Indeed, with President Trump the talks of bigotry and racism are back in full swing, and much to the chagrin of the naysayers during the Obama era, the "post-race" utopia arguably never existed.

In what was perhaps the sleeper hit of the year, Get Out (2017) provides a unique narrative to the horror genre. In his directorial debut, Jordan Peele (known most for his sketch comedy television series Key \& Peele) wrote Get Out as a commentary to contemporary systemic and societal racism. In the film, the audience is invited to perceive the discomfort that colourblind racism enacts through the eyes of the main character, Chris (played by British actor Daniel Kaluuya). Chris is a young, dark-skinned African-American man in a romantic relationship with a white woman named Rose (played by Allison Williams). Peele, whose mother is white, and father is black, felt responsible for creating a movie in which this type of "mixedrace" relationship was represented. Perhaps because of the remnants of American anxieties of miscegenation and blood purity, "mixed-race" romantic relationships are not very common in 
mainstream cinema. Peele began writing the script during the Obama administration, which he considered the "post-race lie" (Ramos, 2017). Peele had noted that in his experience as a mixedrace person in America, he perceived an obvious difference between himself and others and he felt frequently subjected to colour-blind forms of micro-aggressions. As Collins had noted of black women experiencing the contradictions of their daily lives from the dominated images of themselves, Peele also experienced a similar contradiction of "post-race" ideology, and the routinized racism he frequently experienced. For Peele, racism in America continued to be omnipresent and he wanted to portray that through film arguing that "by the middle - or even earlier in the film - everyone is Chris... The movie was bringing people together instead of tearing each other apart" (Ramos, 2017). Furthermore, Peele stated that he wanted to keep away from the "white saviour" narrative of films that he had been rampant in cinema and wrote the film where "every white person in this movie is evil" (Ramos, 2017)

According to a Time.com article, Get Out was the most profitable film of 2017. With a budget of $\$ 4.5$ million, by August 2017, it had grossed over $\$ 252$ million giving it a $630 \%$ return on investment (Fuster, 2017). Get Out also received four Oscar nominations, including best picture, and won the Academy Award for Best Original Screenplay, making Peele the first ever African-American to win the award. In a modern version of Guess Who's Coming to Dinner? (1967) meets The Stepford Wives (1972), we are met with a familiar plot device of a Hollywood "problem picture". Guerrero explains that the "problem picture" as a narrative formula was "distilled from a long-established strategy of ideological containment that allowed Hollywood to stay current, keeping abreast of the contemporary social and political climate and simultaneously upholding the status quo and containing all insurgent political impulses. By introducing topical political issues into stable, easily recognized and consumed genres, narratives and plot structures, Hollywood's conservative ideology [goes unchallenged]" (1993, pg.76). 
However, as previously outlined by Peele, the "problem picture" is subverted when all the white characters are made evil rather than the heroes or saviours.

At the beginning of the film, we are introduced to Chris and Rose, the two central characters of the film. Rose lies on the couch with Chris' dog, Sid, as Chris reluctantly packs his bag. Something appears to be on Chris' mind as Rose tells Sid to "give me a minute, we have to pry something out of your dad". When Rose asks Chris, "what is wrong with him", he replies to her "do they know I'm black?", referring to Rose's parents. In this exchange, we are instantly reminded of the social landscape of America in which being a white person and dating a black person comes with an extra set of presumed rules and precautions. Had Chris been white, the plot of the film is entirely lost. Instead, the plot of Get Out hinges on the implied racial difference between Chris and Rose and perhaps the hope for white audience members that race won't matter, confirming their colour-blind ideological preference.

The reality for Chris is that Rose's parents might not know that he's black, or they might know that he's black and be upset with Rose for dating outside her "race". Either way, the implication of Chris' question to Rose demonstrates to the audience of his lived experience as a black man which has cautioned him that whiteness and blackness do not seamlessly mix in contemporary America. Although Rose is clearly accepting of him as her boyfriend by her facial expressions and comforting embrace, with her parents, it is presumed that an older generation will possibly be less tolerant given America's racial history. Rose responds to Chris' question of if her parents know that he is black with “No. Should they?". Chris, almost embarrassingly, chuckles and breaks eye contact.

What this scene does at situating it as a "problem picture" is that it presents the film to the audience with a contemporary social issue; inter-racial dating. This socially relevant plot keeps 
the audience engaged and it keeps the film up-to-date. Rose, so far, has presented herself as the heroine and has embodied the critical voice of the anti-racist. Fleras outlines "anti-racism" as the "process that challenges racism through direct action at different levels. A commitment to antiracism is all-consuming by challenging white advantage and eradicating structural barriers to full participation and equal citizenship rights" (2017,pg.107). More than just accepting colourblindness as an ideology, throughout the film, Rose becomes an active participant at challenging racist micro-aggressions and police profiling towards Chris. She is depicted as the white saviour that will bridge the gap between her parents and her boyfriend and will attempt to break down the social barriers of racism in America. This is highlighted during the next exchange between herself and Chris who continues to be skeptical of Rose's parents accepting him because he is a black man.

Chris: It seems like it's something you might wanna, you know, mention Rose: Mom and Dad, my black boyfriend will be coming up this weekend and I just don't want you to be shocked that he's a black man Chris: (laughing) You said I was the first black guy you ever dated. Rose: Yeah, so what? Chris: Yeah, so this is uncharted territory for them. You know, I don't wanna get chased off the lawn with a shotgun

Rose: You're not going to. First of all, my dad would've voted for Obama a third time if he could've. Like, the love is so real.... They are not racist.

For Chris, he is practicing a standard procedure of dating a white woman by making sure that her parents are aware of his blackness. For him, he does not want his blackness to become a bait-and-switch in which "boyfriend" is symbolically attached to the norm of whiteness. By him being black, he fears it will shatter the expectation Rose's parents have of him. Rose, as the antiracist, does not think she needs to qualify her black boyfriend is any different than just boyfriend. Chris' anxiety about the whole ordeal invites the audience to sympathize with him and to gain a clear perspective of contemporary racism. Clearly this is a situation that romantic partners of the same race do not typically experience. Rose's mocking 
emphasis of "my black boyfriend" further indicates that, for her as the anti-racist, it would be an absurd and pointless detail to include when speaking to her parents that Chris is black.

Chris pushes a bit more by stating that since she has never dated a black guy before, it would be "uncharted territory" for them. The use of "unchartered territory" suggests a metaphorical double entendre. Firstly, it assumes that because Rose's parents had not experienced the novelty of Rose having a black boyfriend, there may be some innate, unknown differences in how to act and behave. If boyfriend was "universal" and automatically meant "white", the territory would have already been chartered for Rose's parents, but black boyfriend adds a layer of complexity and unfamiliarity. Secondly, "unchartered territory" evokes the symbolic language of colonialism and whiteness travelling to new lands in order to tame and conquer. For them, Rose's parents, Chris is "unchartered territory" that has yet to be controlled and tamed. This bit of foreshadowing hints that perhaps Rose's parents (and Rose, herself!) are not as altruistic and genial as Chris would hope. Finally, when Rose qualifies her parents as "not racist" because her dad would have "voted for Obama a third time", it conjures the familiarity of colour-blind strategies used to defer or deny being racist. Using Obama as a litmus test for being "not racist" was exemplified by Bonilla-Silva's argument in which white people were collectively shouting that they are "beyond race" because of Obama's presidency (2018,pg. 204).

Following the conversation between Chris and Rose, the next scene is one that sets the tone for the rest of the film. While Rose is driving her and Chris to her parents' house, Chris is sitting in the passenger side of the car and calls his best friend, Rod. Throughout the film, Rod represents the comic relief, a familiar stereotype in popular film. His character, at first, is used to fill the expected black character that uses "boisterous and improper grammar, exaggerated 
motions and facial expressions, and intense emotion, often in stark contrast to standardized, White, middle-class behavior" (Gooding, 2017, pg.57). Though Rod's character becomes more complex as the film progresses, his introduction is a familiar and recognizable stereotype. Scenes including Rod are used to break up the tension and the discomfort Chris is experiencing being amongst Rose and her white family. The juxtaposition of these scenes highlights the difference of Rod's blackness, demonstrated through his language, slang, and comedy, and the "normal" and "civilized" behaviours of the white middle-class.

Peele's mention of wanting to subvert character tropes and stereotype in his film were not lost on Rod's character. Instead of comic relief, Rod ends up being the voice of reason throughout the film to the point where in the final scene of the movie, he becomes the black saviour. Though Rod is logical and often correct in his assumptions of not trusting white people, his clever foreshadowing is veiled by his comedic and outrageous skepticism. Rod's blatant warnings to Chris of how races don't mix provide comedic fodder and a misdirection to the audience from the familiar narratives they are used to seeing which is exemplified in their phone-call. Rather than recognizing Rod's buffoonery as accurate foreshadowing, Rod's character presents him as a "reverse racist".

Rod: Sup?

Chris: Yo, you at work?

Rod: yeah, yeah, I'm at work. Look, Chris, tell me this, okay? How can I get in trouble for patting down an old lady? It's standard procedure. Gary jus' think 'cause an elderly bitch is elderly, she can't hijack no motherfuckin' plane. C, wait, wait, wait. I know you laughin'. I'm serious, man. The next 9/11 is gonna be on some geriatric shit. Straight up.

In the first interaction between Chris and Rod, the vernacular is noticeably different than that between any other characters in the film. Rod's profanity and slang are used to contrast the way that Chris speaks when among Rose's family. This noticeable plot point also foreshadows why Chris finds the interaction he has later in the film with Andrew Logan King (Played by 
Lakeith Stanfield) strange because King doesn't act or "talk" black. When King fails at greeting Chris with a "fist bump", it immediately triggers in Chris a sense that something is not all well at the Armitage residence. With Rod however, his musings about an elderly woman hijacking a plane elicits laughter from Chris and is similarly meant to elicit laughter from the audience. Rod frequently breaks up the tension throughout the film with comedic relief and serves as a constant reminder of Chris' blackness. Furthermore, because Peele had admitted that he purposely subverted the character tropes in mainstream film, Rod's character is also meant to subtly mock white audiences by presenting himself as an expected trope yet ending the film as the hero. The more Chris gets involved with meeting Rose's family; the more Rod tries to pull him back to his "proper place" of blackness. While Rose is trying to bring Chris to meet her family and to be a part of a white family, Rod constantly pulls Chris back attempting to convince Chris of his blackness.

Following this segment of the conversation, Rod advises Chris that he shouldn't be visiting a "white girl's parents' house". Chris promptly hangs up on Rod, inviting the audience to join him in dismissing Rod's warning as close-minded, ridiculous, and even "racist to whites". In the opening scenes, Rose had already established herself as the "anti-racist" character making Rod's skepticism seem even more unwarranted. Shortly after Chris hangs up on Rod, Rose hits a deer with her car and pulls over on the side of the road. When a policeman shows up to the scene of the collision, he asks Chris to provide identification even though he was not the one driving the car. This scene is meant to elicit the familiar occurrence of police harassment and the disproportionate targeting of black males in America. Being routinely and frequently "carded" by police is another way in which power is enacted through colour-blind micro-aggressions with the plausible deniability of "just doing one's job”. 
Policeman: Sir, can I see your license, please?

Rose: Wait, why?

Chris: (to the officer) Yeah, I have State ID

Rose: No, no, no. He wasn't driving.

Policeman: I didn't ask who was driving, I asked to see his ID.

Rose: Yeah, why? That doesn't make any sense.

Chris: Here... (Leans in to hand the police officer his ID)

Rose: No, no, no. Fuck that. You don't have to give him your ID 'cause you haven't done anything wrong.

Chris: Baby, baby. It's okay. Come on.

Policeman: Any time there is an incident, we have every right to ask...

Rose: That's bullshit

Though it becomes clear later in the movie that Rose's intentions are to hide Chris' identity from any form of authority that might later be able to help him, during this scene Rose is heroically standing up for Chris once again. In the familiar case of police profiling, Rose represents the change that proponents of colour-blindness want to see in themselves. Along with Rose, the audience is invited to be a part of the resistance in which Chris is being unfairly and racially targeted. When Rose cuts off the policeman by claiming "that's bullshit", the police officer gives up on pursuing the matter any further and tells Rose to get her mirror and headlight fixed as he leaves back to his police cruiser. Because Rose was able to intervene and keep Chris from unnecessarily showing his ID, it legitimized the assumption that this was a case of needless police profiling and again portrays Rose as the anti-racist white saviour, proactively engaging and combatting racist structures and sentiments.

In what Guerrero calls a "dominant cinema maneuver of displacement” (1993, pg.77), so far in the film, the prejudice has primarily come from Rod who warns Chris of "white" parents, rather than from Rose who has constantly defended Chris from being racially targeted and feeling alienated. Rod's mistrust of "white" people, and Rose's ability to immediately stand up for Chris, gives the audience the impression that not only is it possible that white people can be the 
victims of racist attitudes too, but through Rose, they are also actively participating in the resistance of racism.

When Chris and Rose arrive at her parents' house, Rose's dad, Dean (played by Bradley Whitford), gives Chris a tour of his home. Through his tour, the audience is introduced to Georgina, the black housekeeper, and Walter, the black groundskeeper. Chris begins to look visibly uncomfortable during the tour, and audiences can easily recognize the stereotypically racist portrayals of black servility. Dean explains to Chris that the "cliché" of having "black servants" is a benevolent act of keeping them employed after his parents died. Chris, after a few brief encounters, notices that there is something strange and ominous about Georgina and Walter. Since Rod had previously established himself as the embodiment of blackness, the mannerisms of Georgina and Walter (and later, Logan King) become noticeably unusual to Chris.

As Dean continues his tour, he begins to embody colour-blindness and "post-race" ideology. Dean motions to some lamps that he "picked up in Bali" and explains to Chris, "I'm a traveler and I can't help it. I keep bringing souvenirs back. It's such a privilege to be able to experience another person's culture". In a bit of irony, Dean then shows Chris a picture of his dad whose claim to fame was racing against Jesse Owens in the 1936 Berlin Olympics. "What a moment", Dean begins explaining to Chris, "I mean, Hitler's up there with all his perfect Aryan race bullshit. This black dude comes along, proves him wrong in front of the entire world. Amazing". At a first glance, it would appear as though Dean is being quite genuine towards the atrocity of Nazism, and of racism, until it is later revealed in the film that he and his family have been transplanting white brains into black bodies on the belief that black people are genetically superior. Dean is the "smiling face" of racism who says all the right things and who presents as 
genial, but "behind-the-scenes", has been enslaving, kidnapping and auctioning off black people from his family ranch.

Though it is still necessary for the Armitage family to continue having mental and intellectual control over themselves, the black body becomes a vehicle of increased speed, power, and style. As Richard Dyer explains in his book, White (1997), "genetics has also sometimes granted a bodily superiority to non-white people, for instance, attributing black sports prowess to superior musculature, powers of endurance and inborn fleetness of foot” (pg. 24). However, what Dyer goes on to explain, is that despite this physical prowess, "white blood and genes carry more intelligence, more spirit of enterprise, more moral refinement" (pg.24), so it is necessary that during the transplantation, that the "white spirit" be left intact to control that of the black body. Dean testifies to Chris that he would have voted for Obama a third time if he could in a final bid to win Chris over. Dean's conversations with Chris is a play on the subtleties of colour-blind racism and displaying a sense of "white guilt" by trying to prove to Chris that he is "different" from people who "are" racist.

As for Chris, he is undecided on if he fully trusts Dean, primarily precipitated by Rod, the representative of "real blackness", who had told Chris that he should not have gone to a "white girl's parents house" in the first place, and secondly by the strangeness of everything going on around him. As the movie concludes, it is clear that Dean and the Armitage family have been kidnapping and luring black people back to the house to lobotomize and surgically alter their brains in such a way that white friends and family (Dean's parents included, who are revealed to be Georgina and Walter) can implant their own thoughts and free will, but acquire complete control over the black bodies. In retrospect, the facetious comments made by Dean about privilege and the "superior Aryan race bullshit" become a thinly veiled form of impression 
management to gain Chris' trust so that he can more easily keep Chris around, auction him off, lobotomize him, and financially profit from his sale.

Trusting a white family has becomes Chris' worst nightmare turned reality. The scenes in which Dean tries to court Chris retrospectively reinforce the thin veil of colour-blind racism. It is easy enough to tolerate and to be courteous, but what goes on in the "back stage" is fundamentally unchanged. Jordan Peele argues that this is part of the "post-racial lie" that he personally experienced in his daily life. Peele notes that in the "post-race" era "calling out of racism was almost viewed as a step back" (Keegan, Vanity Fair, 2017). Therefore, when Dean is commenting on race and on blackness, Chris simply nods along in uncomfortable silence. Chris constantly struggles on if he is overreacting on the potential dangers that he could experience at the Armitage residence, or if he should trust his instinct and leave. This indecision demonstrates the power of micro-aggressions to other softly, and Chris' inner struggle demonstrates that overreacting about race in the "post-race" era as a black man makes him the one overly concerned about race. With Rose's constant reassurance, and Chris' likelihood of not being taken seriously if he expressed legitimate concerns about Rose's family being racist, Chris ends up staying at the house longer than is safe. Because Chris is correct in assuming that events around him are indeed strange (and dangerous), and that the Armitage family have been feigning racial acceptance and have insidiously put on a face of warmth and hospitality (something Rod had warned Chris about), the film hints to the potential dangers and the need for skepticism from black people during moments of white interaction despite white pleas that they are "not racist", "voted for Obama" or that "racism no longer exists". Interactions between Chris and the Armitage family are always uncomfortable for Chris. This emotion is picked up by audiences watching the film who are invited to a glimpse of the everyday micro aggressions and insidious 
forms of color-blind racism that continue to exist and are instructed (for example, by Rose to Chris during the Armitage's annual "auction" party) to be dealt with a smile.

Rose pretends to share Chris' concerns about her family's racism. Picking up on the fact that Chris won't openly state his discomfort (not wanting to take "a step back"). Rose takes this opportunity to point out all the instances in which Chris was a victim of subtle racism, beginning with her brother, Jeremy.

Rose: "He was gonna put you in a fucking headlock. What is his problem? He has never treated any of my boyfriends that way. Ever, ever, ever. Chris: Mmm-hmm

Rose: Oh, my God. And then my dad with the "my man" stuff. "My man, my man." I don't think he's ever heard that or said it. And now he just... It's all he says. Oh, and my mom being rude to Georgina? What the fuck was that about? That was so crazy. I mean... how are they different than that cop? That's the fucking bummer of it all Chris: mmm-hmm

Rose: Mmm-hmm? Anything more you'd like to add?

Chris: (reluctantly) I told you so, like...I didn't want to say it. I didn't want to say it. I didn't want to say that.

Rose: How are you so calm?

Chris: Honestly, it's nothing.

Rose: Oh, Fuck. The party.

Chris: How bad can it be?

Rose: They are so white. Like, so white!

Chris: It's all good. You know, with my genetic makeup, shit gonna go down. I'm a beast. I'm a beast!

Rose's brothers' comments at the dinner table about Chris having a strong "frame" and "genetic makeup" that could be useful in physical altercations, have Chris starting to become uncomfortable with the entire family. As a character in the film, Chris is not very physically muscular, or very tall, but is characterized as such by Rose's brother. Nancy Yuen writes in Reel Inequality (2018) that "Darren Wilson - the white police officer who shot and killed Michael Brown, an unarmed black man, in Ferguson, Missouri - characterized Brown as a "demon" and a "hulk". Journalists pointed out that Wilson's descriptors came from the "black brute" racial stereotype, a "stock figure of white supremacist rhetoric in the lynching era of the late $19^{\text {th }}$ and 
early 20"t centuries", as popularized in Hollywood films" (Yuen, pg.8). Chris is beginning to embody several black, racial stereotypes in this film that are reflections of contemporary society and the tendency to overestimate the size and strength of black people. When Rose explains to Chris that Jeremy has "never, ever, ever, ever" treated one of her boyfriends that way, Chris' "Mmm-hmm" reply is indicative of the fact that because Rose has told Chris that he was the first black person she has dated, it suggests to him that the way Jeremy treated him was because he is black.

Next, she indicates to Chris that Dean's use of "my man, my man" is a subtle and colourblind method of "talking black". Because Rose says that Dean has "never said that" before, it again indicates that his selective use of "my man, my man" was for the purpose of speaking to Chris in a more familiarized, and racialized way to him. Finally, Rose says that because her mom was rude to Georgina, her along with her brother and father are no "different than that cop", who was also outed by Rose as a racist for unnecessarily asking Chris to produce a piece of ID though he had not been driving. Though Rose's tactics are all methodically rehearsed (for example, denying the cop to see Chris' ID so he could not be identified had he gone missing), there is enough plausible deniability for the audience to believe that Rose is different than her family and continues to be the "anti-racist" until the films conclusion. Viewers are invited to see Rose as the "one sane" person amongst all the insanity and inappropriateness of contemporary racism. Rose invites the audience to see the absurdity of how her family and the party goers treat Chris and how they talk to him, but in the end the illusion comes crashing down.

Rose's final statements in this scene caution Chris about the "party". Her suggestion that the party-goers are "so white" warn Chris that they are, by nature, less accepting or politically correct about racial difference. Chris and Rose look out of the bedroom window as they see the 
cars of all the party-goers arrive at the Armitage residence. Though the party-goers indeed are primarily white, every single car arriving at the party is black, a metaphorical representation of using black bodies as a vehicle, both literally and figuratively. Rose brings Chris around to meet the party-goers in small groups one at a time. Chris is unaware that he is essentially selling himself to potential buyers. The first couple Rose introduces Chris to are the Greenes.

Rose: Gordon and Emily, this is Chris. Chris, this is Gordon and Emily Greene Chris. Nice to meet you Gordon: Nice to meet you, Chris. Nice to meet you indeed. Oh, that's quite a grip! Chris: Thank you. You too, man

Gordon: You, uh, ever play golf?

Chris: Mmm, once, a few years ago. I wasn't very good.

Emily: Gordon was a professional golfer for years.

Chris: Oh, you kiddin'?

Gordon: Well, I can't quite swing the hips like I used to, though. But, uh, I do know Tiger.

Chris: Oh.

Rose: Oh, that's great

Chris: Super

Emily: Gordon loves Tiger

Gordon: Oh, the best I've ever seen. Ever. Hands down. So, Chris, uh, let's see your form.

In this transaction, Chris' physical prowess intrigues Gordon based on the strength of his grip. Though Chris tells Gordon he is not a golfer, Gordon is still interested in seeing Chris' form and indicates that "Tiger" is the best he's ever seen. Gordon's "racial matching" of Chris to Tiger Woods unmistakably suggests that not only does Gordon believe that black people are superior athletes, but that Chris, because he's black, may be interested to hear more about Tiger Woods, because he's a prominent black golfer. This claim is part of an essentializing prejudice which assumes that because someone is black, they must be aware of and celebrate all wellknown black celebrities. Next at the party is Nelson and Lisa.

Rose: This is Nelson and Lisa.

Chris: hey, how you doin'?

Lisa: So, how handsome is he?

Rose: I don't know, are you handsome? 
(Lisa walks over to Chris to clutch his arm)

Lisa: Oh! Not bad. Eh, Nelson? So, is it true? Is it better?

Chris: Oh, wow

Emily: Wow...

In this transaction, Chris is blatantly racialized by Lisa who brings up the symbolic "black buck" trope, a strong black male with superior sexual stamina and abilities. Rocchio argues in Reel Racism that the black buck "functions metaphorically to equate Afro-American men with overly developed sex drives and sexual prowess. The stereotype is based on an analogy between the physical demands of sexual prowess and the physical prowess demanded by forced labor that Afro-American men had to endure" (2000, pg. 21). Lisa's wildly inappropriate comment is automatically understood by both Chris and Rose, and by the audience, perpetuating anxieties about having to qualify inter-racial romantic relationships by something other than sexual conquest. If Chris were white, the question of "is it better?" would never be asked. Instead, seeing as how the relationship would be "normal" by virtue of being the same "race", Chris would typically get questions about his character, his job, his hobbies, etc. However in this interaction, because Chris is black, he is sexualized, and because Rose is white, she falls victim to the presumption that she is dating a black man for a better sexual experience.

Interestingly, the "buck" becomes a recurring theme in the movie starting with when Rose first hits a deer with her car. When she tells her dad, Dean, that she had hit a deer with her car, he replies;

"Well, you know what I say? One down, a couple hundred thousand to go. No, I don't mean to get on my high horse, but I'm telling ya. I do not like the deer. I'm sick of it. They're taking over. They're like rats. They're destroying the ecosystem. I see a dead deer on the side of the road, I think to myself, that's a start"

Dean's hatred of deer "taking over" is a metaphor for his disdain of black people, and his rant against deer foreshadows his family's anti-black racist agenda. 
Finally, during the latter part of the film when Chris is the basement to prepare him for the brainwashing phase of his pre-surgery lobotomy, he wakes up after being hypnotized tied to a chair facing a television screen and the head of a buck mounted in the wall. Facing across from him is a television set where blind art dealer, Jim Hudson, debriefs Chris about the final stage of the transplantation. Chris asks Jim "Why us? Why black people?". Jim replies "Who knows? People wanna change. Some people wanna be stronger. Faster. Cooler”. Though Jim assures Chris that he personally only wants his body for his eyes, clearly the Armitage family and their friends are interested in "stronger", "faster", "cooler", and more sexually potent black bodies. Before Chris falls victim to the final stage of transplantation, he is able to pick cotton from the armrests on his chair and fill his ears so that he doesn't fall asleep to the hypnosis emitting from the television set. When he is untied from the chair, he violently escapes captivity by beating Jeremy over the head with a blunt object. Chris's focus falls on the taxidermy head of a buck mounted on the wall and in the film's turning point, Chris uses the wall-mounted buck to kill Dean by thrusting the antlers through his body; a symbolic act of restitutive violence.

Chris leaves the basement and eventually the house before driving away from the Armitage house. Rose, who becomes aware that Chris is driving away, chases after his car with a shotgun. After Chris drives into a tree, Rose's grandfather runs after Chris, only to be brought back to consciousness through the flash of Chris' cellphone. The grandfather then takes Rose's shotgun and shoots her through the body before turning it on himself. Chris realizes that Rose is not dead and begins to choke her in order to finish the job. After realizing he can't kill her out of remorse, while over top her, Chris and Rose hear the sound of a police siren and see the blue and red emergency lights. Though Chris is the victim, and though he has been attempting to escape for his life, the social implications of the siren and the lights are clear. Rose calls out for help 
while Chris gets to his feet and raises his arms above his head. Before any instructions have been given, and before Rose and Chris see who is driving the car, it is clear to the audience that the circumstances of having a black male overtop a white woman at night in the middle of the road won't bode well for Chris. Throughout the film, Rose had been continuously trying to smooth over to Chris that "race doesn't matter", but in the final scene of the film, it is clear to Rose, Chris and the audience that to the police and to law enforcement, that race absolutely matters in terms of culpability.

In a final twist of events, the man driving the car is revealed to be Rod in his Airport Security car. When Chris realizes it is Rod, he lowers his hands and walks to the car. In a final act of comic relief, Rod looks over at Chris, shakes his head, and tells him "I mean, I told you not to go in that house". This final I-told-you-so moment is Rod's legitimation of his earlier caution not to "mix the waters". In the end, Get Out provides a commentary on interracial romantic relationships, the attempts to smooth over anxieties about contemporary racism, and then ultimately cautions that indeed it does.

In conclusion, Chris is constantly told by Rose that "race doesn't matter", and that her dad would have voted for Obama a "third time if he could". Rose, who starts off the movie as the anti-racist character that America wishes it was, ends the film by showing her true colours of the smiling villain as it is revealed she has been implicit in the seduction of black men so that her family can brainwash and control them. Director Jordan Peele subverted the stereotype of the white savior and consciously made a film depicting "all white characters as evil". Throughout the film, anti-miscegenation, black buck metaphors, black house keepers, and a plantation looking big house all situated in the film in a familiar "slave narrative" film in a modern setting, reminding viewers that racism is alive and well, colour-blindness and "post-race" ideology have 
simply contributed in masking it. By writing and directing a film which demonstrated the salience of micro-aggressions and racial othering by a middle-class, white family, Jordan Peele's successful box-office smash hit provided the much-needed counter-narrative to the plethora of films which insinuate that "race no longer matters".

\section{La La Land (2016)}

The buzz around La La Land during its release was that it was a nod to classic cinema, and particularly to the great musicals of the past. With references ranging from Singin' in the Rain (1952), Funny Face (1957) and Rebel Without a Cause (1955), director of La La Land, Damien Chazelle, opted to shoot the film in "2.55 CinemaScope, a format that was used primarily throughout the 1950s" (Dugan, 2017), to really bring the nostalgic feel of a romantic classic cinema to life. In a formula that proved successful, La La Land won every Golden Globe Award that it was nominated for, with a record-breaking seven wins, and received fourteen nominations at the Academy Awards, tying that record with All About Eve (1950) and Titanic (1997). La La Land is a film largely about daring to dream, staying true to yourself, and white privilege, and ultimately ends in success for both of the main lead characters (Emma Stone, who plays Mia, and Ryan Gosling who plays Sebastien). La La Land was certainly one of the biggest movies of the year and cashed in on a romanticized nostalgia of a Hollywood past.

After the opening dance scene in the film, we are introduced to Mia who is rehearsing lines for an audition in her car while driving to her job at a coffee shop. When she arrives at the coffee shop, Mia's mind continues to be focused on her audition, indicating her big dreams and aspirations as a famous actress. A woman in a red dress walks to the counter to order a cappuccino. Mia, looking star struck, replies "Yes, of course", but before she can move her body, 
her manager brings the cappuccino and tells the lady in the red dress that it's "on us". This preferential treatment of the well-dressed white woman sets the stage for the possibilities for Mia's future, whose dreams far transcend her work as a barista. As the woman walks out of the coffee shop, Mia continues to watch her as two men talk amongst each other; "did you see who that was?" one says to the other.

As the woman rides off, Mia, with her head in the clouds, is brought back to Earth by her phone alarm reminding her of her audition. This scene articulates to the audience who Mia's character is. Mia has big dreams of becoming a famous actress, but indicated by her job as a barista, she endears herself to the audience as the "average person" with big dreams. When Mia's audition goes poorly, she exits the room and walks past ten other actresses waiting for their chance to audition as well. All ten women are white, slim, and have long flowing light hair. In this scene of art imitating life, Hollywood ironically admits its preference for a "white beauty standard". There are no actresses of colour waiting to audition. This is possibly because the casting call only requested "white" actresses, however it is never addressed, and as the film progresses, the erasure of people of colour from La La Land becomes more evident. This scene, however, is also used as a plot device to illustrate to the audience that Mia is "just like everybody else"; she's just like you! Mia's character hinges on the audience being able to relate and sympathize with her and struggle. Like in I, Tonya, Mia wishes to stand out and to realize her American Dream as a professional actress. Subtly implied in this scene is the implication that whiteness is the gatekeeper of opportunity, and that the Other is not even considered. This becomes evident as Mia enters the elevator to leave the building when two more women, equally tall, thin, and white, pass her by as they presumably audition for themselves. 
In the next scene, Mia enters her apartment and falls face-first onto her bed before taking a shower. Her three roommates, presumably actresses as well, attempt to convince Mia to join them as they get ready to go to a party. All three of her roommates display the recognizable aesthetic of the "white beauty standard"; white, thin, and long-flowing hair, all wearing slim fitting dresses cut above the knee. Despite being a barista, Mia still has the means of living in a massive apartment in Los Angeles and the social capital that affords her invitations to grandiose pool parties with rich and successful people and flowing champagne. Though Mia's access to social and economic capital goes largely unquestioned in the film, it is an important detail of white privilege. Mia only sees herself as unsuccessful and will continue to view herself in that way until she "makes it in Hollywood".

Throughout the movie however, Mia auditions for several acting roles and continues attending upscale parties for networking opportunities, all while living in the expensive city of Los Angeles. Frustrated with the lack of call-backs, Mia eventually decides to write her own one-woman play. "I'm not getting paid, I'm paying to do it" Mia tells her mom over the phone. It is not that Mia doesn't have opportunities; in fact, she has many. Mia is seldom met with any resistance outside of her own lack of ability and failure to secure acting roles. Mia's failure to achieve her American Dream at this point in the film has had nothing to do with the social inequalities that non-white aspiring actors face in terms of hiring discrimination, opportunity, or lack of economic and social capital to pursue auditions while working a full-time job. Unlike Tonya who displayed the ability to be a top figure skater in the United States but failed to "fit in" because of her lower class, Mia fits in almost too well. Mia is among a plethora of female actors that look just like her, and the acting jobs are clearly so homogenous that Mia is just another needle in the proverbial haystack. 
Unequal social realities typically go uncontested in films that are meant to be "universal". Because La La Land is "not about race", it is pointless to address social barriers that impact American Dream ideology, because it is presumed that there are none. In colour-blind, "postrace" America, meritocracy is the primary concern for Mia's success. Mia's character is meant to relate to a "broad" audience who can sympathize with the fact that good is not good enough, and that it must be through her own hard work that she achieves the successful career she desires. Mia's failures are meant to show that the American Dream has its ups and downs, but with perseverance, eventually she will climb to the top. The stark contrast of Mia's character with that of Tonya's again demonstrates the layers of whiteness that impact social capital.

When Mia leaves one of the parties that her roommates invite her to, she meets Sebastien for the first time. Sebastien is a down on his luck jazz pianist, who also has big dreams of opening his own jazz club called "Chicken on a Stick". Sebastien also wishes to be the singular saviour of jazz music and wishes to revive it to the tour de force music genre he thinks it should be. Sebastien already has his eyes set on the location of his future club at the old Van Beek, which currently has been converted into a "samba and tapas" place. "Samba. Tapas. Pick one. Y'know? Do one right" Sebastien tells his sister in disgust when he hears the news. Sebastien's look of abhorrence at the prospect of having samba and tapas take over his beloved jazz club mimics the all too familiar unwelcome feelings of anti-immigrant sentiment. Though non-white actors are almost entirely left out of the casting in La La Land, the "Tapas \& Tunes" samba spot symbolically represents one of the only ethnic references in the film. Los Angeles County was reported as having nearly fifty percent of its population identifying as Hispanic or Latin American according to a 2016 census, the same year as the film's release. This singular ethnic reference of "samba and tapas" is the bane of Sebastien's existence, and he vows to 
eventually take over the spot and rightfully claim it as his own. For Sebastien, the maintenance of "history", and protecting the Van Beek from Latin American immigrants is his way of "Making Jazz Great Again", and "protecting the borders" of what he considers part of his territory. "It's got to be the Van Beek" Sebastien tells Mia, "I can't let them samba all over its history". Ironically, not only is Sebastien wanting to reclaim the spot as a jazz club, which is a familiar narrative of the white saviour maintaining an art form that historically has its roots in African-American communities (Sebastien tells Mia that it comes from a little flop house in New Orleans), but also Sebastien wants to call his jazz club "Chicken on a Stick" (because Charlie Parker loved chicken).. "Chicken, beer, jazz. Chicken on a Stick." Sebastien tells Mia, "I'm not dropping the chicken". Do one right.

In Black Feminist Thought, Patricia Hill Collins notes that African-American music as art has provided an aesthetic community of resistance, which in turn encouraged and nurtured a political community of active struggle for freedom" (1990, pg. 99). These musical art forms included spirituals, blues, jazz and rap music which all form part of a "continuum of struggle which is at once aesthetic and political" (1990, pg.99). Sebastien's desire to "keep jazz from dying" places him at the center of continuing the struggle for freedom for African-Americans. Thus, a major plot point in La La Land is the white man's burden of continuing a non-white art form that black people seemingly no longer care about. Because there are hardly any black people in the film to begin with, Sebastien's quest also hints that the struggle is over and black people have their freedom. This becomes clear in a later scene during an interaction between Sebastien and an old friend of his, Keith.

After Mia and Sebastien begin dating, they are both struggling with finances. Both Mia and Sebastien decide to commit to their dreams, meaning that they have invested their time, 
money and efforts into their crafts rather than working any old job to pay the bills. While sitting on the bed and noticing the water damage that has begun to affect the ceiling of his apartment, Sebastien overhears Mia talking to her mom over the phone about Sebastien's job prospects. "No, he doesn't have a steady gig" Mia explains to her mom. When he hears this, Sebastien decides to swallow his pride (temporarily) and call up an old connection who had earlier offered him a job. Keith (played by African-American actor and musician, John Legend) is the only African-American credited in the film. Keith's story is largely unexplained in the film, aside from Sebastien explaining to Mia that they went to school together, and that things between them are "always weird". John Legend's character is another example of a minority role being filled by a widely recognizable pop-star who is not known for his acting, but rather for his music. As Yuen explains in Reel Inequality, "the film industry often seems to have tunnel vision when it comes to black talent" (2017, pg.54) and would rather not take a chance on a lesser known actor when it comes to minority roles. Furthermore, Keith's lack of character development is a common theme for black actors in minority roles. Because the story does not revolve around Keith, it is not as important to detail his character's origin as it is to simply include him in the film as a symbolic token of racial inclusion. Though a film about jazz music set in Los Angeles would seemingly be more diversely cast, by accepting colour-blindness and "post-race" ideology, it arguable does not have to be.

In Dr. F.W. Gooding, Jr.'s book You Mean There's Race In My Movie?, he details racialized tropes in Hollywood film, one being the "Angel archetype" who is

"instrumental in facilitating an emotional catharsis for the central White character. Such catharsis is often necessary for the White character to transcend to a higher level of understanding, receive an increase in status, or step closer towards accomplishing their goal... Essentially, Angels are important only to the degree that they influence the central character, who is then empowered to right the wrongs at the end of the day" (2017, pg.72). 
Ultimately, Keith is there for Sebastien's convenience; to offer him a job, to pay him well, and to give him a spotlight in the public eye (as indicated by the hundreds of thousands of YouTube hits the band's interview gets on WTJM Chicago 98.8 FM), so that Sebastien can eventually open his own club and fulfill his altruistic goal of saving jazz music. "I know. It's different" Keith tells Sebastien of his new sound, "but you say you want to save jazz. How you gonna save jazz if no one's listening? Jazz is dying because of people like you. You're playing to ninety-year-olds at the lighthouse. Where are the kids? Where are the young people? [...] You're holding on to the past, but jazz is about the future". As Sebastien dejectedly nods his head, it becomes clear to him that he won't allow Keith's new-age, synthetic pop style of jazz to "samba all over history". As the self-appointed gatekeeper of jazz music, only Sebastien seems concerned about maintaining the roots and authenticity of the genre, something Keith, despite being African-American, cares little for.

Patricia Hill Collins argues that the commodification of jazz and blues music and its transformation into marketable crossover music "virtually strip[s] it of its close ties to the African-American oral tradition" (1990, pg.102). Rather than maintaining the struggle for African-Americans, Keith instead strips away the oral tradition of his music in order to financially profit and cater to the "young people" and the "future". Like "post-race" ideology, Keith implores Sebastien to stop "holding on to the past" in order to make some money now. In La La Land, Keith's character is utilized as not just the only black person in the movie, but also as the ideological surrogate of "post-race" colour-blindness. His position in the film is not to maintain jazz music as an authentic musical art form rooted in the African American struggle for freedom, but to suggest to audiences that the struggle is over and to look to the future. 
In the film's conclusion, Sebastien and Mia's relationship fizzles as they are both chiefly concerned with the pursuit of their individual goals. Mia, whose big break came from her onewoman play, is seen walking in to the same coffee shop that she had once worked at as a barista to the same wide eyes and preferential treatment (two iced coffees, on the house) as the woman in the red dress at the beginning of the movie. Mia's mere presence will inevitably inspire the young, "white", female barista to continue the cycle of the rags-to-riches pursuit of stardom. For whatever reason, La La Land's decision to cast mostly "white" actors, even in minor roles such as the barista, reinforce the generations of the past, present, and future. The star before Mia was "white", she is "white", and the star after her will be "white". The implications of course suggesting that "La La Land" (or, Hollywood) be kept for the brightest, and "whitest". La La Land reinforces the desired aesthetic of female beauty as white and provides examples through Mia and Sebastien of how meritocracy, authenticity, and hard work pay off. Though Mia and Sebastien did not end up happily ever after together, they both achieved their initial dreams of success through their perseverance and individual ability and, although bittersweet, grants the audience closure as the movie comes to an end.

\section{Conclusion}

Though both films are wildly different in their overall story, character development, and plot, both films consciously and unconsciously situated themselves in the "post-race" era of America. In La La Land, the implications were more subtle. Sebastien, who represents the white savior of jazz music, displays a constant disdain for Latin American immigrants "taking over" his spot and "dancing all over history". Though these subtle racist digs and micro-aggressions likely were lost in the overall plot of someone relentlessly pursuing their dreams as altruistically and authentically as possible, $\mathrm{La} \mathrm{La} \mathrm{Land} \mathrm{curiously} \mathrm{left} \mathrm{actors} \mathrm{of} \mathrm{colour} \mathrm{almost} \mathrm{entirely} \mathrm{out} \mathrm{of} \mathrm{the}$ 
film. With this, Sebastien's dreams were America's dreams of "maintaining history" and keeping immigrants from "moving in". Furthermore, Mia's character throughout her acting auditions was constantly in a sea of women who looked just like her, perpetuating the idea that what Hollywood is looking for is only thin, white women displaying the normative beauty standard of whiteness. Mia, who begins and ends the movie at the coffee shop, first as barista, second as star, leaves in her place a new girl behind the counter taking her order. Mia, who has inspired by the star at the beginning of the film, became that star, and is now the inspiration for the next generation; another young, thin, white woman. Finally, Keith's character remained undeveloped and peripheral to Sebastien, but provided the tokenism required to keep the cast from being exclusively white. 
"Listen, we made a film about a gay man, an immigrant

who lived his life just unapologetically himself, and the fact that

I'm celebrating him and this story with you tonight is proof

that we're longing for stories like this."

- Rami Malek's acceptance speech for Bohemian Rhapsody (2019)

\section{Chapter 5 - Conclusion}

\section{Summary}

This thesis developed a framework for the critical analysis of contemporary film and their racial implications. With the theoretical tools of semiotics, discourse analysis, and narrative control, I have demonstrated how colour-blindness has saturated contemporary Hollywood films in order to ideologically align viewers with either the dominant in-group of America, or the dominated group. Colour-blindness depends on eschewing biological explanations of racial difference in favour of cultural differences, but still ideologically organizes society in terms of a racial hierarchy. "Race" is socially constructed yet is so ubiquitous in American society that it is nearly impossible to ignore its real-world impact. On an individual level, I have argued that although there is agency involved in terms of how individuals read media texts and how they interpret and de-code "race", mainstream Hollywood films continue to produce films which deal explicitly with anti-black racism making it difficult for audience members not to position themselves along the colour line. By illuminating the contradiction between celebrating a "post-race" utopia with the continued racial disparities that exist in America, I have demonstrated that Hollywood films aim to ideologically smooth over race relations and to present as more racially progressive than it is. 
Though "post-race" films are not inherently about race, race and racism continue to be popular themes among Oscar nominated films in the last decade. During the most recent Academy Awards, Black Panther, BlacKkKlansman, Green Book, and Bohemian Rhapsody were all nominated for the Best Picture category, and all specifically dealt with stories of racial minorities. During Rami Malek’s acceptance speech for his performance of Freddy Mercury in Bohemian Rhapsody, he suggested that people are longing for stories that go against the grain of white heteronormativity. For a long time, whiteness has been the "norm" of American society, and thus has been excluded from being heavily scrutinized as a racial category. From the investigation of La La Land, I discussed how colour-blindness positions this film as "not about race" and is meant for "universal appeal". Despite this, La La Land contains themes which “others" Latin immigrants, holds whiteness as a female beauty standard, uses the "white saviour" stereotype to save jazz music, and visually eliminates people of colour from its setting in Los Angeles. With the analysis of I, Tonya, I have also shown that whiteness as a racial category is more complex than just skin colour. Dyer had suggested that "enterprise" was important to upper-class whites during imperialism, and similar intangible qualities continue to impact whiteness. Tonya's ability did not contribute to her success in figure skating in the way that universal liberalism and meritocracy suggests it should. Instead, Tonya was "white trash", thus eliminating her from the privilege of upper-class whiteness. Tonya's downfall demonstrated the social barriers which impact racialized people and highlights the contradiction between colourblind ideology and the realities of pretend pluralism.

Colour blindness is a formidable political ideology in maintaining the colour line while denying racist intent. In Get Out, Chris was subjected to constant micro-aggressions and racial profiling. This film demonstrated that racial stereotypes are ambivalent, and again illuminated 
the contradictions of colour-blindness and the lived experienced of black people in America. Jordan Peele, who wrote the script, successfully subverted the stereotype of the white saviour by playing on audience expectations of formulaic mainstream cinema. By portraying Rose as the anti-racist character in the film, Peele was able to perform a successful bait-and-switch which kept audiences speculating at the films conclusion. When all white characters were revealed to be evil, Peele's tongue in cheek message to America was to rethink the "post-race" era to the "post-race" lie. Peele is continuing to write scripts for mainstream Hollywood films which do not include white main characters because, as he said, I've seen that movie before! Continuing to follow the work of Jordan Peele may provide valuable insight into colour-blindness and the "post-race" era, as he has shown that he is willing to do things his way rather than to be complicit Hollywood's dominant formula.

In my film analyses, I have shown how Hollywood decision-makers, who are primarily white, continue to legitimize and justify stories, casting decisions, and narratives through colourblindness and universal liberalism. By "not seeming racist", the racial status quo remains intact by controlling the narrative of mainstream cinema. Though there are moments of celebration, such as Black Panther, and Get Out, it is difficult to predict whether these films will simply be consumed ala Blaxploitation era by Hollywood production because of their ability to be successful at the box office. The question remains on if these films a predictor of a better and more liberated black cinema, or will these films serve as moments, few and far inbetween, which simply amount to short-term financial successes? In the introduction of Framing Blackness, Ed Guerrero had predicted Malcolm X (1992) to be a trailblazer of things to come for black cinema. He suggested that black cinema in the 1990s would continue to challenge Hollywood dominant apparatus of cinematic representation, yet nearly three decades later Spike 
Lee had called for a boycott to the Oscars for the Academy's failure to nominate a black actor or actress in a leading role. In the "post-race" era, we are one once again at a moment in which mainstream cinema has seemingly recognized the impact of films which center around race and racism. In 2019, BlackKklansman, Black Panther, Bohemian Rhapsody, and Green Book were all nominated for Best Picture. The breakthrough of these films is either indicative of a longing for stories that eschew whiteness at the center of representation, as Remi Malek had suggested in his Oscar Award acceptance speech, or a strategic profit-driven manoeuvre by Hollywood to breathe new life into its formulaic approach.

\section{Areas of Future Study and Limitations}

This thesis was a qualitative content analysis, and as such, falls to the subjectivity and bias of interpretation. Though stereotypes are harmful depictions and reduce racialized minorities to a small subset of overall qualities, actors are undecided on a unilateral direction of whether to act in films or reject them for stereotypes.

For example, though Sidney Poitier was harshly critiqued by many black scholars as being an "Uncle Tom", he is still the first every African-American to win an Oscar in a leading role and was arguably a trailblazer for black actors and inspired many that the face of Hollywood success could also be black. Similarly, although Hattie McDaniel was lambasted by some in the black community for accepting her Oscar for her portrayal as "Mammie", McDaniel had the support of other members of the community and argued that she'd rather make money and win awards as an actor, than be a real-life maid for her career. What this goes to show is that often the community is divided, and the individuals, who do not always have to represent an entire population group, are awarded the benefits and splendor of mainstream actors. 
With the box-office success of Black Panther, and Get Out, attention should be paid to movies in the future which depict blackness onscreen as diverse characters rather than peripheral stereotypes to white centrality. Though Get Out began as a story of a mixed-race couple, it ultimately cautioned viewers of the horrors that went with dating "outside of your race". Future mainstream films need to be analyzed to see how, moving forward, if they can subvert the stigma of mixed-race romantic relationships, and if these films can be just films rather than films about race.

Finally, the interpretation of Hollywood and other media images is subjective and open to a variety of meanings dependent on the individual. Often, films can have split readings in which audience members can enjoy the film while ideologically disagreeing with its message. Furthermore, because racial categories are multifaceted and complex, whiteness or blackness cannot be homogenized as uniform groups of consumers. Agency is still a factor in both "races". Though cinematic images, themes, and narratives are not causally responsible for racism, they can be responsible for re-affirming negative thoughts about race and contributing to ideologies which impact race relations. If Hollywood maintains its ideological chokehold on the dissemination of mainstream cinematic narratives, it will predictably continue to create content which satisfies the dominant group for financial profit. More attention can be paid to independent films which go against the grain of Hollywood's dominant apparatus. As the title of Eduardo Bonilla-Silva's book suggests, "Racism without Racists", colour-blindness and the "post-race" era have attempted to construct an America in which there are no racists, yet racism and racial inequalities continue to be omnipresent in most quantifiable metrics of social life. How can there be racism if no racists exist? Because we are part of society, it is important to 
continue to critically analyze the images and messages disseminated through mass media, and to continue to question how these images impact us and those whom we live with in society. 


\section{References}

Abdo, Nahla. (1996). Sociological Thought: Beyond Eurocentric Theory. Canadian Scholars'

Press

Bobo, Lawrence. (2017). Racism in Trump's America: Reflections on Culture, Sociology, and the 2016 Presidential Election. BJS. Retrieved October 15, 2018, from https://onlinelibrary.wiley.com/doi/pdf/10.1111/1468-4446.12324

Bonilla-Silva, Eduardo. (2018). Racism without Racists: color-blind racism and the persistence of racial inequality in America. Rowman \& Littlefield

Boyle, Danny. (2008). Slumdog Millionaire. Celador Films

Brace, C. Loring. (2005). "Race” is a Four-Letter Word: The Genesis of the Concept. Oxford University Press

Brooks, Dwight. (2006). Gender, Race, and Media Representation. Sage

Bryant, Nick. (2017). Barack Obama legacy: Did he improve US race relations? BBC News.

Retrieved January 12, 2019, from https://www.bbc.com/news/world-us-canada-38536668

Butler, David. (2001). Whitewashing Plantations: The Commodification of a Slave-Free

Antebellum South. International Journal of Hospitality \& Tourism Administration. Retrieved

January 18th, 2019, from: https://doi.org/10.1300/j149v02n03_07

Capote, Truman. (1961). Breakfast at Tiffany's. Jurow-Shepherd

CBC News. (2018). Trudeau to apologize Nov. 7 for 1939 decision to turn away Jewish refugees

fleeing Nazis. CBC. Retrieved October 30, 2018, from https:/www.cbc.ca/news/politics/justintrudeau-st-louis-november-seven-1.4813667 
Cea, Max. (2017). “Moonlight” vs. “La La Land”: Fighting for symbolism, or more? Salon. Retrieved March 26. 2019, from https://www.salon.com/2017/02/26/moonlight-vs-la-la-landfighting-for-symbolism-or-more/

Chazelle, Damien. (2016). La La Land. Summit Entertainment

Cheryan, S. (2005). Where are you really from?: Asian Americans and Identity Denial. Journal of Personality and Social Psychology. Retrieved February 2, 2019, from http://dx.doi.org/10.1037/0022-3514.89.5.717

Cheung. Michelle. (2005). Redress at last for Chinese head tax. CBC. Retrieved November 21, 2018, from https://www.cbc.ca/archives/entry/redress-at-last-for-chinese-head-tax

Cieply, Michael. (2009). And the Winners are... The Press Democrat. Retrieved January 3, 2019, from https://www.pressdemocrat.com/news/2264647-181/and-the-winners-are?gallery=2360648 Clark, Alexis. (2018). “How 'The Birth of a Nation' Revived the Ku Klux Klan”. History. Retrieved March 27, 2019, from https:/www.history.com/news/kkk-birth-of-a-nation-film Collins, Patricia. (1990). Black Feminist Thought: Knowledge, Consciousness, and the Politics of Empowerment. Routledge

Coogler, Ryan. (2018). Black Panther. Marvel Studios

Dawson, Michael. (2009). One Year Later and the Myth of a Post-Racial Society. Harvard Donaghey, River. (2019). Jordan Peele Says He'll Never Have a “White Dude” Star in His Movies. Vice. Retrieved April 1, 2019, from https://www.vice.com/en_ca/article/eve3kp/jordanpeele-wont-cast-white-actor-as-star-movies-interview-us-get-out-ive-seen-that-movie-vgtrn Dugan, Patrick. (2017). What Technology was Used to make 'La La Land' So Visually rich and colorful? Forbes. Retrieved November 12, 2018, 
from https://www.forbes.com/sites/quora/2017/03/03/what-technology-was-used-to-make-la-laland-so-visually-rich-and-colorful/\#6d4640463b58

Dyer, Richard. (1997). White. Routledge

Egner, Jeremy. (2015). Emmy's 2015: HBO Dominates and Viola Davis makes history. The New York Times. Retrieved December 21, 2018, from https://www.nytimes.com/live/emmys2015/viola-daviss-emotional-emmys-acceptance-speech/

Fanon, Frantz. (2005). The Wretched of the Earth. Grove Press

Fleras, Augie. (2017). Unequal Relations. Pearson Canada

Foucault. Michel, (1977). Discipline \& Punish: The Birth of the Prison. Penguin Books France, Lisa. (2018). More than a movie, Black Panther is a movement. CNN Entertainment. Retrieved January 12, 2019, from https://www.cnn.com/2018/02/15/entertainment/blackpanther-movie-movement/index.html Fuster, Jeremy. (2017). 'Get Out’ Is 2017's Most Profitable Film So Far. The Wrap. Retrieved March, 26, 2019, from https://www.thewrap.com/get-out-split-box-office-returninvestment-2017/

Manring, M.M. (1998). Slave in a Box: The Strange Career of Aunt Jemima. University of Virginia Press

Mtshali, Khanya. (2018). Black Panther is Great. But let's Not Treat it as an Act of Resistance. The Guardian. Retrieved March 26, 2019, from https://www.theguardian.com/commentisfree/2018/feb/15/black-panther-resistance Goldberg, David Theo. (2002). The Racial State. Blackwell Publishing Gooding, Jr. F.W. (2017). You Mean, There's Race in my Movie? On the Reelz Press 
Gormley, Paul. (2013). The New-Brutality Film: Race and Affect in Contemporary Hollywood Film. Intellect.

Gorman, Steve. (2009). "Slumdog Millionaire” wins Oscar gold. Reuters. Retrieved October 20, 2018, from https://www.reuters.com/article/us-oscars/slumdog-millionaire-wins-oscar-goldidUSTRE51L0IO20090225

Graham, Chris. (2017, August 23). Mexico Border Wall: What is Donald Trump planning, how much will it cost, and who will pay for it? The Telegraph. Retreived November

20, 2018, from https://www.telegraph.co.uk/news/0/mexico-border-wall-donald-trumpplanning-much-will-cost-will/

Griffith, D.W. (1915). The Birth of a Nation. David W. Griffith Corp.

Guerrero, Ed. (1993). Framing Blackness: The African American Image in Film. Temple University Press

Hall, Stuart. (1997). Representation: Cultural Representations and Signifying Practices. Sage Publications

Hayes, Christal. (2018). Trump condemns 'all types of racism' on Charlottesville anniversary; critics slam wording. USA Today. Retrieved October 10, 2018, from https://www.usatoday.com/story/news/politics/2018/08/11/donald-trump-charlottesvilleanniversary-condemn-all-racism/965715002/

Hitt, Jack. (2005). Mighty white of you. Harper's Magazine. Retrieved March 27, 2019, from http://www.middlebury.edu/media/view/157971/original/jack_hitt_mighty_white_of_you.pdf Hoberman, J. (2016). 'Triumph of the Will': Fascist Rants and the Hollywood Response. The New York Times. Retrieved March 26, 2019, 
from https://www.nytimes.com/2016/03/06/movies/homevideo/triumph-of-the-will-fascist-rantsand-the-hollywood-response.html Hooks, bell. (2000). Where We Stand: Class Matters. Routledge Ignatiev, Noel. (2008). How The Irish Became White. Routledge Jenkins, Barry. (2016). Moonlight. A24

Kang, Sonia. (2016) Whitened Resumes: Race and Self-Presentation in the Labor Market. Sage Kawash, Samira. (1997). Dislocating the Color Line. Stanford University Press Keegan, Rebecca. (2017). Jordan Peele on the "post-racial" lie that inspired Get Out. Vanity Fair. Retrieved November 12, 2018, from https://www.vanityfair.com/hollywood/2017/10/jordan-peele-get-out-screening Khosla, Proma. (2018). Kumail Nanjiani expertly dropped the mic on representation in film. Mashable. Retrieved October 21, 2018, from https://mashable.com/2018/03/04/oscarsdiversity-video/\#brn4JJzllsqc

Konrad, Alison. (2017). Denial of Racism and the Trump Presidency. Emerald Publishing Limited Lebron, Christopher. (2018). 'Black Panther' Is Not the Movie We Deserve. Boston Review. Retrived February 15, 2018, from http://bostonreview.net/race/christopher-lebron-blackpanther Lee, Spike. (2018) BlackKklansman. Blumhouse Productions Loriston, Tamara. (2018). "Black Panther” Is More Than Just A Movie, It's a Movement. Odyssey. Retrieved February 12, 2018, from https://www.theodysseyonline.com/black-panthermovie-movement 
Macnamara, Jim. (2011). Media content analysis: Its uses; benefits and best practice methodology. University of Technology Sydney. Retrieved December 2 ${ }^{\text {nd }}, 2018$, from https://amecorg.com/wp-content/uploads/2011/10/Media-Content-Analysis-Paper.pdf Mahtani, Minelle (2004). Interrogating the Hyphen-Nation: Canadian Multicultural Policy and 'Mixed-Race' Identities. University of British Columbia Marshall, Alex. (2019). Trump Calls Spike Lee's Oscar Speech a 'Racist Hit on Your President'. The New York Times. Retrieved March 31, 2019, from https://www.nytimes.com/2019/02/25/movies/spike-lee-trump.html Morrison, Toni. (1992). Playing in the Dark: Whiteness and the Literary Imagination. Vintage Books

Montgomery, Daniel. (2017). Oscar upset explained: Top 5 reasons 'Moonlight' beat 'La La Land' for Best Picture. Golderby. Retrieved March 26, 2019, from https://www.goldderby.com/article/2017/2017-oscars-upset-moonlight-best-picutre-la-laland/

Narain, Atticus. (2009). Rethinking post-colonial representation after Slumdog Millionaire. Darkmatter. Retrieved October 25, 2018, from http://www.darkmatter101.org/site/2009/03/09/rethinking-post-colonial-representationafter-slumdog-millionaire/ Neuendorf, Kimberly. (2015). Media, Racial Identity, and Mainstream American Values. Howard Journal of Communications. Retrieved January 12, 2019, from https://academic.csuohio.edu/kneuendorf/vitae/Fujioka\&Neuendorf15.pdf 
Newman, Don. (2008). A long-awaited apology for residential schools. CBC. Retrieved November 23, 2018, from https://www.cbc.ca/archives/entry/a-long-awaited-apology-forresidential-schools

Peele, Jordan. (2017). Get Out. Universal Pictures

Pettigrew, Thomas. (2009). Post-Racism? Putting President Obama's Victory in Perspective.

Du Bois Review

Ramos, Dino-Ray. (2017). ‘Get Out' Director Jordan Peele On Divisiveness, Black Identity \& The "White Savior". Retrieved February 1, 2019, from https://deadline.com/2017/10/jordanpeele-get-out-film-independent-forum-keynote-speaker-diversity-inclusion-1202192699/ Rocchio, Vincent. (2000). Reel Racism: Confronting Hollywood's Construction of AfroAmerican Culture. Westview Press

Rosenberg, Alyssa. (2017). The Insane end of the Oscars sent a false message about racial progress. The Washington Post. Retrieved March 26, 2019, from https://www.washingtonpost.com/news/act-four/wp/2017/02/27/the-insane-end-of-theoscars-sent-a-false-message-about-racial-progress/?utm_term=.bf326b883a53

Said, Edward. (1979). Orientalism. Vintage

Shaheen, Jack. (2003) Reel Bad Arabs: How Hollywood Vilifies a People. Interlink Books Smith, Jamil. (2018). The Revolutionary Power of Black Panther. Time. Retrieved October 29, 2018, from http://time.com/black-panther/

Stracqualursi, Veronica. (2018). DHS Secretary says Trump used 'tough' language on immigration but denies hearing specific slurs. CNN. Retrieved January 2, 2018, from https://www.cnn.com/2018/01/16/politics/kirstjen-nielsen-dhs-secretaryhearing/index.html 
Taylor, Keeanga-Yamahtta. (2016). Why should we trust you? Clinton's big problem with young black Americans. The Guardian. Retrieved November 18, 2018, from https://www.theguardian.com/us-news/2016/oct/21/hillary-clinton-black-millennial-voters Thomas, James. (2013). Affect and the sociology of race: A program for critical inquiry. Sage Journals

Wacquant, Loic. (2000) The New 'Peculiar Institution': On the Prison as Surrogate Ghetto. Sage

Watkins, Eli. (2018). Trump decries immigrants from 'shithole countries' coming to US. CNN Politics. Retrieved January 20, 2019, from https://www.cnn.com/2018/01/11/politics/immigrants-shithole-countries-trump/index.html Weinbaum, Alys. (2004) Wayward Reproductions: Genealogies of Race and Nation in Transatlantic Modern Thought. Duke University Press

Willingham, AJ. (2017). Study: We think black men are bigger than white men (even when they're not). CNN. Retrieved November 19, 2018, from https://www.cnn.com/2017/03/13/health/black-men-larger-study-trnd/index.html Yuen, Nancy. (2017). Reel Inequality: Hollywood Actors and Racism. Rutgers University Press 